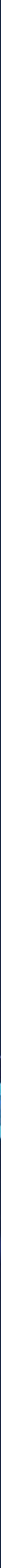

FEBRUARY 2022

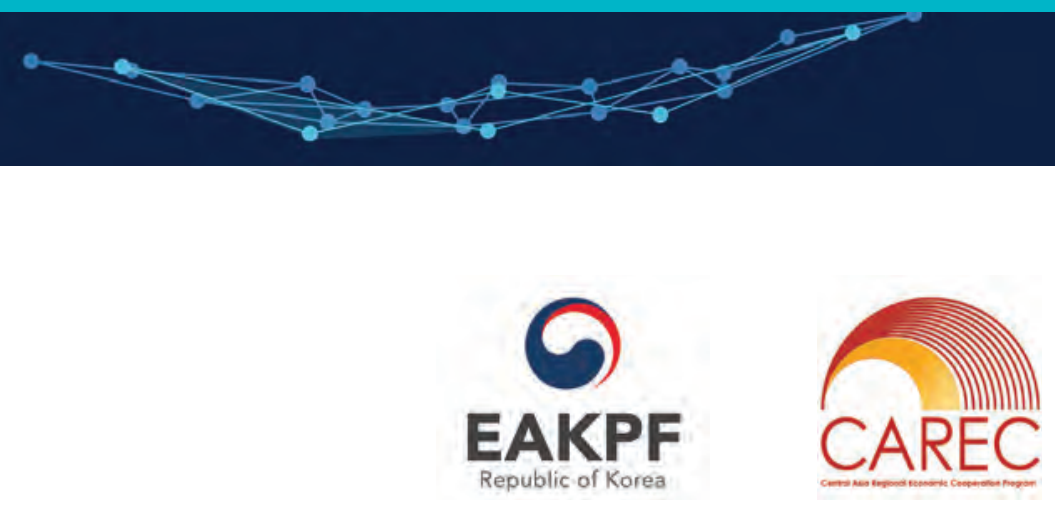




\section{CAREC DIGITAL STRATEGY 2030}

ACCELERATING DIGITAL TRANSFORMATION FOR REGIONAL COMPETITIVENESS AND INCLUSIVE GROWTH

FEBRUARY 2022

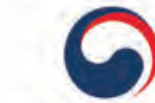


(C) 2022 Asian Development Bank 6 ADB Avenue, Mandaluyong City, 1550 Metro Manila, Philippines

Tel +632 8632 4444; Fax +63286362444

www.adb.org

Some rights reserved. Published in 2022.

ISBN 978-92-9269-364-0 (print); 978-92-9269-365-7 (electronic); 978-92-9269-366-4 (ebook)

Publication Stock No. SPR220042-2

DOI: http://dx.doi.org/10.22617/SPR220042-2

The views expressed in this publication are those of the authors and do not necessarily reflect the views and policies of the Asian Development Bank (ADB) or its Board of Governors or the governments they represent.

ADB does not guarantee the accuracy of the data included in this publication and accepts no responsibility for any consequence of their use. The mention of specific companies or products of manufacturers does not imply that they are endorsed or recommended by ADB in preference to others of a similar nature that are not mentioned.

By making any designation of or reference to a particular territory or geographic area, or by using the term "country" in this document, $A D B$ does not intend to make any judgments as to the legal or other status of any territory or area.

This work is available under the Creative Commons Attribution 3.0 IGO license (CC BY 3.0 IGO)

https://creativecommons.org/licenses/by/3.0/igo/. By using the content of this publication, you agree to be bound by the terms of this license. For attribution, translations, adaptations, and permissions, please read the provisions and terms of use at https://www.adb.org/terms-use\#openaccess.

This CC license does not apply to non-ADB copyright materials in this publication. If the material is attributed to another source, please contact the copyright owner or publisher of that source for permission to reproduce it. $\mathrm{ADB}$ cannot be held liable for any claims that arise as a result of your use of the material.

Please contact pubsmarketing@adb.org if you have questions or comments with respect to content, or if you wish to obtain copyright permission for your intended use that does not fall within these terms, or for permission to use the ADB logo.

Corrigenda to ADB publications may be found at http://www.adb.org/publications/corrigenda.

Notes:

In this publication, "\$” refers to United States dollars.

ADB recognizes "China" as the People's Republic of China and "Russia" as the Russian Federation.

ADB placed on hold its assistance in Afghanistan effective 15 August 2021.

This publication is supported by the Republic of Korea e-Asia and Knowledge Partnership Fund. All photos by ADB.

Cover design by Raja Umar Rehman. 


\section{Contents}

Table and Figures

Abbreviations

Executive Summary

$1 \quad$ INTRODUCTION 1

$\begin{array}{lll}1.1 & \text { Purpose and Approach } & 9\end{array}$

1.2 Document Structure 12

2 CAREC DIGITAL STRATEGY 2030: VISION, MISSION, AND OBJECTIVES

3 DIGITAL ADOPTION ACROSS CAREC: CURRENT STATE OVERVIEW 6

4 ALIGNING THE NONDIGITAL FOUNDATIONS FOR DIGITAL DEVELOPMENT 7

5 CAREC DIGITAL STRATEGY 2030 PILLARS: STRENGTHENING THE 8 DIGITAL FOUNDATIONS

5.1 Pillar 1: Leadership, Governance, and Investment in the Digital Economy 9

5.2 Pillar 2: Digital Policy Enablers and Safeguards 12

5.3 Pillar 3: Digital Infrastructure, Resilience, and Platforms 14

5.4 Pillar 4: Digital Skills and Competencies 16

5.5 Pillar 5: Innovation, Entrepreneurship, and Information and Communication Technology 17 Competitiveness

6 CAREC SECTOR AND CLUSTER TRANSFORMATION 20

6.1 Leveraging Digital Technologies to Accelerate CAREC Operational Cluster Transformation 20

6.2 Government as a Platform 20

6.3 Economic and Financial Stability: E-Finance/Fintech 20

6.4 Trade, Tourism, and Economic Corridors $\quad 21$

6.5 Infrastructure and Economic Connectivity: Connecting Smart Cities and Villages across CAREC 23

6.6 Agriculture and Water Cluster: Digital Agriculture 24

6.7 Human Development 24

7 IMPLEMENTING THE CAREC DIGITAL STRATEGY 2030

7.1 Establishing Implementation Principles 26

7.2 Establishing a Governance Structure for Regional Digital Development 27

$\begin{array}{ll}7.3 \text { Key Implementation Priorities } & 28\end{array}$ 
8 CONCLUSION $\quad 32$

APPENDIXES

1 CAREC 2030 Institutional Framework $\quad 34$

2 Digital Transformation Framework $\quad 35$

3 Stakeholder Input Analysis 36

$4 \quad$ CAREC Member Countries' National Digital Transformation Strategies $\quad 41$ and Priorities as Reflected in Strategy Documents

5 Regional Digital Transformation Opportunities and Challenges: 43 Strengths, Weaknesses, Opportunities, and Threats Analysis

6 Global Best Practices in Digital Strategy Implementation $\quad 47$

7 Digital Adoption across CAREC: Current State Overview 51

8 Potential Areas for Regional Cooperation in the CAREC Digital Space 56

9 Accelerating the Digital Transformation of CAREC Operational Clusters 64

10 Potential Areas of Implementation of the CAREC Digital Strategy 203069

$\begin{array}{ll}\text { REFERENCES } & 71 .\end{array}$ 


\section{Table and Figures}

\section{TABLE}

A7 International Indexes: CAREC Member Country Rankings

\section{FIGURES}

Pillars of the Digital Foundations $\quad 8$

A1 CAREC 2030 Institutional Framework

A2 CAREC Digital Ecosystem Framework

A3.1 Opportunities for Regional Digital Cooperation: Public Sector Priorities 37

A3.2 Obstacles to Regional Digital Cooperation: Public Sector Perceptions 38

A3.3 Opportunities for Regional Digital Cooperation: Private Sector Priorities 39

A3.4 Obstacles to Regional Digital Cooperation: Private Sector Perceptions 40

A7.1 CAREC Countries in the Global Digital Race

A7.2 International Bandwidth per Internet User: CAREC vs. Other Regions 52

A7.3 Access to Fixed Broadband: CAREC vs. Other Regions 52

A7.4 Internet Users: CAREC vs. Other Regions 53

A7.5 International Indexes: CAREC Member Countries Average Ranking 54

A8.1 Government Incentives Needed to Encourage Private Sector Regional Digital Cooperation 57

A8.2 Role of Data in the Production Process: Pathways to Development 58

A8.3 CAREC Platform Economy 60

A9 CAREC Population: Urban vs. Rural 66 


\section{Abbreviations}

$\begin{array}{ll}\text { ADB } & \text { Asian Development Bank } \\ \text { AI } & \text { artificial intelligence } \\ \text { ASEAN } & \text { Association of Southeast Asian Nations } \\ \text { CAREC } & \text { Central Asia Regional Economic Cooperation } \\ \text { CASA } & \text { Central Asia-South Asia } \\ \text { CITA } & \text { CAREC Integrated Trade Agenda } \\ \text { COVID-19 } & \text { coronavirus disease } \\ \text { EAEU } & \text { Eurasian Economic Union } \\ \text { EU } & \text { European Union } \\ \text { FAO } & \text { Food and Agriculture Organization of the United Nations } \\ \text { ICT } & \text { information and communication technology } \\ \text { IOT } & \text { internet of things } \\ \text { IT } & \text { information technology } \\ \text { ITU } & \text { International Telecommunication Union } \\ \text { OECD } & \text { Organisation for Economic Co-operation and Development } \\ \text { PPP } & \text { public-private partnership } \\ \text { PRC } & \text { People's Republic of China } \\ \text { R\&D } & \text { research and development } \\ \text { SME } & \text { small and medium-sized enterprise } \\ \text { STEM } & \text { science, technology, engineering, and mathematics } \\ \text { SWOT } & \text { strengths, weaknesses, opportunities, and threats } \\ \text { UNESCAP } & \text { United Nations Economic and Social Commission for Asia and the Pacific } \\ \text { UNESCO } & \text { United Nations Educational, Scientific and Cultural Organization } \\ \text { WEF } & \text { World Economic Forum }\end{array}$




\section{Executive Summary}

According to multiple studies, digital transformation based on effective data management can positively impact economic growth, jobs creation, and social inclusion. Today, as the world is dealing with the unprecedented challenges posed by the coronavirus disease (COVID-19) pandemic, it is becoming increasingly evident that countries that have invested in national broadband infrastructure and whose people and businesses are connected through digital platforms are faring better than others. For example, countries with strong connectivity had seen students benefit from online schooling, companies have shifted to online work, and government services are available through online government portals. In contrast, countries without a national broadband infrastructure have been caught off guard by the pandemic. The sudden transition to telework and distance learning has been a challenge for many in the Central Asia Regional Economic Cooperation (CAREC) region, where more than half of the population remains unconnected.

There is broad agreement across CAREC that digitalization will not only help COVID-19 recovery but also allow member countries to develop robust solutions in important areas such as health care, education, agriculture, finance, trade, and tourism. These solutions will fuel the development of CAREC's operational clusters in line with the CAREC Strategy 2030, which prioritizes information and communication technology (ICT) as a cross-cutting issue as well as sectoral strategies for energy, tourism, trade, and transport, ultimately leading to higher economic growth, new jobs, and better services across the region. The CAREC Digital Strategy 2030 is intended as a catalyst for regional cooperation on digital matters and a mechanism to promote policy design, capacity building, and dialogue on the ways social and economic challenges in the region can be addressed with the help of digital technologies.

CAREC countries must learn from the COVID-19 crisis and utilize digital technologies that have proven essential to managing the pandemic and the recovery period. A focus on addressing the existing imbalances in digital development across the CAREC region, regional digital collaboration, and sharing of best practices will enable CAREC member countries to take advantage of the opportunity in this crisis and lay the basis for a sustainable and inclusive economic recovery. Boosting regional cooperation on digital transformation, adopting digital technologies to leverage existing ties and create new ones, and focused investment in regional interoperable digital infrastructure will help accelerate COVID-19 recovery.

The CAREC Digital Strategy 2030 was prepared by the CAREC Secretariat supported by the Asian Development Bank (ADB). The CAREC Secretariat partnered with the CAREC Institute and the United Nations Economic and Social Commission for Asia and the Pacific (UNESCAP). The draft strategy was also shared with other development partners and feedback was received from the Eurasian Fund for Stabilization and Development, Islamic Development Bank, and the World Bank.

\section{CAREC Digital Strategy 2030 Vision and Mission}

In line with the overarching CAREC 2030 vision of "Good Neighbors, Good Partners, and Good Prospects," the CAREC Digital Strategy 2030's vision is to create a common CAREC Digital Space, which will lead to inclusive economic growth and social 
well-being, new jobs (including for the disadvantaged and minority populations of the region), better services, and higher regional competitiveness. The CAREC Digital Space is an interconnected digital ecosystem that enables the development of new digital products and services, power digital transformation, and support a freer flow of data across the region.

To achieve this vision, the CAREC Digital Strategy 2030 adopts the mission of creating a data-driven digital regional economy with fast and reliable online access to relevant information and trusted, real-time, user-friendly digital services for all citizens, businesses, and administrations across the CAREC region. This mission will be achieved through the following objectives:

- Encourage investment in the digital infrastructure across the region to close connectivity gaps.

- Harmonize digital and data legislature to promote an enabling environment.

- Develop new digital skills, including for women, disadvantaged, and minority populations, to create jobs.

- Attract talent into the region to strengthen CAREC's innovation ecosystem.

- Reduce regional trade barriers to increase cross-border trade and expand business opportunities for companies across the region, particularly in e-commerce.

- Improve the digital foundations (represented through the pillars in Section 5) and create interoperable digital platforms to enable the development of CAREC's operational clusters.

These objectives have been formulated based on inputs from stakeholders (received during a series of collaborative consultations) and will address the gaps needed to attain the above mission statement. These gaps include investment in networks, research and development for digital innovation, harmonized legislation and regulation to enable digital cooperation at the regional level, and interoperability in digital infrastructure.

\section{Five Pillars of the CAREC Digital Strategy 2030}

To achieve these objectives, the CAREC Digital Strategy 2030 will strengthen the following five interconnected pillars through improved cooperation between CAREC member countries.

\section{Pillar 1: Leadership, Governance, and Investment in the Digital Economy}

The adoption and implementation of the CAREC Digital Strategy 2030 requires strong and dedicated regional leadership with high-level commitment to digital transformation. A coordination mechanism to ensure multistakeholder participation and undertake consultations and dialogue on CAREC digital issues will be implemented. The CAREC Secretariat will facilitate the coordination and organization of this process. This mechanism will create incentives for regional cooperation in the CAREC Digital Space and seek to attract the needed investments. It will also leverage digital technologies to pursue cross-cutting Sustainable Development Goals to promote inclusion, innovation, sustainability, resilience, partnerships, and participation.

\section{Pillar 2: Digital Policy Enablers and Safeguards}

To create the common CAREC Digital Space and enable a freer flow of data and services in the region, CAREC member countries will work to eliminate legal barriers and harmonize policies, regulations, and standards. This will reduce the existing barriers to cross-border trade, especially by implementing e-commerce and e-payments and establishing digital platforms within and across CAREC sectors and priority clusters.

Member countries will also work on aligning the data policies across the region to safeguard data privacy, enable public consultation, ensure transparency and nondiscrimination, and strengthen security. 
This will create trust in online services, as well as the broader digital economy and society, and support the development of artificial intelligence (AI) and related technologies in the region.

\section{Pillar 3: Digital Infrastructure, Resilience, and Platforms}

The CAREC member states' digital infrastructures should be connected based on common standards and principles of interoperability, scalability, and security. Sustaining these standards and principles is critical to the mobilization of digital platforms and the efficient operation of the common CAREC Digital Space. CAREC members will take joint action for building capacity for regional digital resilience to ensure the agility and adaptability of the infrastructure underpinning digital systems to withstand and bounce back from crises and shocks.

A CAREC regional platform economy is the key direction for a collaborative regional digital transformation effort. Integrated platforms will be built to implement digitalization in CAREC's operational sectors and these foundational pillars.

\section{Pillar 4: Digital Skills and Competencies}

CAREC member countries face a shortage of skilled digital talent across sectors in the economy. Unless addressed, this shortage will deepen as the digitalization of industry and government accelerates. CAREC member countries must tackle the critical issue of unemployment, migration, and brain drain from the region by developing and enhancing digital skills. Both basic digital literacy skills of the population and advanced digital skills for professionals across all sectors of the economy will be addressed. Boosting the digital skills and competencies of public sector employees, including at senior levels, will be a priority. Improving the quality of national education systems and leveraging digital technologies to boost digital competencies across the region through advancing training, upskilling and reskilling, and promoting life-long learning will be the key focus areas in this space.

\section{Pillar 5: Innovation, Entrepreneurship, and Information and Communication Technology Competitiveness}

The innovation gap is at the heart of the digital divide, as digital technologies are developing faster than governments and institutions are able to formulate policies to regulate these technologies and leverage their benefits for the larger good of society. To develop and boost innovation ecosystems in the absence of sufficient allocation in most national budgets, the CAREC Program will foster quick adoption, dissemination, and scaling of existing innovative products and solutions across the region and promote frugal innovation and entrepreneurship.

Promoting innovation and adoption of digital products will require educational initiatives and training programs to build digital skills that can help users understand the benefits of these solutions. Other key initiatives for building innovative enterprises include nurturing the digital innovation ecosystem across the CAREC region, promoting the adoption and effective use of digital technologies by small and medium-sized enterprises (SMEs), promoting regional content, and supporting local ICT companies across the region to address regional demand for digital solutions and boost ICT exports.

\section{CAREC Sector and Priority Cluster Transformation}

The CAREC 2030 Strategy emphasizes that integrating ICT across the spectrum of CAREC operations will be a cross-cutting priority. It is, therefore, important to establish the path for accelerating digital adoption within CAREC's five operational clusters to achieve higher productivity, efficiency, and customer satisfaction gains at the sectoral level, which will drive the digital dividends of higher growth, new jobs, and better services.

A comprehensive list of sector-wise solutions includes the following: fintech and e-finance solutions to boost the CAREC region's economic 
and financial stability: digital tourism, cross-border services, e-logistics, e-commerce, e-customs, and e-procurement to power CAREC's efforts in trade, tourism, and economic corridors; $4 \mathrm{G}$ and $5 \mathrm{G}$ rollout, digital government as a platform, regional cloud infrastructure, data centers, smart cities, and villages to support CAREC's infrastructure and economic connectivity initiatives; digital agriculture, geospatial, and smart water management solutions and platforms to accelerate the growth of CAREC's agriculture and water sectors; as well as digital skills and competencies initiatives to empower CAREC's human development activities. Member country governments will also participate in this process by adopting a "government as a platform" approach to promote the digitalization of government services.

\section{Implementing the CAREC Digital Strategy 2030}

At its onset, the CAREC Digital Strategy 2030 is ambitious in its vision and will serve as a living document that will be updated to reflect according to changing needs. In its implementation, it is essential to combine the longer-term view with agile frameworks, focusing on a prioritized project portfolio and an implementation road map. This road map will highlight quick wins and low-hanging fruit in the shorter term and progress to more strategic projects while strengthening critical elements such as regional governance and institutions, partnerships, leadership skills, and execution capacity.

A CAREC Digital Strategy steering committee will be established to determine the appropriate leadership and governance structures as well as the regional institutional framework to drive the implementation of the CAREC Digital Strategy 2030. The steering committee will be led and constituted by the governments of CAREC member countries and facilitated by the CAREC Secretariat. The committee will engage all members of the CAREC Digital
Space in the implementation process, relying on mutual goodwill and an inclusive multistakeholder consultation model that brings together public and private sector organizations across CAREC, academic institutions, the expert community, international donor organizations, global and regional technology giants, citizens, and other players. The steering committee, in line with the five pillars, will implement the following priorities:

develop the CAREC Digital Transformation Project portfolio,

- launch specific initiatives to strengthen the enabling environment by harmonizing the legal and regulatory environment and by building capacity,

- build and maintain a multistakeholder consensus across the region,

- gather and share best practices for regional digital development,

- develop and launch a strategic communications plan,

- prioritize the CAREC Digital Transformation Project portfolio and create the CAREC Digital Strategy 2030 implementation road map,

work with development partners to secure project funding,

- build public-private partnerships (PPPs) for project implementation,

- establish a monitoring system to measure progress, and

- future-proof the strategy to adapt to changing scenarios and needs.

The CAREC leadership must leverage global and regional best practices to enable effective implementation. Sufficient financial resources must be allocated early on to support universal broadband access across the region, the creation of common digital infrastructures and digital platforms, and the implementation of the prioritized CAREC portfolio of digital transformation projects in the region. 
Multiple studies indicate that digital transformation based on effective data management can have an impact on economic growth, new jobs creation, and social inclusion. ${ }^{1}$ Today, as the world is dealing with the unprecedented challenges posed by the coronavirus disease (COVID-19) pandemic, it is becoming increasingly evident that countries that have invested in a national broadband infrastructure and whose people and businesses are connected through digital platforms are faring better than others. As the pandemic carries on, digital technologies have enabled many activities including contact tracing, lockdown enforcement, cooperation on vaccine development, online education, and teleworking. As millions shifted to teleworking and online schooling, in just the first few months of the crisis, data traffic increased by at least $20 \%$, while cyberattacks on the health sector infrastructure and mobile networks have increased by $150 \%{ }^{2}$

Countries without a national broadband infrastructure have been caught off guard by the pandemic and the sudden transition to telework and distance learning has posed a challenge for many countries. In Central Asia Regional Economic Cooperation (CAREC) member countries, more than half of the population remains unconnected. ${ }^{3}$ The COVID-19 crisis has also exposed the severity of the rural and urban digital divide, exacerbating social and economic inequalities, hitting disadvantaged populations in remote areas, especially women, children, the elderly, the sick, and the disabled. Some CAREC member countries, such as Kazakhstan, the Kyrgyz Republic, and the People's Republic of China (PRC) were able to shift to distance learning at scale. ${ }^{4}$ In other countries, children were left without schooling for many months, as not everyone was able to benefit from online education. ${ }^{5}$

The COVID-19 pandemic has also brought significant disruption at the regional level. As countries imposed lockdowns and quarantines, supply chains were disrupted, trade slowed, and tourism and business travel stalled. It is crucial to start looking outward again during the recovery period while taking stock of the lessons learned from the COVID-19 crisis and utilizing digital technologies that have proven essential to managing the pandemic. Focusing on regional cooperation and digitalization can enable CAREC member countries to lay the basis for a sustainable economic recovery.

1 World Bank. 2016. World Development Report 2016: Digital Dividends. Washington, DC. The World Economic Forum (WEF) observes that "the digital economy permeates all aspects of society, including the way people interact, the economic landscape, the skills needed to get a good job, and even political decision-making." V. Espinel. 2016. The Digital Economy: What Is It and How Will It Transform Our Lives? World Economic Forum. 10 November. The World Bank's research suggests that "just 10 percent increase in broadband connectivity can add at least 1 percent to economic growth, while $1 \%$ increase in Internet connectivity corresponds with a 4.3 percent of export growth." World Bank. 2020. COVID-19 Prompts Urgency of Bridging Digital Divide in Central Asia. Press release. 2 December.

2 World Bank. COVID-19 Crisis Response: Digital Development Joint Action Plan and Call for Action.

3 Global System for Mobile Communications Association (GSMA). GSMA Mobile Connectivity Index (accessed 15 May 2021 ).

4 M. Levina. 2020. Central Asia Countries Switch to Remote Learning amid COVID-19 Outbreak. The Times of Central Asia. 3 April.

5 According to recent data, around $40 \%$ of Europe and Central Asia combined online education with TV and radio to reach rural areas and those without an internet connection. In South Asia, around $40 \%$ of the countries used broadcast alone (TV or radio only) due to the lack of internet access. E. Vegas. 2020. School Closures, Government Responses, and Learning Inequality around the World during COVID-19. Brookings. 14 April. 
Regional organizations worldwide place digital technologies at the heart of their economic development and COVID-19 recovery strategies. The European Commission considers the digital economy as "the single most important driver of innovation, competitiveness and growth in the world." ${ }^{6}$ The Association of Southeast Asian Nations (ASEAN) intends to accelerate its digital integration, which has the potential to generate a $\$ 1$ trillion uplift in the gross domestic product by 2025. ${ }^{7}$ The United Nations Economic Commission for Latin America and the Caribbean also aims to develop the regional digital market to boost socially just and environmentally sustainable development in the region, drive the growth of connectivity for citizens and business, and simplify the online exchange of goods and services. The Gulf Cooperation Council-particularly the governments of the United Arab Emirates, Bahrain, and Saudi Arabia-"have been directing vast resources toward the digitalization of their infrastructure by creating the needed institutions, amending legislation, partnering with 'Big Tech,' and building local human capital." 8 The Eurasian Economic Union (EAEU) has adopted the EAEU Digital Agenda 2025 aimed at creating a common digital space and a single digital economy in the region and achieving associated digital dividends expressed in higher regional economic growth, new jobs creation in the digital and non-digital sectors, and new and better services. ${ }^{9}$ Similarly, boosting regional cooperation for digital transformation in the CAREC Program will allow leveraging of digital technologies to strengthen old ties and create new ones to help accelerate the COVID-19 recovery process.

\subsection{Purpose and Approach}

The CAREC 2030 Strategy prioritizes information and communication technology (ICT) as a cross-cutting issue across its operational clusters (Appendix 1), providing the institutional basis for the CAREC Digital Strategy 2030. CAREC leaders at the Asian Development Bank's (ADB) 54th Annual Meeting of the Board of Governors on 4 May 2021, outlined several priorities for digital transformation at the regional level. ${ }^{10}$ Those priorities included bridging the digital divide through investing in broadband infrastructure, leveraging digital technologies to cope with the COVID-19 crisis and its fallout, harmonizing regulation and legislation to enable e-commerce across the region, and developing digital solutions for CAREC's operational clusters.

The CAREC Digital Strategy 2030 is intended as a catalyst for regional cooperation on digital matters and a mechanism to promote policy design, capacity building, and dialogue on the ways social and economic challenges in the region can be addressed with the help of digital technologies. The rapid development of disruptive technologies, coupled with the challenges of the COVID-19 crisis, requires stronger regional cooperation and trust to accelerate digital transformation. This is an opportunity in crisis: leverage digital technologies to recover and build-back-better for a resilient and inclusive economy and society.

6 S. Treagust. 2017. Fire Up Your Digital Transformation and Increase Profitability 26\% Using a Connected Strategy. IFS Blog. 23 March.

7 Huawei. 2020. ASEAN to Accelerate Digital Integration for Post-COVID Economic Recovery. News. 10 December.

8 M. Soliman. 2020. COVID-19 and the Digital Landscape in the Gulf. Middle East Institute. 13 May.

9 J. Navas-Sabater and O. V. Petrov. 2018. The EAEU 2025 Digital Agenda: Prospects and Recommendations - Overview Report (English). Washington, DC: World Bank.

10 ADB. 2021. CAREC at 20: Reimagining Regional Cooperation through Digital Transformation. 54th Annual Meeting of the Board of Governors. 4 May. 


\subsubsection{Adopting a Holistic Digital Transformation Framework}

A holistic digital transformation framework (Appendix 2) will allow CAREC member countries to take advantage of complementarities and synergies, align the CAREC Digital Strategy 2030 with the development agenda outlined in the CAREC 2030 Strategy, and support the implementation of the six priorities for CAREC regional digital cooperation identified by CAREC public and private sector stakeholders (Appendix 3). The digital transformation framework comprises digital foundations, which act as enablers of the digital transformation process and include digital leadership, policies and institutions, digital infrastructure, digital platforms, digital skills, digital data, the digital innovation and entrepreneurship ecosystem, and digital industry and support services. Digital foundations rest on nondigital foundations such as the business environment, education, competition, financial policies, governance, access to electricity, etc. Digital solutions cover ICT applications in key economic sectors such as education, health, tourism, trade and finance, transport, energy, urban development, and agriculture. ${ }^{11}$ Strong digital foundations are fundamental to extracting digital dividends from sectoral transformation initiatives. Moreover, a holistic approach to digital strategy is essential to maximizing the digital dividends and securing equitable benefits and inclusive economic growth. ${ }^{12}$ Digital transformation cuts across all sectors at the local, national, and regional levels and requires the engagement and collaboration of the entire ecosystem: the public and private sectors, the expert and academic community, the innovation ecosystem, development partners, and citizens.

\subsubsection{CAREC Digital Strategy 2030: Preparation and Inputs}

The CAREC Digital Strategy 2030 has been prepared by the CAREC Secretariat supported by $A D B$. The CAREC Secretariat partnered with the CAREC Institute and the United Nations Economic and Social Commission for Asia and the Pacific (UNESCAP). The draft strategy was also shared with other development partners and feedback was received from the Eurasian Fund for Stabilization and Development (EFSD), Islamic Development Bank (IsDB), and the World Bank.

The CAREC Digital Strategy 2030 is a collaborative effort relying on consultation sessions with stakeholders from the CAREC region. The sessions were held in the summer of 2021, supported by a number of analytical exercises including an analysis of stakeholder inputs received through responses to CAREC questionnaires (Appendix 3); a review of national digital transformation strategy documents of CAREC member countries (Appendix 4); a strengths, weaknesses, opportunities, and threats (SWOT) analysis of the enabling environment and the nondigital and digital foundations of digital transformation across the CAREC region (Appendix 5); a review of global best practices in driving digital transformation at the regional and country levels (Appendix 6); and an analysis of secondary sources including global development organizations reports, global digital development indexes, scientific papers, and notes and articles on digital development (Appendix 7).

\footnotetext{
11 For more details, see N. K. Hanna. 2016. Mastering Digital Transformation: Towards a Smarter Society, Economy, City and Nation. Bingley, United Kingdom: Emerald Publishing Limited; and N. K. Hanna. 2020. Assessing the Digital Economy: Aims, Frameworks, Pilots, Results, and Lessons. Journal of Innovation and Entrepreneurship. 9 (16).

12 World Bank. 2016. World Development Report 2016: Digital Dividends. Washington, DC.
} 


\subsection{Document Structure}

The strategy document consists of the main text of the CAREC Digital Strategy 2030 and supporting appendixes. The main text opens with the strategy's vision, mission, and objectives and provides an overview of the current state of digital development across the CAREC region. It then discusses the six CAREC stakeholder priorities for digital transformation in the region and addresses the five pillars that constitute the foundations required to support CAREC stakeholders' regional digital transformation agenda, including priority areas for cluster-level digital adoption. The main text concludes with strategy implementation guidelines. The appendixes provide more context, research, analytical and background material, and more detailed recommendations to various sections of the strategy. 


\section{SECTION \\ CAREC Digital Strategy 2030: Vision, Mission, and Objectives}

In line with the overarching CAREC 2030 vision of "Good Neighbors, Good Partners, and Good Prospects," the CAREC Digital Strategy 2030 vision is to create a common CAREC Digital Space-an interconnected digital ecosystem that enables the development of new digital products and services, powers digital transformation, and supports a freer flow of data across the CAREC region. The CAREC Digital Space will generate higher digital dividends across the region, expressed in inclusive economic growth and social well-being, new jobs (including for the disadvantaged and minority populations), better services, and higher regional competitiveness.

To achieve this vision, the CAREC Digital Strategy 2030 adopts the mission of creating a data-driven digital economy with fast and reliable online access to relevant information and trusted, real-time, user-friendly digital services for all citizens, businesses, and administrations across the CAREC region. This mission will be based on high-speed internet and secure, scalable, and interoperable digital platforms and digital infrastructure that are resilient to cyberattacks and other crises.
The mission translates into the following objectives, which have been derived from the priorities identified by the CAREC stakeholders: ${ }^{13}$

- Encourageinvestmentinthe digitalinfrastructure across the region to close connectivity gaps.

- Harmonize digital and data legislature to promote an enabling environment.

- Develop new digital skills, including for women, disadvantaged, and minority populations, to create jobs.

- Attract talent into the region to strengthen CAREC's innovation ecosystem.

- Reduce regional trade barriers to increase cross-border trade and expand business opportunities for companies across the region, particularly in e-commerce.

- Improve the digital foundations (represented through the pillars in Section 5) and create interoperable digital platforms to develop CAREC's operational clusters.

13 See Appendix 3 for details. 


\section{SECTION \\ Digital Adoption across CAREC: Current State Overview}

The levels of digital development across the CAREC region vary significantly, and most CAREC member countries have underdeveloped digital ecosystems. ${ }^{14}$ According to the World Bank's classification of countries based on their level of digital development into three groups (transforming, transitioning, and emerging), ${ }^{15}$ CAREC member countries fall into the emerging and transitioning categories. Emerging countries include Afghanistan, Pakistan, Tajikistan, and Turkmenistan. Transitioning countries include Azerbaijan, Georgia, Kazakhstan, the Kyrgyz Republic, Mongolia, the PRC, and Uzbekistan. The differences between CAREC member countries are also reflected in the rankings of CAREC member countries in global digital development indexes. ${ }^{16}$

CAREC member countries realize the wide-ranging opportunities for digitalization. An analysis of CAREC members' national digital transformation strategies reveals that all CAREC member countries have included digital transformation as a priority in their national development strategies, and some have adopted initial concept documents or more detailed programs, strategies, and plans related to various aspects of digital transformation. ${ }^{17}$ There is broad agreement that digitalization will not only provide economic benefits but also allow member countries to develop robust solutions in important areas such as health and education and fuel the development of CAREC's operational clusters through digital trading platforms, digital taxation, automated payment systems for rail and road freight, etc. They also acknowledge the existence of barriers to regional digitalization that relate to the lack of (i) physical infrastructure; (ii) a supportive policy environment; (iii) interoperability among existing systems; and (iv) private sector investment, and they recognize the need for integrated regional solutions to these challenges. A SWOT analysis of the region conducted to prepare the CAREC Digital Strategy $2030^{18}$ concluded that it is important to close the gaps in digital adoption within CAREC member countries to accelerate digital transformation across the CAREC region and achieve digital dividends. This requires CAREC members to invest in strong digital foundations and cooperate on best practices and knowledge sharing so that emerging countries can accelerate the adoption of solutions and benefit from lessons learned by the transitioning countries. The main priorities for member countries are highlighted in the next section.

\footnotetext{
14 While the PRC is a leader in digital development, only 33.9\% of the rest of CAREC's population can access the internet. Broadband access across the region is also far below global and other regional averages (only $6.6 \%$ of the population has access to fixed broadband). See Appendix 7 for more details.

15 T. Kelly et al. 2017. Reaping Digital Dividends: Leveraging the Internet for Development in Europe and Central Asia. Washington, DC: World Bank.

16 See Appendix 7 for more details.

17 See Appendix 4 for more details.

18 See Appendix 5 for more details.
} 


\section{SECTION Aligning the Nondigital Foundations
for Digital Development}

The digital economy rests upon a number of nondigital foundations that provide a conducive environment. These nondigital foundations include economic factors such as competition, finance, governance, regulation, and trade. They are derived from the economy's macro-policy foundations and serve as enablers to the digital foundations. ${ }^{19}$ They manifest in the form of a positive business climate that is conducive to investment in innovation and entrepreneurial activity; the presence of an educated and skilled workforce; a streamlined and supportive legislative and regulatory environment; and strong local, national, and regional governance institutions.

Initiatives to improve the business climate across the region include the deregulation of the telecommunications sector and the encouragement of competition to secure reliable, affordable, and accessible internet services. Modernizing the institutional, legal, and regulatory frameworks; removing restrictions on access to wholesale and retail internet services (including international gateways); and simplifying licensing procedures are keysteps to strengthening the nondigital foundations. Adopting and harmonizing regional legislation to enable cross-border trade and other services and simplifying government operations and procurement will also create a better enabling environment across the region (the CAREC Program, under the CAREC Integrated Trade Agenda [CITA] 2030, is already implementing steps to reduce trade barriers). While on average, CAREC member countries rank higher on human capital than on other development indexes, most education systems across CAREC are nevertheless not sufficiently agile to respond swiftly to the new skills and competencies required in digital transformation across economic spheres. It is important to strengthen the education ecosystem, bolstering science, technology, engineering, and mathematics (STEM) education and digital innovation. The COVID-19 crisis has highlighted the potential of online education. Bridging the digital divide to ensure universal access to online education and training across the region should become a top regional priority. Establishing regional education platforms will be an efficient and effective mechanism to address education and training gaps, develop digital economy skills, and expand professional networks across the region.

Other nondigital foundations, such as infrastructure (logistics, electricity) and taxation, also impact digital transformation, and any changes should be designed with this framework in mind.

\footnotetext{
19 See Appendix 2, which charts out the nondigital and digital foundations.
} 


\section{SECTION \\ CAREC Digital Strategy 2030 Pillars: Strengthening the Digital Foundations}

Strong digital foundations are essential to scale and diffuse digital applications and best practices across the public and private sectors. The CAREC Digital Strategy 2030 digital foundations consist of the five pillars shown in the Figure. These pillars are closely interconnected and must be addressed concurrently. They will, in turn, support digital transformation across CAREC's operational clusters.

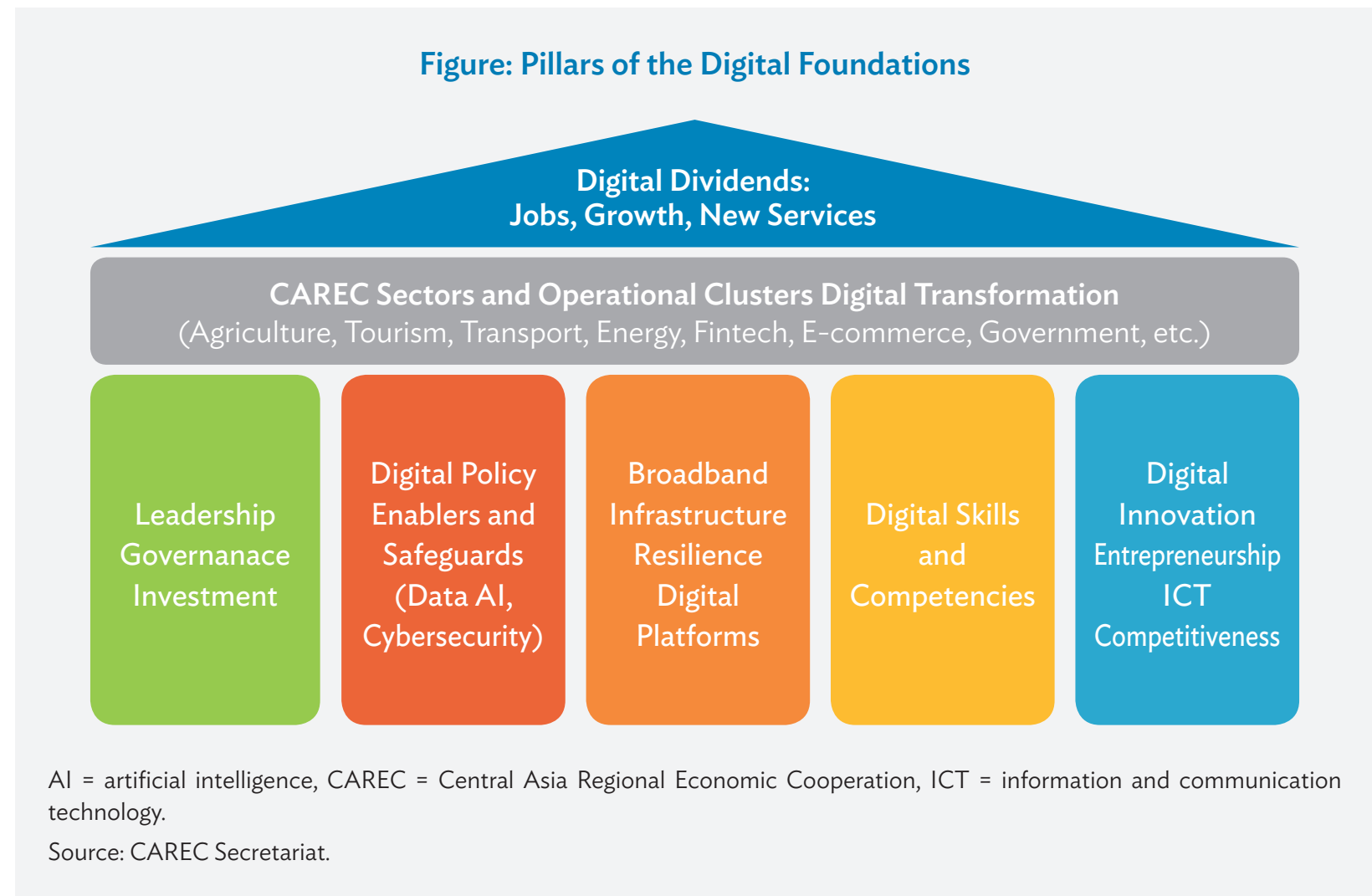




\subsection{Pillar 1: Leadership, Governance, and Investment in the Digital Economy}

\subsubsection{Strengthening Regional Institutions for Digital Leadership}

Strong regional leadership and coordination will achieve buy-in into the common vision and objectives of the CAREC Digital Strategy 2030. It is important to create an effective governance structure in the region to drive the implementation of the strategy and strengthen the institutional structure of the entities responsible for designing, implementing, and following up on the various initiatives and projects. Therefore, regional digital transformation initiatives should be supported by leadership committed to digital transformation at the national level in CAREC member countries.

For coordinating at the regional level, a mechanism to ensure multistakeholders participation and undertake consultations and dialogue on regional digital issues will be implemented. The CAREC Secretariat will facilitate the coordination of this process. This mechanism will aim to create incentives for regional cooperation in the CAREC Digital Space and attract the needed investments. It will also leverage digital technologies to pursue cross-cutting Sustainable Development Goals to promote inclusion, innovation, partnerships, resilience, and sustainability.

\subsubsection{Creating Incentives for Regional Cooperation in the CAREC Digital Space}

Sharing best practices and scaling successful solutions are convenient starting points to lay the ground for further regional cooperation. CAREC member governments have proposed several areas for best practice sharing across the region, building on successful digital initiatives at the national level, such as creating digital awareness, nurturing innovation and entrepreneurship, and extending broadband connectivity to remote and mountainous areas. ${ }^{20}$ The experience of more digitally advanced CAREC members can help emerging countries accelerate their digital transformation progress. To enable this process, they will create a best practice sharing and solution scaling platform to facilitate collaboration.

Developing regulations to create an enabling environment for smaller-scale connectivity providers, including broadband cooperatives, municipal networks, and local businesses, would also help improve connectivity and close the digital divide. License exemptions and tax incentive schemes for smaller operators and telecom providers could be considered where service provision is not commercially viable. Innovative financing models and public-private partnerships (PPPs), such as the indefeasible right of use mechanism, will be explored to attract private sector investment in broadband connectivity projects, including in rural and remote areas. Capacity building and alignment of member countries' legal and regulatory frameworks would be required to implement innovative financing approaches. Ambitious regional infrastructure development initiatives such as the Giga Initiative-a United Nations Children's Fund (UNICEF) and International Telecommunication Union (ITU) partnership to connect every school in the world to the internet-can provide inspiration. Kazakhstan, the Kyrgyz Republic, and Uzbekistan are already among the first 11 Giga country participants.

20 As proposed by member countries during the CAREC country consultation session in June 2021. See Appendix 3 for more details. 
Other regional initiatives include the World Bank's Digital Central Asia-South Asia (CASA) Program, the PRC's Belt and Road Initiative and the Digital Silk Road Strategy, the IsDB's South-South Cooperation and Reverse Linkage program. ${ }^{21}$

The private sector led by ICT companies should be the driving force of regional digital cooperation and sectoral transformation. Governments must provide, simplify, and align legislation and policy to create the enabling environment that encourages and supports regional digital cooperation and promotes investment and entrepreneurship. During the consultation process, private sector stakeholders prioritized partnering on digital solutions at the regional level through collaboration between ICT companies across the region. They also proposed establishing regional tax-free zones for digital solutions development and creating special tax regimes to attract investors and start-ups in digital transformation. A regional digital tax-free innovation zone will be explored as a pilot initiative within the CAREC Digital Space to create a restriction-free digital innovation and collaboration environment. Private sector stakeholders also highlighted the need for the introduction of tax incentives for research and development and the creation of regional ICT export support agencies and other regional governance organizations that would help ICT companies across the region introduce and scale their solutions across CAREC and beyond.22

\subsubsection{Attracting Investment in the Digital Economy}

Investment is one of the key drivers of digital transformation, so CAREC member countries should actively seek out public and private investment partners as well as global donor organizations to fuel digital transformation projects in the region. Lack of investment in the digital economy across CAREC member countries has been highlighted as the top obstacle to regional digital cooperation by CAREC private sector stakeholders. Therefore, it is important to ensure sufficient investment in basic digital infrastructure. ${ }^{23}$ In some CAREC countries, better telecom sector governance and an improved legislative and regulatory framework are prerequisites for private sector-led broadband infrastructure development. CAREC governments should focus their efforts on expanding infrastructure that may not be profitable for private investors, such as broadband connectivity in remote and rural areas. Whereas profitable regional projects - such as smart city transformation; e-commerce platforms; digital agriculture; and industry transformation through the implementation of Industry 4.0 and associated disruptive technologies such as the industrial internet of things (loT), 3D printing, digital twins, digital identity infrastructure, fintech, etc.-should be brought to the attention of private investors.

21 The World Bank's Digital CASA Program aims to increase access to more affordable internet, crowd-in private investment, and improve participating governments' capacity to deliver digital government services in Central Asia and parts of South Asia by developing a regionally integrated digital infrastructure and enabling environment. The PRC's Belt and Road Initiative and the Digital Silk Road Strategy aim to provide investment in a single digital infrastructure across a larger region, which includes CAREC member countries.

22 See Appendix 8 for more details.

23 According to a recent WEF Survey, the top three elements that global investors care about when investing in new digital activities in a particular country or region are: (i) data security regulations, (ii) copyright laws to protect intellectual property, and (iii) data privacy regulations. The top three elements that investors care about in deciding to adopt digital technologies are the: (i) availability of e-payment services, (ii) support for starting digital businesses, and (iii) support for local digital skills development. The top three regulatory elements that investors care about when investing in digital infrastructure are the: (i) ease of receiving licenses for digital infrastructure, (ii) availability of skilled local engineers and other workers, and (iii) use of international standards and regional coordination for infrastructure investment (tied for the third spot). The top three physical elements that investors care about when investing in digital infrastructure are: (i) international connectivity, (ii) national connectivity, and (iii) urban connectivity. These global investor priorities tie in with CAREC country priorities for regional digital cooperation. Therefore, they should be considered and aligned at all stages of implementing the CAREC Digital Strategy 2030 to ensure adequate investment in the regional digital economy and attract funding for priority digital initiatives.

Source: M. Stephenson. 2020. Digital FDI: Policies, Regulations and Measures to Attract FDI in the Digital Economy. World Economic Forum White Paper. September. 
CAREC member countries will consider developing a venue, potentially a digital platform, to convene international investors to support innovative infrastructure, venture financing, and explore different investment models in digital infrastructure and projects across the region. Building on this, and depending on the level of response, CAREC member countries will consider events such as an annual CAREC Digital Transformation Investment Conference, where proposals for new regional digital projects can be presented to attract financing. A prioritized investment portfolio of digital projects will be created to help guide investors to specific opportunities in the region.

CAREC governments must align their regulatory frameworks to ensure they are conducive to private sector investment, especially in relation to small and medium-sized enterprises (SMEs) and start-ups that may not have the needed resources to navigate excessive regulatory and licensing demands.

\subsubsection{Promoting an Inclusive Regional Digital Economy}

Given the considerable variation in the levels of digitalization across the CAREC region, CAREC member countries must adopt an integrated and holistic approach to digital development, bridging the divide between digital hubs and innovation centers in urban areas and the digitally underdeveloped communities in rural, mountainous, and unconnected parts of the region. The COVID-19 pandemic has exacerbated the digital divides across the region. Digital technologies must be used proactively to close those digital divides and engage the youth, women, senior citizens, rural communities, the unemployed, people with lower levels of education, and the disabled in participating in the digital economy and society and benefiting from digital services.
To improve inclusion, CAREC member countries will consider developing region-wide distance education programs that leverage each other's strengths. These may include tools and content designed for mobile devices in low-connectivity settings or to assist teachers in remote areas in improving their digital skills and integrating distance learning into the teaching process.

\subsubsection{Leveraging Digital Technologies to Pursue Cross-Cutting Sustainable Development Goals}

The UN Sustainable Development Goals of inclusion, innovation, sustainability, resilience, partnerships, and participation will apply broadly to the CAREC Digital Strategy's efforts to provide meaningful connectivity across the region.

To ensure alignment with these principles, the CAREC Digital Strategy 2030 will

- promote partnerships among the public and private sectors, universities, and civil society organizations;

- encourage the creation of digital public goods to realize the benefits of increased internet connectivity across the region;

- establish acomprehensiveand nondiscriminatory perspective in public policies for digital inclusion; ${ }^{24}$

- promote telework in the region, updating labor policies to ensure adequate social protection, especially for vulnerable groups;

- leverage the use of digital technologies to mitigate the effects of climate change and natural hazards, reduce greenhouse gas emissions, and promote green sustainable development; and

$\checkmark$ promote civil society participation in assessment, mediation, transparency, capacity building, and consumer protection.

24 In line with United Nations efforts in this space, annual scorecards on digital inclusion can be created to measure both digital inclusion and literacy. Source: United Nations. 2020. Report of the Secretary-General: Roadmap for Digital Cooperation. 


\subsection{Pillar 2: Digital Policy Enablers and Safeguards}

\subsubsection{Harmonizing Legislation and Regulations across CAREC Member Countries and Adopting Regional Legislation to Promote Digital Partnerships}

Creating the common CAREC Digital Space requires eliminating legal barriers and harmonizing regulations, taxation, and digital identification systems to enable a freer flow of data between CAREC member countries. Digital infrastructure (Section 5.3.1) should be based on common standards and principles of interoperability, scalability, and security. Sustaining these standards and principles is critical to mobilizing digital platforms and providing cross-border e-government services, enabling e-commerce and trade and the overall efficient operation of the common CAREC Digital Space.

The CITA 2030 is undertaking measures to reduce existing barriers to cross-border trade. By coordinating with the CITA 2030, especially on implementing e-commerce and e-payments, both producers and consumers of digital services will benefit. Further cross-border competition between firms will allow the realization of economies of scale at a regional level. CAREC member countries will adopt regional standards for digital identity, digital signature, e-apostille, and electronic medical records.
Harmonizing regional policies and standards requires an inclusive consultation process within the region's digital ecosystem. This should consider best practices from other regional organizations, such as the European Union (EU) and ASEAN, that promote data harmonization and common standards to empower cross-border digital transformation and the implementation of new technologies such as artificial intelligence $(\mathrm{Al}){ }^{25}$

\subsubsection{Enhancing the Cybersecurity of the CAREC Region}

According to the Global Cybersecurity Index 2020, the most cyber-secure countries in the CAREC region are Kazakhstan (31st), the PRC (33rd), and Azerbaijan (40th). Georgia, Pakistan, and Uzbekistan have some levels of commitment to cybersecurity, while Afghanistan, the Kyrgyz Republic, Mongolia, Tajikistan, and Turkmenistan still face significant challenges. ${ }^{26}$

CAREC member governments should become more active in global cybersecurity initiatives and further strengthen relations with the international community and the private sector on cybersecurity to undertake measures at both national and regional levels. Measures for consideration include harmonizing cybersecurity regulations, improved computer emergency response team cooperation among CAREC members, additional training, and capacity building. ${ }^{27}$

As cybersecurity is a top priority for global funding organizations, including the International Finance Corporation and the World Bank, which launched

25 For example, the European Single Digital Market is a framework designed to facilitate access and trade leveraging digital data. Similarly, the EU-African Union Digital Economy Task Force is a platform for partnerships between the private sector, donors, international organizations, financial institutions, and civil society to progress African digital transformation for cross-border digital integration and to bring benefits to all citizens. In Asia, the ASEAN Framework on Digital Data Governance aims to harmonize data standards, data governance, and data protection frameworks regionally to enable innovation, cross-border trade, and cybersecurity. See also World Bank. 2021. Thought Leadership and Fresh Insight from the World Bank's Digital Development Practice. Brief. 10 May.

26 International Telecommunication Union (ITU). 2021. Global Cybersecurity Index 2020: Measuring Commitment to Cybersecurity.

27 See Appendix 8 for more recommendations on regional cybersecurity initiatives. 
the Cybersecurity Multi-Donor Trust Fund under the umbrella of the Digital Development Partnership, CAREC member countries will explore collaboration with these institutions to boost cybersecurity.

\subsubsection{Aligning Data Policies across CAREC Member Countries}

Effective digital transformation and implementation of new disruptive technologies, such as $\mathrm{Al}$, the loT, blockchain, etc., requires alignment of data policies across the region. CAREC member countries will explore options for adopting regional data policies that address the shared needs and requirements of the common CAREC Digital Space while also ensuring the harmonious development of data strategies at the country level to bring in effective data management (which includes data creation, collection, protection, sharing, processing, storage, analysis, use, and reuse).

Such CAREC regional data policies must emphasize the need for trustworthy regional data infrastructures to collect, share, process, store, analyze, and archive data to support the implementation of priority regional digital transformation initiatives. They should address the importance of setting data standards across the region and issue semantic interoperability guidelines for data sharing. Effective data management at the regional level also requires appropriate governance structures overseeing the complete data life cycle. To propel regional digital transformation initiatives, CAREC member countries should ensure that regional data policies address the following: (i) sharing, using, and reusing data across the CAREC region; (ii) aligning existing data policies, laws, and regulations; (iii) setting up regional institutions for data governance; (iv) ensuring provisions for data sovereignty at the country level; ( $v$ ) developing new data policies to ensure trust in the data economy; (vi) creating mechanisms to harness the value of regional data and translate it into data-powered products and services; and (vii) creating an integrated data system to manage all aspects of the data life cycle in the region.

After aligning data policies across the region, CAREC member countries will be able to create a regional data governance regime to include data policies; data governance regulations; data infrastructures, platforms, and architectures; data analytics; data skills; and other elements. ${ }^{28}$

\subsubsection{Supporting the Development of Artificial Intelligence in the Region}

Regional efforts to strengthen and align data regulations and policies should inform the development of regional AI policies, as effective data management across the region is fundamental to developing Al-based applications and services across CAREC, including in CAREC's operational clusters. Alignment of regional and national $\mathrm{Al}$ policies should aim to help CAREC members catch up and leapfrog in their digital development. These policies should include (i) building Al capabilities and robust digital economy foundations; (ii) building capacity at the regional level; (iii) convening and aligning stakeholders, particularly the private sector, around a common regional $\mathrm{Al}$ agenda; (iv) lowering costs and barriers to entry for businesses; ( $v$ ) delivering innovative business models superior to traditional solutions; and (vi) reaching the underserved through Al solutions. At the same time, regional Al policies should address security issues and the need to upgrade the skills of the labor force to prepare for the job displacement that can result from these technologies.

28 See Appendix 8 for more details on regional data policies. 


\subsection{Pillar 3: Digital Infrastructure, Resilience, and Platforms}

\subsubsection{Connecting Digital Infrastructure to Bridge the Digital Divide}

While most CAREC member countries have high mobile penetration rates, many of them lag in broadband access. This issue warrants extending wireless networks to unserved and underserved areas and building terrestrial backbone infrastructure. As mentioned in an ADB report, "substantial fiber-based national backbones and backhaul infrastructure will be essential" to "support growing broadband use and data traffic...(and) stimulate the development of online government services and business innovation." 29 Affordable mobile access is crucial to ensure digital inclusion and offer mobile connectivity opportunities in rural, mountainous, underdeveloped, and difficult-to-access areas. Underserved communities should be proactively offered mobile broadband connectivity as a public good requiring a dedicated effort by governments and innovative partnerships with the private sector.

Improvements in digital connectivity can provide leapfrogging opportunities to CAREC member countries currently lagging in digital development due to digital connectivity gaps or slow mobile internet speeds. Encouraging the use of cost-efficient technologies to bring affordable broadband access to remote, rural, and semi-urban areas; fostering sustainable investment models; and developing alternative connectivity providers such as community networks can help bridge the digital divide across the region.
Appropriate metrics to measure the efficient use of the radio-electronic spectrum are also needed. Spectrum is a key input to expanding access to mobile broadband access. With the need to increase 4G uptake and prepare for $5 G$, governments need to ensure that their spectrum policy provides a long-term and predictable investment environment for the license holders, enhances digital inclusion, and aligns with global standards. Governments also need to balance the trade-off between increasing government revenue and achieving digital inclusion objectives: high spectrum prices tend to translate to higher prices and lower quality access to end-users, especially in developing countries. Infrastructure sharing and cross-sector co-deployment can minimize costs, disruption, and environmental impacts. ${ }^{30}$ Co-deployment of fiber-optic cables or mobile towers alongside roads, water mains, and power transmissions is a strategic approach to accelerate the rollout of broadband networks and help future-proof the infrastructure assets. To ensure equitable digital access across the region, CAREC member countries will adopt policies and plans with specific targets relating to affordable universal access, stipulating the deployment of resilient high-capacity broadband networks.

Lastly, CAREC member countries must consider greener approaches to designing digital infrastructure projects, such as regional data centers and telecom infrastructure that leverage renewable energy and explore opportunities for infrastructure sharing across the region.

\subsubsection{Building Digital Resilience Capacity}

Digital resilience refers to the agility and adaptability of the laws, regulations, institutions, human resources, and the infrastructure underpinning core digital

29 ADB. 2015. Unleashing the Potential of the Internet in Central Asia, South Asia, the Caucasus and Beyond. Consultant's report. Manila. p. 68.

30 Columbia Center on Sustainable Investment. 2017. Toolkit on Cross-Sector Infrastructure Sharing. New York; C. Park, A. Yershov, and A. Kobsev. 2020. ICT Infrastructure Co Deployment with Transport and Energy Infrastructure in North and Central Asia. Asia-Pacific Information Superhighway Working Paper Series. Bangkok: UNESCAP. 
systems to withstand and bounce from crises and shocks. Digital technologies, infrastructure, and tools are becoming increasingly critical. Governments and businesses use them to enable key operations and processes and to address and manage crises. As digital transformation accelerates, more critical services and processes are provided in digital form or rely on digital infrastructure, resulting in higher cyberattack risks.

CAREC private and public sector representatives highlight digital resilience as a top priority for regional digital collaboration. The CAREC region is vulnerable to various types of natural hazards. It is one of the world's most seismically active areas. "An analysis of the transmission map of fiber optic cables in Central Asia shows that the existing ICT infrastructure may be exposed to seismic, flood, and landslide risks," leading to internet disconnection, with risks especially high in Turkmenistan and Uzbekistan, and moderate for Azerbaijan, the Kyrgyz Republic, and Tajikistan. ${ }^{31}$ CAREC member countries will adopt legal, regulatory, and policy frameworks to promote the resilience of digital infrastructure and services such as data centers, terrestrial fiber-optic cables, power generators, etc. In the framework of collaboration on disaster risk management across the region, a CAREC Geospatial Information Platform will be considered during implementation to help share geospatial data across borders, particularly environmental information that can be leveraged in disaster responses.

A complementary pillar for resilience is also cybersecurity (Section 5.2.2). CAREC member countries should consider adopting an integrated standards-based risk management framework to build regional digital resilience capability. ${ }^{32}$
The region should also learn from the COVID-19 experience that has revealed the infrastructure, policy, and response management shortcomings across CAREC and should create targeted programs to address those gaps. It is important to develop, strengthen, and sustain the resilience and security of specialized digital infrastructure to ensure business continuity and the uninterrupted availability and security of digital government services, digital education, e-health, online research and development, and other key services across the region to withstand potential natural hazards, security crises, pandemics, and other unexpected events.

\subsubsection{Building a CAREC Regional Platform Economy}

Platform-based business models create value by connecting users (both consumers and producers) on an online network. ${ }^{33}$ In a platform economy, "the platform does not own the means of production, but rather creates the means of connection. The strength of the platform economy lies in its ability to eliminate trade barriers by using increased information sharing between different players and circulation of data to its advantage. This creates a much more open economic system, with much greater participation of its users (footnote 33 )."

For CAREC, platforms offer unprecedented opportunities for regional connectivity, integration, innovation, and economic growth. They can boost innovation across the region; power local content development; and transform the industry, business, and SMEs by matching supply and demand for products and services. They can bring together various stakeholders to scale education, training,

\footnotetext{
31 UNESCAP. 2018. Enhancing E-Resilience for Digital Economy in Central Asia. Asia-Pacific Information Superhighway Policy Briefs. No. 2. Bangkok. p. 3.

32 See Appendix 8 for a list of cybersecurity initiatives.

33 Deloitte. 2019. The Rise of the Platform Economy. The Netherlands.
} 
digital skills development, and capacity building efforts, including for minorities and disadvantaged communities in remote areas. They can help create a regional job market and connect talent with job opportunities. Platforms can also boost tourism and travel; transform agriculture, energy, transport, and other strategic sectors; and power smart cities and villages. They can also help identify sources of funding for specific digital transformation projects. While global and regional platforms are active across the CAREC region, nurturing national and subregional platforms is important to empower local producers and consumers to facilitate trade across borders.

To deliver digital dividends, a regional platform economy requires strong digital foundations including ubiquitous broadband connectivity, cloud infrastructure, basic and advanced digital skills, interoperability of digital infrastructures across the region, common regional data and $\mathrm{Al}$ policies, and the application of emerging technologies. Moreover, investment in strong, scalable, and secure regional cloud infrastructure is required to support regional digital platforms. CAREC member countries will consider adopting the hybrid cloud model including a "cloud first" policy to create cloud-based virtual environments, with appropriate data safeguards in place.

CAREC member countries will consider CAREC Digital Space Portal to provide access and link all of the region's future interconnected digital platforms and platform clusters such as (i) the digital innovation platform; (ii) the digital industry, digital SMEs, and fintech platforms; (iii) the digital skills, education, training, and job opportunities platforms; (iv) the digital agriculture and food platforms; and (v) other platforms that will continue to appear as the digital transformation process takes hold. The CAREC Digital Space Portal will input its data from the CAREC Open Data Portal, which will host publicly available information at a single point of access. ${ }^{34}$

\subsection{Pillar 4: Digital Skills and Competencies}

Most CAREC member countries face a shortage of skilled digital talent across all sectors of the economy. This digital skills shortage will get worse as the digitization of industry and government accelerates.

CAREC member countries will address the critical issues of unemployment, migration, and brain drain from the region by developing and enhancing digital skills broadly across the CAREC population. These should be both basic digital literacy skills for everyone and advanced digital skills for the young people and professionals across all sectors of the economy to fill the existing talent gaps, evolve their careers, and take up new and better jobs. CAREC governments will focus on establishing strong education systems, particularly in STEM fields, while investors can work with the private sector and the academic community to roll out e-education platforms with specific training programs focusing on professional, managerial, advanced, and other types of digital skills.

To accelerate the development of digital skills across CAREC, the member countries should introduce digital literacy programs for all citizens. Priority must be assigned to developing professional and managerial digital skills for public sector employees, including at the senior management level, especially in light of the competencies required to implement the CAREC Digital Strategy 2030. CAREC member countries will consider CAREC Digital Skills Platform to launch (i) basic digital skills programs and courses for the general population; (ii) advanced digital skills courses on various subject areas for digital professionals, such as courses related to specific skillsets, new technologies, or sector-specific solutions and architectures; and (iii) digital leadership and management courses for senior public and private sector workers. This platform could link to existing global and regional digital skills platforms

\footnotetext{
34 See Appendix 8 for more details.
} 
such as the Asian and Pacific Training Centre for ICT for Development Virtual Academy. ${ }^{35}$

CAREC member countries will consider a CAREC digital literacy and digital skills action plan to be coordinated with and adopted by the member states to develop regional digital skills programs using common e-learning platforms and tools. Specific policies will be based on an analysis of the labor market dynamics and address basic universal digital skills for everyone, as well as specific digital skills needs at various educational levels. ${ }^{36}$

\subsection{Pillar 5: Innovation, Entrepreneurship, and Information and Communication Technology Competitiveness}

\subsubsection{Nurturing the Digital Innovation Ecosystem}

The innovation gap is at the heart of the digital divide, as digital technologies are developing faster than government and institutions are able to formulate policies to regulate these technologies and leverage their benefits for the larger good of society. ${ }^{37}$ There is a need to develop appropriate policies, programs, resources, and know-how to empower innovation across the region and encourage collaboration between key stakeholders including the public and private sectors, the academic and expert communities, research and development institutes, angel networks, and venture capital to support the region's entrepreneurs in delivering innovative solutions required to compete in the digital age.
The importance of technology start-ups in the digital economy presents an opportunity for the CAREC region to leapfrog and develop a unique regional innovation ecosystem. Most innovation ecosystems define their area of influence or their constituency locally or subnationally. A regional (cross-border ecosystem) would bring considerable advantages as well as challenges, which CAREC can help tackle. Even more importantly, to enable leapfrogging despite humble budget allocation for innovation in most national budgets and to boost the innovation ecosystem, CAREC needs to develop a mechanism to foster the quick adoption, dissemination, and scaling of existing innovative products and solutions across the region, leveraging its combined market size. Effective innovation and the adoption and scaling of existing digital products and solutions will require a change in traditional cultures and mindsets through awareness raising, trust building, educational initiatives, as well as digital skills training programs that would help users understand the benefits and advantages of new digital solutions.

Product, service, data, and regulatory sandboxes across CAREC can encourage innovation, strengthen the innovation ecosystem, encourage co-creation of value, and allow companies in CAREC member countries to experiment with new ideas and reach scale at the regional level. Linkages with national education, research, and scientific institutions will bring the innovations to the market by realizing their commercial viability. Cooperation between the public and private sectors and the academia within the regional digital ecosystem will be encouraged by CAREC member countries to accelerate the development of technology companies, starting with incubators, accelerators, business networking, and digital ecosystem observatories and onto the

\footnotetext{
35 Asian and Pacific Training Centre for Information and Communication Technology for Development. https://www.unapcict.org/.

36 See Appendix 8 for more information on the CAREC digital skills initiatives.

37 According to the Global Innovation Index, there is a lot of room for improvement in CAREC member countries' innovation performance, except for the PRC (ranking 14th). While Mongolia (58th), Georgia (63rd), and Kazakhstan (77th) have reached some degree of success in building innovation ecosystems, more innovation focus is required across the rest of the region.
} 
prototyping, piloting, and scaling of new digital applications, products, and services. Complementary pillars including developing necessary digital skills and know-how; expanding digital inclusion to help solve the problems of the poor and disadvantaged communities across the region; and leveraging new technologies such as $\mathrm{Al}$, loT, and data analytics in the innovation process will be given priority in this process.

CAREC member countries should develop national and regional digital innovation policies and build an associated digital platform to scale effective policy solutions and mechanisms for encouraging digital innovators. Regional policies should provide a set of instruments that incentivize investors and companies to innovate and keep talented people in the region. The CAREC program's work on start-ups ecosystem development can serve as the pilot for these initiatives to build on. The CAREC Digital Innovation Platform will provide "easy access to knowledge, learning resources, indicators and communities of practice on the design, implementation, and evaluation of innovation policies." ${ }^{38}$ It would help governments and nongovernment organizations learn from good practices on developing digital innovation policies across CAREC member countries and elsewhere. The CAREC Digital Innovation Platform would be integrated into the CAREC Digital Space Portal.

National and regional public relations campaigns are needed to improve the public perception of digital entrepreneurs and boost the value of innovation and digital adoption. These campaigns may feature personal stories of entrepreneurs and innovators and success stories of start-ups in different areas of the region's social and economic life. These initiatives will be part of the regional strategic digital transformation communication plan. ${ }^{39}$

\subsubsection{Promoting the Adoption and Effective Use of Digital Technologies by Small and Medium-Sized Enterprises}

Digital technologies offer unprecedented opportunities for companies, notably SMEs, to enter new markets by enabling them to participate in regional and global digital supply chains. Similar to other regional initiatives that leverage digital technologies to boost SME development, such as that of the EU, ${ }^{40}$ CAREC member countries should focus on improving the framework conditions for the smart use of digital technologies in its key operational clusters and consider the establishment of the CAREC Digital SMEs Program and CAREC Digital SMEs Platform. ${ }^{41}$

A vibrant regional digital economy requires developing local and regional digital services, systems integration, and software development companies serving local governments and businesses. Therefore, opportunities for local ICT companies to grow within the CAREC region are particularly valuable as they can create a testing ground and a competitive environment for local companies to become regional players and extend their product and service offering and experience beyond their native countries.

CAREC member countries will consider the CAREC Digital Business Platform to enable local ICT companies to gain regional visibility by promoting their products and services on the platform and learn about government tenders and contracting opportunities across the CAREC region. Governments across the region would be encouraged to conduct their tendering and procurement of ICT services through this platform. The platform can also connect various

\footnotetext{
38 F. Silva and A. de Carvalho. 2016. Research and Development, Innovation and Productivity Growth in the Steel Sector. Paris: Organisation for Economic Co-operation and Development (OECD). p. 7.

39 See Section 7 for more details on the strategic communications plan.

40 European DIGITAL SME Alliance. https://www.digitalsme.eu/.

41 See Appendix 8 for more information on regional SMEs initiatives.
} 
ICT parks and innovation and technology parks across the region to establish an innovation network.

\subsubsection{Promoting Regional Content}

Leveraging digital technologies to close the digital content gap at the regional level can contribute to preserving the cultural heritage of CAREC member countries. It can also help preserve the cultural and linguistic wealth and diversity of CAREC member countries, promote cultural expression and local languages, as well as complement the development of the tourism sector in the region. Local digital content development and sharing at the regional CAREC level will also enable member countries to benefit from more regional cooperation opportunities by leading to new business opportunities in trade, agriculture, transportation, tourism, media, and ICT sectors.

The CAREC Regional Content Development Platform will provide local content developers with an opportunity to create, manage, and distribute their content across the region. This platform can help build an inclusive knowledge society across CAREC and create opportunities for minorities and disadvantaged groups to participate in content creation and exchange. It would also widen access to local content across the region and enable the collection, localization, preservation, and dissemination of local and regional content. At the regional level, the production of digital content through intellectual property protection policies as well as funding mechanisms should be encouraged. Critical thinking and media, information, and digital literacy skills are important in developing an enabling environment for local content creation, including online training programs to improve basic literacy. CAREC member countries can also work with global development organizations that invest in building local content development skills and opportunities, such as the United Nations Educational, Scientific and Cultural Organization (UNESCO) Programme for Creative Content. ${ }^{42}$ As governments collect and distribute relevant and local information, CAREC member countries will also consider creating government platforms across the region during the strategy's implementation. ${ }^{43}$

42 UNESCO. Programme for Creative Content.

43 Internet Society, Organisation for Economic Co-operation and Development (OECD), and UNESCO. 2012. The Relationship between Local Content, Internet Development and Access Prices. 


\section{SECTION \\ CAREC Sector and Cluster Transformation}

\subsection{Leveraging Digital Technologies to Accelerate CAREC Operational Cluster Transformation}

The CAREC 2030 Strategy emphasizes that integrating ICT across the spectrum of CAREC operations will be a cross-cutting priority. ${ }^{44}$ Therefore, establishing the path for accelerating digital adoption within CAREC's five operational clusters is essential to achieving higher productivity, efficiency, and customer satisfaction gains at the sectoral level, which will drive the digital dividends of higher growth, new jobs, and better services.

The CAREC Digital Strategy 2030 implementation will further develop cluster-level digital transformation strategies, project portfolios, and implementation road maps. Some of the ways these will be pursued are described in the following sections.

\subsection{Government as a Platform}

The government's digital transformation is a key element in creating the CAREC Digital Space. Sharing data and services between public administrations within and across borders facilitates freer movement of goods, capital, services, and people.

Joint efforts from CAREC member countries are required to ensure the efficiency of cross-border digital public services through enabling data exchanges and interoperable digital public service delivery. In line with global best practices, CAREC governments will adopt the "government as a platform" (GaaP) approach to deliver innovative public services nationally and regionally in more efficient and user-friendly ways. This approach enables the co-creation of a wide range of services by all economic actors including administrations, citizens, and businesses, whereas governments evolve to the role of ecosystem moderator from their traditional role as a service provider. ${ }^{45}$ CAREC member governments should emphasize facilitating new, improved regional and cross-border services; reusing common components and platforms; consolidating infrastructures; sharing data with third parties and between administrations in priority areas; and developing trusted, user-centric digital solutions.

\subsection{Economic and Financial Stability: E-Finance and Fintech}

The finance sector often leads in leveraging disruptive digital technologies. To establish online marketplace lending platforms in the region, services to match lenders with borrowers (especially to SMEs and individuals, at lower interest rates without the need for collateral) is a speedy and convenient way to offer credits across the region. Technology platforms and e-payment solutions can also facilitate access to finance across the value chain for product suppliers and distributors, help gather data about SMEs to

44 ADB. 2017. CAREC 2030: Connecting the Region for Shared and Sustainable Development. Manila.

45 Accenture. 2018. Government as a Platform: 2018 GaaP Readiness Index. 
enable lending decisions, and provide SMEs access to business management tools.

Mobile money solutions can expand the reach of financial services to the unserved and underserved populations of the CAREC region. FinTech can help address the gender gaps in financial inclusion by giving women greater control over their finances and removing the barriers of distance, physical safety, and cultural perceptions through online solutions. While women across the region have become more active users of financial services over the last decade, the gender gap persists. ${ }^{46}$ Fintech can contribute to economic and financial stability in the region. ${ }^{47}$ A recent CAREC Institute working paper noted that the region "trails the world and other regions on financial inclusion" but has "immense potential for financial inclusion by harnessing financial technologies." ${ }^{8}$ Coordinated regulatory reform will encourage the use of such technologies to promote financial inclusion and boost growth. Governments can learn how other countries (for example, in sub-Saharan Africa) have encouraged private sector partnerships between banks and mobile network operators to enable financial inclusion. It is important to ensure regional interoperability of mobile payments and banking systems. Alignment and standardization can smooth cross-border transactions, strengthen financial integration, and promote stability.

Appropriate supervision of the sector and updated regional policies on security, data management (including data standards and personal data protection), and interoperability of financial systems are required to leverage fintech solutions in the region and spur the emergence of new players and SMEs in this field. It is, therefore, recommended to define system architecture, information architecture, and transformation road map for the finance sector.
Financial systems architecture, interoperability guidelines, and information technology (IT) standards for finance sector transformation across CAREC will be developed based on the sector stakeholders' proposals for legislation and regulatory supervision, data management, and data protection. The resulting regulatory and supervisory framework would encourage existing firms and new entrants to provide innovative services and financial products for clients across the region. ${ }^{49}$

\subsection{Trade, Tourism, and Economic Corridors}

CAREC's geographical position as a hub between Asia and Europe emphasizes the opportunity to leverage digital solutions to accelerate the development of trade, tourism, transportation, and economic corridors across the region.

\subsubsection{E-Logistics, Cross-Border Services, and E-Customs}

The objective of the Customs Cooperation Committee under the CITA 2030 includes promoting innovations in digital trade initiatives, such as in customs technology, supply chain management, and paperless trade. The CAREC Digital Strategy 2030 will work in sync with the CITA 2030 to implement e-logistics services and supplement their agenda by introducing the latest developments in supply chain and logistical technologies. These supplementary activities will include activities such as (i) creating a regional hub for the transit of goods for the transformation of the logistics and transportation sectors; (ii) leveraging emerging technologies such as loT combined with mobile technologies; and

\footnotetext{
46 E. P. Sioson and C. J. Kim. 2019. Closing the Gender Gap in Financial Inclusion through Fintech. ADBI Policy Brief. No. 2019-3. Tokyo: ADB Institute.

47 CAREC Program. 2021. CAREC at 20: Reimagining Regional Cooperation through Digital Transformation: A Policy Note for the High-Level Session during the ADB Annual General Meeting. ADB 54th Annual General Meeting. 4 May. Manila.

48 K. Umar. 2021. Financial Inclusion and Fintech in CAREC: Constraints and Prospects. CAREC Institute Working Paper. Urumqi. p. 14.

49 This process should be followed to map out the digital transformation road map for each of CAREC's priority sectors.
} 
(iii) ensuring interoperability at all levels, including a common legal framework, business processes, standard document, data formats, and technically compatible infrastructures. This strategy will enable the development of interconnected solutions for warehousing, transport, and delivery of goods based on regional and global supply chains. Other integrated solutions, such as introducing automated payment systems for rail and road freight to improve efficiency, will also be considered.

CAREC member countries will develop a cross-border e-logistics platform to support the information exchanges underpinning cross-border and transnational supply chains. Integrating logistics, customs clearance, finance, and insurance functions on a single unified platform will enable smoother functioning of cross-border operations. ${ }^{50}$

For cross-border services and e-customs, business process reengineering should be based on the "digital by default" principle to support paperless transactions across the region. The paperless systems should be interoperable, scalable, and secure and support the common customs processes. The CAREC Digital Strategy 2030 will also promote initiatives such as online licensing and certification, unified checkpoint models, electronic queues at border points, and information sharing mechanisms using digital platforms.

\subsubsection{E-Commerce}

Another area where coordinated regulatory reform will encourage technology adoption and provide regional benefits is e-commerce (footnote 45). Most CAREC members are not well integrated into the global economy (excluding the PRC, CAREC accounts for less than $1 \%$ of global trade). Digital technologies offer an opportunity for increasing trade volume and scope.
In line with the CITA 2030, the CAREC Digital Strategy 2030 will promote the growth of e-commerce across the region by harmonizing regulations for the taxation of cross-border e-commerce and improving the exchange of financial information between revenue authorities. In particular, the CAREC Digital Strategy 2030 will address the low public trust in online transactions by supporting policy for the online resolution of complaints and improving user protection. Legislation and standards-based regulations for smartphone services (m-commerce), back-office cloud-based e-commerce, digital currencies, and cybersecurity for financial transactions will be necessary to gain the trust of users and ensure a level playing field for developers and new entrants into the e-commerce domain.

\subsubsection{Digital Tourism}

Digital technologies will be a key element for developing the tourism sector across CAREC and addressing some of the existing challenges including the impact of the COVID-19 pandemic, the global lack of awareness of the CAREC region's cultural wealth, the perceived safety, security and travel risks, and the sector's fragmentation.

The CAREC Tourism Strategy 2030 has introduced digital solutions to address these issues by, for instance, implementing the CAREC Tourism Portal. By building further on the portal, the strategy will develop the CAREC Tourism Platform to promote cooperation and horizontal linkages between all the stakeholders in the CAREC region's tourism ecosystem, including public administrations; health and education authorities; transportation, travel, tourism, hospitality, finance, insurance, food, and agriculture industries; and tourism promotion agencies and organizations. The platform can be used for destination awareness building, marketing and promotion, the latest augmented reality and virtual reality technologies (which are also being

50 The example of Singapore's National Trade Platform can be studied as a best practice. 
developed by companies and start-ups in the region), information sharing, advocacy, on-going training, capacity building, best practice sharing and skills development, creation and positioning of new products and services, networking, and cross-sectoral linkages. In addition, it will consider to launch future initiatives such as a single CAREC e-visa, the use of national IDs as travel documents for CAREC citizens, liberalization of the CAREC air space, and other regional marketing initiatives. The CAREC Tourism Platform will thus contribute to the overall sustainable development of a competitive tourism industry across CAREC with spillovers into other sectors.

Other platforms such as the CAREC Cultural Heritage Digital Platform and CAREC Gastronomy Platform will also be considered for implementation as further initiatives that will be undertaken as part of the tourism sector's digital transformation. ${ }^{51}$

\subsubsection{E-Procurement Platform for Public Administrations}

Public procurement of goods and services represents a significant part of the CAREC economy. Digital procurement offers opportunities for both governments and suppliers to streamline and simplify their processes and make them more efficient and transparent by cutting delays and reducing costs. Implementing a common CAREC E-procurement Platform comparable with the EU's Peppol projector would enable cross-border procurement between an administration in one country and suppliers in another country. Developing an open source CAREC E-procurement Platform for member states' public administrations through a public-private partnership (PPP) with suppliers would create an agile and transparent procurement mechanism and could engage not only large private sector companies but also SMEs and start-ups.

\subsection{Infrastructure and Economic Connectivity: Connecting Smart Cities and Villages across CAREC}

Migration to cities, refugee crises, and the COVID-19 pandemic have emphasized the increased need for digital technologies to address urban and rural challenges. To scale the rollout of inclusive peoplecentric smart city solutions across the CAREC region, CAREC will consider developing a regional platform-based CAREC Smart Cities Program to accelerate the efforts of individual cities to become "smart." The program would (i) enable cities across CAREC to learn from each other by sharing local and international best practices; (ii) help create the institutional and governance structures to manage complex smart cities projects across the region; (iii) plan the required infrastructure investments; (iv) reinforce the nondigital and digital foundations for smart cities development; and ( $v$ ) create a regional ecosystem connecting urban government, telecommunications and technology providers, the academic and scientific communities, development and funding partners, as well as city resident representatives. Smart cities across CAREC will contribute to developing CAREC's key operational clusters by fostering tourism, trade, and economic connectivity. ${ }^{52}$

Given the need to bridge the urban-rural digital divide across the region, the CAREC Smart Cities Program would also include a focus on smart villages by extending the reach of broadband infrastructure and regional platforms to the rural areas and enabling towns and villages across the region to (i) access digital services such as e-health and e-education, (ii) take advantage of digital agriculture technologies, (iii) implement $\mathrm{Al}$ solutions for agribusiness, and (iv) engage in e-commerce and trade with other villages and cities across the region and beyond..$^{53}$

\footnotetext{
51 See Appendix 9 for more details.

52 See Appendix 9 for more information on CAREC Smart City Development.

53 See the PRC's Taobao Villages example in Appendix 9.
} 
Success in scaling and connecting smart cities and villages across CAREC will strengthen the innovation and entrepreneurship ecosystem across the region and boost the development of CAREC's key operational clusters. A network of connected smart cities and villages across the region will accelerate the emergence of CAREC as a smart region boasting a high level of inclusive economic and social development and global competitiveness.

\subsection{Agriculture and Water Cluster: Digital Agriiculture}

Despitegeneral urbanization trends, CAREC member countries still have high percentages of populations living in rural areas. ${ }^{54}$ Thus, expanding broadband connectivity to rural areas, raising awareness of digital technologies among rural populations, and developing digital skills and competencies in rural areas are key to bridging the digital divide and achieving digital dividends in the CAREC region. The predominance of rural populations also explains why CAREC member countries identified digital agriculture as a priority for digital transformation in the region. ${ }^{55}$

A comprehensive approach to digital adoption in agriculture is required to transform agriculture into an economic recovery engine for the region, especially in light of the COVID-19 pandemic, raising concerns about food security and the need to make the sector more resilient to climate change. Digital solutions and best practices can help improve the region's global competitiveness and the market reach of its agricultural products. The sector's digital transformation shall become a joint coordinated effort of the CAREC agriculture ecosystem's key stakeholders including ministries; public sector entities; private sector companies from various sectors including storage, transportation, logistics, machinery producers, biotechnology, telecom and chemical industry players, agri-tech and fintech solution providers; academic institutions; and the farmer communities.

CAREC member countries will consider hosting a regional digital platform for food and agriculture; this can link with the International Platform for Digital Food and Agriculture proposed by the Food and Agriculture Organization of the United Nations (FAO). ${ }^{56}$ CAREC member countries will also join in the global digital agriculture collaboration and knowledge sharing through online communities of practice, including existing regional networks such as ESCORENA and AGROWEB, and global platforms such as the e-Agriculture Community of Practice.

\subsection{Human Development}

Greater use of digital platforms can boost the development of skills and help integrate the regional labor market. For example, a regional job search system would help match workers to jobs more efficiently. It would also provide valuable information about the availability or shortage of skills in particular areas.

The CAREC Employment Service Platform will be established to create a potential single labor market across CAREC. The platform would match job vacancies with job seekers across the region and support cross border recruitment. The system would provide information, advice, and recruitment, or job matching services. The system would provide a one-stop shop for employment opportunities. The platform would also establish a network of advisers to offer quality services for both workers and employers.

54 See Appendix 9 for more details.

55 In response to the CAREC Secretariat questionnaire in June 2021.

56 FAO. 2020. International Platform for Digital Food and Agriculture. See Appendix 9 for more details on the CAREC Digital Food and Agriculture Platform. 
The COVID-19 pandemic has highlighted the potential of remote-learning technologies. Given the highest priority assigned by CAREC stakeholders to basic and advanced digital skills development and universal digital literacy, action should be taken to catalyze cross-border cooperation on higher education, adult learning, and technical and/or vocational training based on the pooling of educational resources and expertise. Promotion of regional trade in education services can expand supply and choice while enhancing quality. Digital education platforms created through collaboration and best practice sharing between educational institutions across the region will be explored as options for expanding remote learning.
Similar approach will be taken in health care, in coordination with the CAREC Health Strategy 2030, to utilize digital health solutions. This approach will include telemedicine technology, which allows for remote consultations and the sharing of resources and expertise and greater cooperation between health specialists across the region. The pandemic can also catalyze regional cooperation in monitoring communicable diseases, including the development of early warning systems and disease surveillance centers, and for developing digital solutions for data sharing on vaccinations, including regionwide recognition of e-vaccination certificates and the creation of a unified registry of vaccinated people. 


\section{SECTION \\ Implementing the CAREC Digital Strategy 2030}

The CAREC Digital Strategy 2030 will be a living document that shall be regularly updated to reflect progress and introduce new actions. This approach requires ongoing collaboration between CAREC member states and a clear understanding of the tasks to be performed locally and where central governance is necessary. Close member state collaboration is also required in harmonizing legislation, exchanging data, and developing systems. The member states should agree on appropriate governance structures to ensure that this collaboration becomes the norm.

\subsection{Establishing Implementation Principles}

There are several important principles to follow in the implementation of the CAREC Digital Strategy 2030. ${ }^{57}$

Adopting a holistic digital transformation vision and an inclusive digital ecosystem approach is vital throughout the implementation process, ensuring that sufficient attention is given to strengthening the region's nondigital and digital foundations to support both larger regional digital initiatives and specific operational cluster and sectoral projects. It is also important to adopt an active CAREC policy framework for interoperability at the legal, organizational, semantic, and technical levels. ${ }^{58}$

The CAREC Digital Strategy 2030 is ambitious in its vision. It is, therefore, essential to adopt an agile implementation framework that will enable a collaborative and decentralized approach, and guard against weaknesses in coordination capacity. A prioritized project portfolio and implementation road map will highlight quick wins and low-hanging fruit in the shorter term, and simultaneously strengthen the necessary foundational pillars to progress to long-term, strategic, and harder to execute projects.

Developing regional governance structures, institutions, partnerships, and digital managerial and leadership skills is a critical element of the implementation process required to ensure sustainability. It should be adequately resourced and supported. As a first step, the CAREC Digital Collaboration Platform will be established to enable coordination and best practice sharing across member countries on all issues related to strategy implementation.

57 See Appendix 6 for global best practices in digital strategy implementation.

58 Legal interoperability ensures that legislation is designed to enable uninterrupted economic cooperation, allowing organizations to work together and ensure that data exchanges have legal significance. Organizational interoperability ensures that the business processes of administrations and companies are aligned. Semantic interoperability ensures that the format and meaning of exchanged data and information are preserved and understood by all parties. Technical interoperability ensures that formal technical specifications and standards are complied with while developing and connecting digital services, platforms, systems, and infrastructures. The promotion of interoperability at each level is an indispensable condition for the technological compatibility of digital communications and real-time digital data exchanges, and for the ongoing development and deployment of cross-border cross-sectoral public services. 


\subsection{Establishing a Governance Structure for Regional Digital Development}

A CAREC Digital Strategy steering committee will be established to determine the appropriate leadership and governance structures as well as the regional institutional framework to drive the implementation of the CAREC Digital Strategy 2030. The steering committee will be led and constituted by the governments of CAREC member countries and facilitated by the CAREC Secretariat. The committee will engage all members of the CAREC Digital Space in the implementation process, relying on mutual goodwill and an inclusive multistakeholder consultation model that brings together public and private sector organizations across CAREC, academic institutions, the expert community, international donor organizations, global and regional technology giants, citizens, and other players. ${ }^{59}$ Broad engagement and collaboration are necessary to achieve the regional multiplier effect in digital dividends. Active regional leadership is critical in providing the authorizing environment and enabling linkages between key digital ecosystem stakeholders across the region (local communities, private enterprises, nongovernment organizations, multinational organizations, academia, and government agencies).

The overall implementation of the CAREC Digital Strategy 2030 will be led and guided by CAREC member countries and supported by the CAREC Secretariat in facilitating the process, helping drive the momentum, gaining stakeholder support for the strategy, and implementing the strategic communications plan. The CAREC Secretariat will also enable alignment with the donor and investment communities to help mobilize appropriate resources for strategy implementation, and support policy dialogue and sector-specific digital transformation initiatives. In the short-term, the CAREC Secretariat can:

- build a consensus and encourage policy dialogue within the framework of the CAREC Digital Strategy 2030,

support quick wins and low-hanging fruit projects at the initial implementation phases,

- align development programs and funding with digital transformation goals,

- develop knowledge products and platforms for best practice sharing across CAREC,

- facilitate the mobilization of investment by increasing engagement with multilateral development institutions,

- strengthen public and private sector dialogues for expanded participation of the private sector in mobilizing technical and financial resources needed for digital transformation,

promote the development of a conducive business environment to allow increased private sector participation,

- propose specific initiatives for harmonizing regulation and legislature to enable digital initiatives across the region, and

promote independent regulators and agile regulation to support the establishment of a virtual tax-free digital innovation zone and regulatory sandboxes to allow for innovation and ecosystem development where companies can experiment with new ideas and test them at the regional level.

59 For an example of multistakeholder models, refer to the Community Model of the Internet Corporation for Assigned Names and Numbers (ICANN) Community. 


\subsection{Key Implementation Priorities}

\subsubsection{Developing the CAREC Digital Transformation Project Portfolio and Implementation Road Map}

The CAREC Digital Project Portfolio will be developed by including the projects proposed in this strategy. The portfolio will consider the global and local best practices, inputs received during consultations with CAREC public and private sector stakeholders, projects that have been discussed at various CAREC digital transformation workshops, as well as any additional inputs from member countries during future brainstorming and consultation sessions across the CAREC digital ecosystem. ${ }^{60}$

Projects will be grouped in line to strengthen CAREC's nondigital and digital foundations on the one hand and drive digital adoption in CAREC's priority operational clusters on the other hand, taking into account the priority initiatives proposed by public and private sector stakeholders during the consultation process as well as existing digital initiatives launched in line with CAREC sectoral strategies, such as the CAREC Tourism Portal, the CAREC smart energy grid, e-commerce, intelligent transport initiatives, etc.

A complete portfolio of CAREC regional digital transformation projects reflecting the entire spectrum of CAREC member needs would then be prioritized and translated into a CAREC digital transformation road map, complete with a timeline for implementation and key performance indicators (KPIs) for success measurement. The CAREC Digital Project Portfolio will undergo a thorough prioritization based on the strategic importance of each of the proposed projects on the one hand and its ease or difficulty of execution on the other hand.

It is important to include representatives of the entire CAREC digital transformation ecosystem in the prioritization exercise that would generate the CAREC Prioritized Digital Transformation Project Portfolio and a comprehensive CAREC digital transformation road map, complete with targets, success measures and $\mathrm{KPIs}$, and associated action plans and budgets.

The CAREC Ministerial Conference would agree on this comprehensive road map, action plan, and budget. The strategy should be reviewed and updated regularly to identify new priorities for digital transformation based on economic and political changes in the region and the rapid development of new technologies. CAREC should adopt a long-term view of digital transformation while ensuring agility in the implementation process. Progress in implementing the strategy should be reviewed regularly, and corrective actions and associated budgets should be initiated. Regular reviews should be used to identify new priority sectors/markets for digital transformation based on market and technological developments and political decisions for enhanced economic cooperation. It should also consider the accelerating pace of technological innovation and the shortening of policy gestation cycles.

Common strategy implementation guidelines based on global best practices (Appendix 6) should be shared with policy makers across the region. Digital project management guidelines for implementing the CAREC Digital Strategy 2030 should be adopted to provide project managers across the region with the processes, tools, and techniques necessary to deliver quality digital solutions successfully.

60 See Appendix 10 for more information on the CAREC Digital Project Portfolio. 


\subsubsection{Strengthening the Enabling Environment and Capacity Building}

To ease the strategy implementation, CAREC member countries should pay special attention to strengthening the enabling environment for digital transformation across the CAREC region by establishing predictable enabling policies and safeguards to promote trust in digital technologies. Trust issues need to be addressed with legislation to protect data and create cybersecurity structures. Open internet, data, standards, and source should be promoted.

Digital solutions awareness building as part of the strategic communications plan for the CAREC Digital Strategy 2030 and the rollout of digital and project management skills training for public and private sector managers are important at the early stages of implementation.

\subsubsection{Gathering and Sharing Best Practice for Digital Development}

A CAREC Digital Solutions Center will be considered for establishment in the region to collect regional best practices, adapt and disseminate them through the CAREC Digital Collaboration Platform and at workshops, conferences, and seminars. ${ }^{61}$ The center can sponsor an annual conference as a forum for sharing best practices and exchanging information on experiences and lessons learned across the CAREC region and beyond.

The center could also focus on improving "the measurement of digital transformation and the digital economy by strengthening data collection, analysis and review for official statistics, use of new methods and advanced technologies such as big data analytics, strengthening and harmonization of common frameworks of indicators and their monitoring and evaluation" at the local, national, and regional levels. ${ }^{62}$

\subsubsection{Establishing a Monitoring System for Digital Transformation Progress and Impact}

CAREC member country governments should assess the impact of their digital strategies and adapt them to changing circumstances. Horizon scanning activities should become customary to keep pace with the rates of technological change. A critical issue to be addressed is measuring the benefits of the CAREC Digital Space and monitoring the progress toward achieving them. A results and monitoring framework for the digital strategy will be developed, as well as a measurement toolkit with indicators, metrics, statistics, processes, and tools to measure the benefits of the CAREC Digital Space for member states.

\subsubsection{Building Public-Private Partnerships for Project Portfolio Development and Implementation}

The public and private sectors across CAREC should work closely together throughout the implementation process, particularly in the early stages, to create positive momentum through the launch of high-visibility regional initiatives and the rapid implementation of pilot projects. A special fund will be considered to support the rollout of select pilot projects that demonstrate the value of digital technologies to address key economic and social issues across CAREC and accelerate the pace of digital adoption across the region. Existing available resources, including trust funds from multilateral organizations and private sector resources, will be explored as potential sources for this fund. The public and private sectors across CAREC should collaborate

61 Built upon the UNESCAP proposal for a regional digital solutions center.

62 Economic Commission for Latin America and the Caribbean. 2020. Digital Agenda for Latin America and the Caribbean. Seventh Ministerial Conference on the Information Society in Latin America and the Caribbean. Virtual meeting. 23-26 November. p. 7. 
on the digital transformation project portfolio development and prioritization to decide which existing solutions can be successfully scaled across the region to create quick wins as part of the CAREC Digital Strategy 2030 implementation process.

\subsubsection{Working with Development Partners to Accelerate Digital Transformation across CAREC}

International development partners and donors play a critical role in supporting the development and implementation of the CAREC Digital Strategy 2030 with international expertise, best practice, capacity building, technical assistance, and financing.

$A D B$ has recognized the urgency of leveraging digital technologies to support economic and social development in the CAREC region, especially in light of the ongoing COVID-19 pandemic. It is fully behind the development and implementation of the CAREC Digital Strategy 2030. Other organizations such as the International Finance Corporation, the International Telecommunication Union (ITU), the Islamic Development Bank (IsDB), UNESCAP and other UN agencies, and the World Bank can also provide the needed resources and support. IsDB's South-South Cooperation initiative and its Reverse Linkage program, for example, can help implement specific elements of the CAREC Digital Strategy 2030.

\subsubsection{Future Proofing the CAREC Digital Strategy 2030: Strategic Planning, Futures Thinking, and Strategic Foresight for CAREC Digital Cooperation}

Given the increasing volatility, uncertainty, complexity, and disruption globally and in the CAREC region, it is necessary to apply futures thinking and foresight approaches to the CAREC Digital Strategy 2030 and its future implementation road map. ${ }^{63}$ This would involve exploring and preparing for a wide range of possibilities, planning for different scenarios, identifying potential opportunities and challenges, and designing innovative ways to anticipate change and stay on track with digital transformation under rapidly evolving circumstances.

Following the best practices of the Republic of Korea, Singapore, and others, CAREC member countries can use strategic foresight approaches including scenario planning, horizon scanning, and back casting to improve their capacity to anticipate change and prioritize the implementation of technologies that are likely to become important and promise significant opportunities. Similarly, technology foresight can help identify associated risks to the implementation of the CAREC Digital Strategy 2030.

\subsubsection{Developing a Strategic Communication Plan}

An effective communication plan will be developed to convey the vision, objectives, and key pillars of the CAREC Digital Strategy 2030, as well as the benefits and digital dividends expected as a result of its implementation. It is also key to communicate a sense of urgency, build a regional consensus among all the key stakeholders to implement the strategy, and keep all the stakeholders updated on implementation progress. A powerful digital transformation awareness-building campaign supported by a strategic communication plan will be considered in alignment with the CAREC Digital Strategy 2030. It will aim to ensure high-level visibility and leadership commitment to the strategy and to accelerate the implementation process by generating positive momentum, highlighting successes of regional collaborative digital initiatives, promoting best practices and lessons learned across the region, empowering digital champions, and ensuring digital inclusion.

63 ADB. 2020. Futures Thinking in Asia and the Pacific: Why Foresight Matters for Policy Makers. Manila. 
CAREC governments can work together to establish a network of digital champions appointed at national and regional levels to raise awareness of the challenges and benefits of the transition to a new digital economy and society and share their own personal and business success stories of digital transformation. Individuals who are well-known in their countries for pioneering the digital agenda can be appointed as digital ambassadors to promote all aspects of the CAREC Digital Strategy 2030 in the national and regional media including social media platforms, online seminars, TV programs, regional events, forums, and conferences and to argue the importance of digital education, digital skills, digital innovation and collaboration, sectoral transformation, and citizen participation.

The communications strategy will create a sense of urgency for digital adoption and encourage all stakeholders to assume ownership of the vision to solidify their buy-in and support. High-level workshops to communicate the strategy to key government and private sector stakeholders should be organized. In addition, a public relations campaign will be considered with the media focusing on citizens and businesses to promote the CAREC
Digital Space. Specific initiatives to improve the public perception of digital entrepreneurs and the value of innovation and digital adoption across the region will be undertaken (this can include promoting innovation and digital adoption success stories in different areas of the region's social and economic life. For instance, a CAREC Digital Space Road show, can travel across the region to visit administrations, companies, schools, and universities, explaining the relevance of the CAREC Digital Strategy 2030 and emphasizing the expectations, challenges, and potential benefits for all).

The CAREC Secretariat can support in developing and implementing this communications strategy and also contribute to the interactive CAREC Digital Space Portal. This portal will target citizens, businesses, stakeholders, and others interested in the opportunities presented by the CAREC Digital Space, and will include position papers, policy consultations, progress reports, news, live streams, online conferences and seminars, events, blogs, and a discussion forum. Over time, it can become the "go to" site for all matters related to the CAREC Digital Space. 
The CAREC leadership must leverage global and local best practices to develop the pillars that will address the six priorities at the core of the CAREC stakeholders' digital agenda (Appendix 3). The effective implementation of the CAREC Digital Strategy 2030 will enable CAREC member countries to jointly overcome existing development challenges and achieve a multiplier effect in digital dividends. Regional partnerships in the CAREC Digital Space will fuel the growth of priority clusters, help accelerate the digital transformation of emerging countries, and create new growth opportunities across the CAREC region. In developing the common CAREC Digital Space, countries can rely on their rich history of coexistence, collaboration, and trade and leverage digital technologies to empower regional cooperation.

Sufficient financial resources must be allocated early on to support universal broadband access across the region, create a common digital infrastructure and digital platforms to enable the digitalization of leading economic sectors and operational clusters, and develop regional digital markets enhanced by a favorable regulatory framework. Focused work within the CAREC Digital Ecosystem-comprising the public and private sectors, international funding and donor organizations, the scientific and expert communities, and community representatives-is required to ensure the availability of adequate funding of priority digital infrastructure investments and the prioritized CAREC portfolio of digital transformation projects in the region.

Programs designed to boost digital skills and competencies across the region, both basic and advanced, should be emphasized. PPPs for the implementation of priority initiatives, ongoing dialogue among all interested players in the regional digital ecosystem, and the scaling of the best digital solutions and practices across the region are key to success.

Delays in the implementation of the CAREC Digital Strategy 2030 may cause higher brain-drain from the region and a rise in the influence of global players, leading to the monopolization of CAREC's Digital Space along with lost opportunities for economic growth, job creation, regional competitiveness, and sustainable livelihoods, and leading to a winner-takes-all situation, threatening the region's digital sovereignty.

The first steps on the journey to the CAREC Digital Space include agreement on the CAREC Digital Strategy vision, the endorsement of the CAREC Digital Strategy 2030 by the Ministerial Conference, agreement on the governance model, and the creation of the steering committee. The strategic communications plan will be launched subsequently.

The launch of specific quick-win pilots and low-hanging fruit projects would lay the ground for the implementation process. Priority should be given to those actions with maximum impact in the short term. Successful implementation of a set of projects and actions with both regional and local benefits would create positive momentum and support for the CAREC Digital Strategy 2030 across the region, lay the foundation for the implementation of more complex digital transformation initiatives in the longer term, and raise the status of CAREC and its member countries globally. 


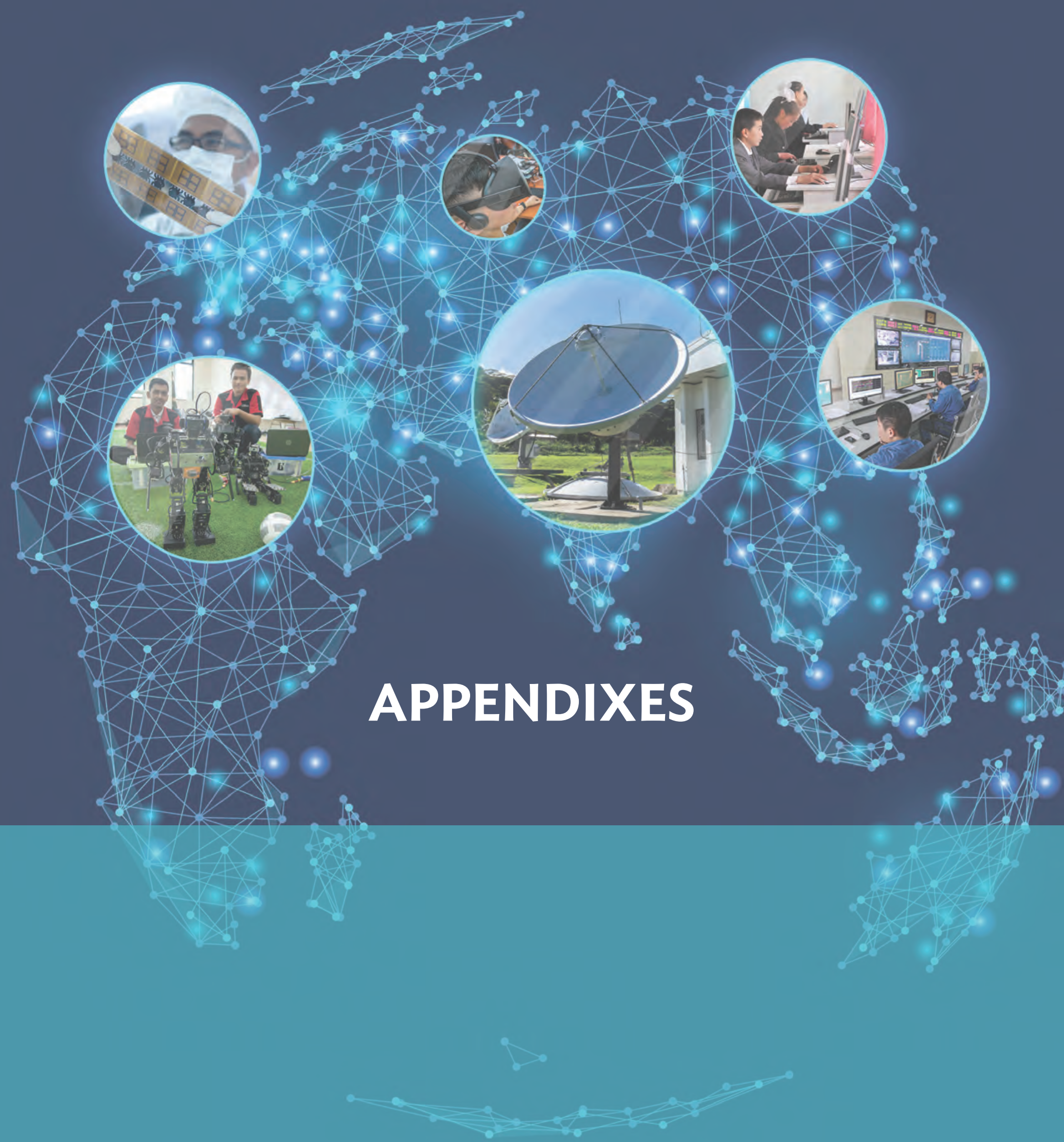




\section{Appendix 1 \\ CAREC 2030 Institutional Framework}

Figure A1: CAREC 2030 Institutional Framework

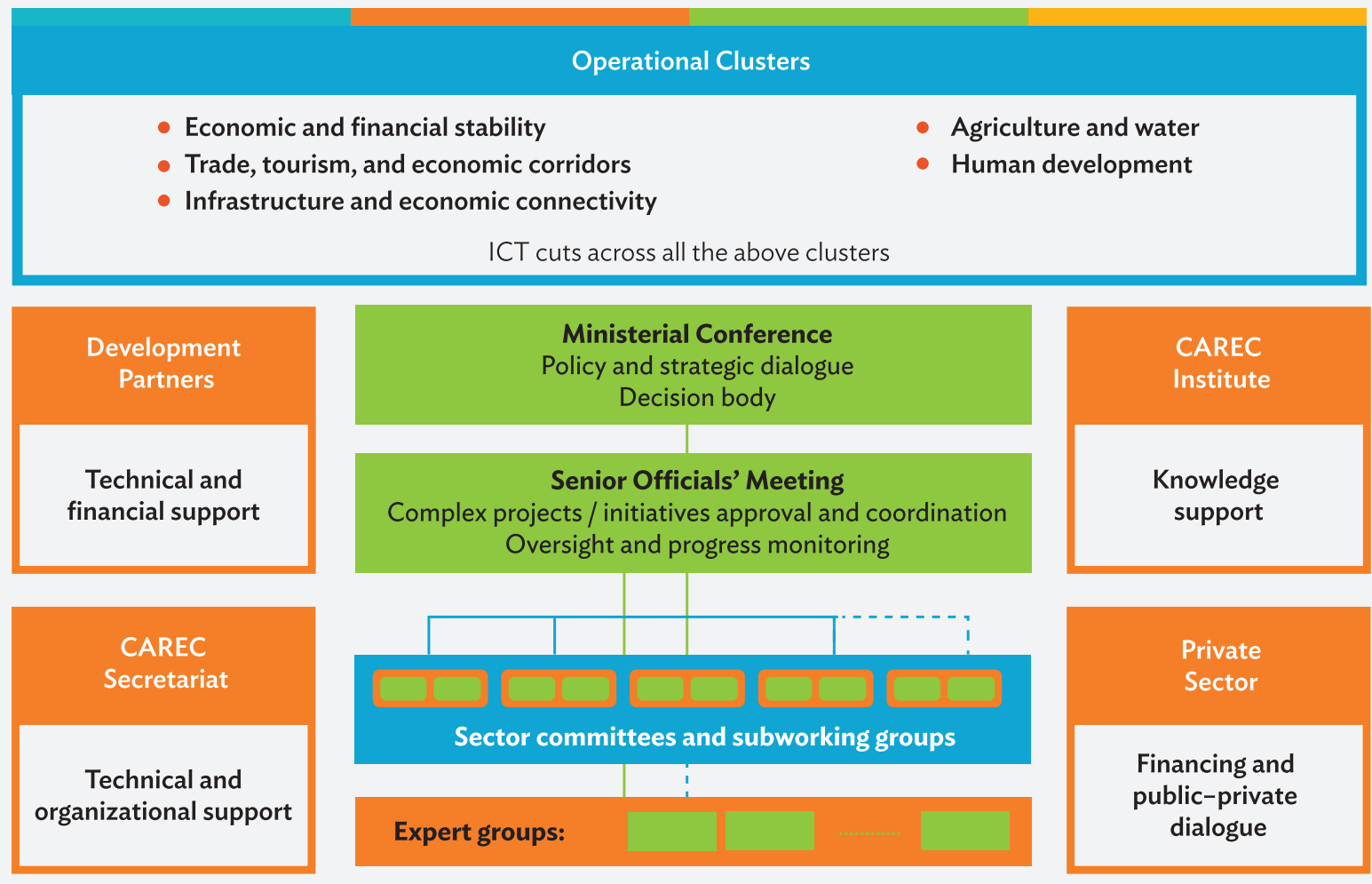

\section{An Open and Inclusive Platform}

CAREC = Central Asia Regional Economic Cooperation, ICT = information and communication technology. Source: CAREC Secretariat. 


\section{Appendix 2 Digital Transformation Framework}

Traditionally, governments and aid agencies have tended to focus on internet access as the primary driver for the digital economy, coupled with free-standing investments in specific sectoral applications but without due attention to the complementary digital and non-digital foundations. There is a growing recognition that a holistic approach to digital strategy is essential to maximizing the digital dividends and securing equitable benefits and inclusive economic growth. ${ }^{1}$

The digital transformation framework helps broaden the focus and redress common imbalances in pursuing digital transformation at the regional level. The digital foundations in this framework informed the pillars in Figure A2.

Figure A2: CAREC Digital Ecosystem Framework

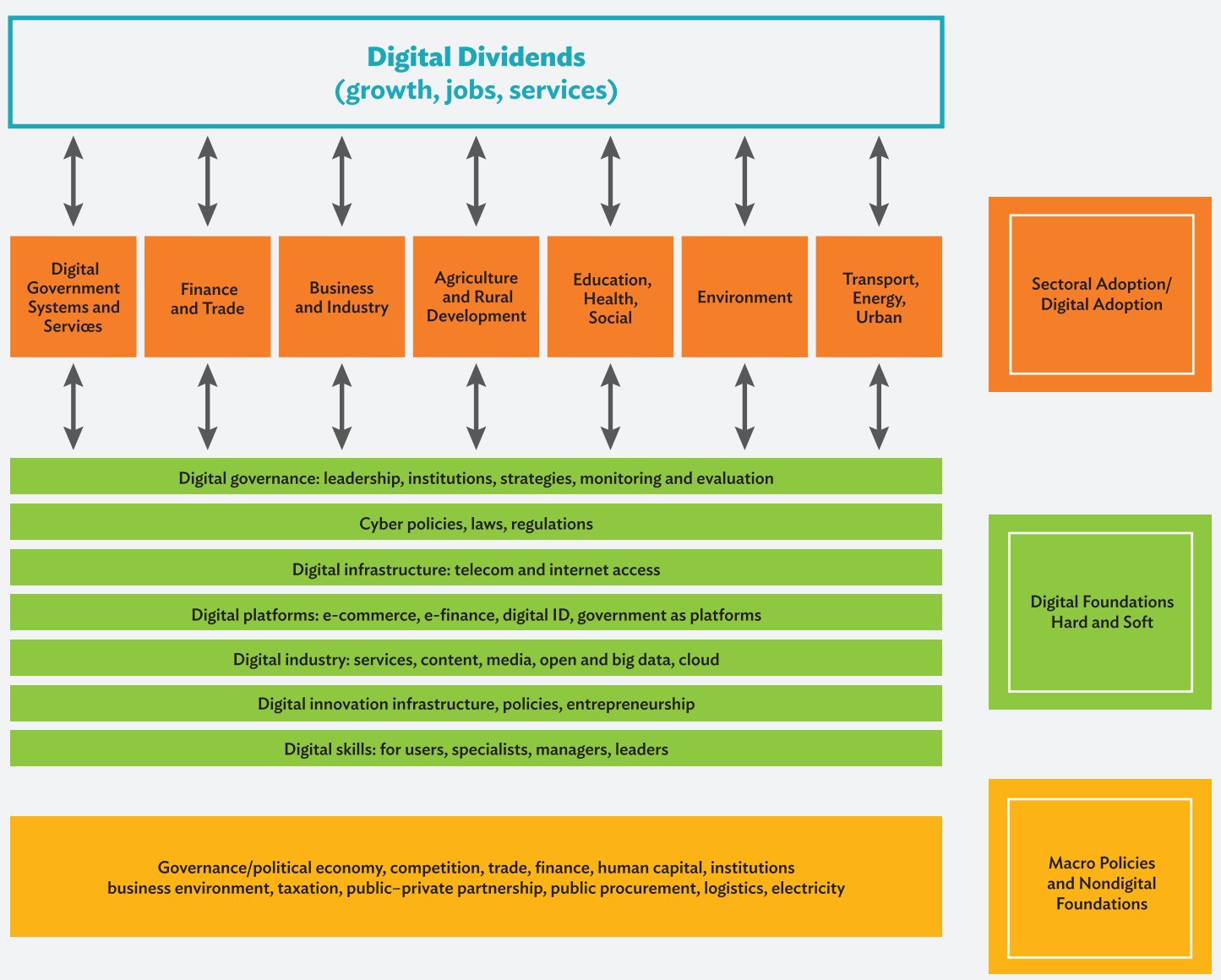

Source: N. K. Hanna. 2020. Assessing the Digital Economy: Aims, Frameworks, Pilots, Results, and Lessons. Journal of Innovation and Entrepreneurship. 9 (16).

1 World Bank. 2016. World Development Report 2016: Digital Dividends. Washington, DC; N. K. Hanna. 2016. Mastering Digital Transformation: Towards a Smarter Society, Economy, City and Nation. Bingley, United Kingdom: Emerald Publishing Limited; N. K. Hanna. 2020. Assessing the Digital Economy: Aims, Frameworks, Pilots, Results, and Lessons. Journal of Innovation and Entrepreneurship. 9 (16). 


\section{Appendix 3 \\ Stakeholder Input Analysis}

Central Asia Regional Economic Cooperation (CAREC) public and private sector representatives agreed that the biggest obstacles to the development of the common CAREC Digital Space are the lack of (i) investment in telecommunications networks, (ii) research and development (R\&D) for digital innovation, (iii) harmonized legislation and regulation to enable digital cooperation at the regional level, and (iv) interoperability in digital infrastructure. Stakeholders also agreed on the following six priorities for regional digital cooperation, reflecting the importance of building strong digital foundations at the regional level:

- building basic and advanced digital skills and universal digital literacy;

- developing and nurturing a regional innovation and entrepreneurship ecosystem through boosting support for innovation and R\&D and creating the governance structures for regional information and communication technology (ICT) partnerships;

- attracting investment in networks and the digital economy while ensuring systems interoperability;

boosting digital resilience and cybersecurity;

- harmonizing regional regulation and legislation to enable regional digital cooperation, including a digital trade and finance system; and

manifesting political will and building trust in regional digital cooperation.

Public sector stakeholders also highlighted the need to provide universal broadband access, especially in remote and mountainous areas. The private sector emphasized the need for partnering on digital solutions through cooperation between ICT companies across the region and the opportunities presented by emerging technologies.

CAREC stakeholders also realize the importance of digital adoption in key sectors. Public sector stakeholders prioritized digital agriculture and tourism, while the private sector emphasized the need to develop digital trade and establish a regional digital finance and payments system.

Digital dividends are achieved through sector and cluster-level transformation supported by strong digital and nondigital foundations. Therefore, it is important to ensure the alignment of nondigital foundations at the regional level and strengthen CAREC's digital foundations to address CAREC stakeholder digital development priorities. 
Figure A3.1: Opportunities for Regional Digital Cooperation

Public Sector Priorities

Developing advanced digital skills and universal digital literacy

Creating a regional innovation and entrepreneurship ecosystem, including the public sector, academic institutions, research and development, industry, businesses, startups, and venture financing Leveraging new disruptive technologies (AI, IoT, Big Data and Data Analytics, blockchain, etc.) Developing basic digital skills especially in remote areas and for women, the elderly and other disadvantaged groups affected by the digital divide Digitization of agriculture (farming/weather information, notification systems, marketing information, food security tracking, finance/insurance)

Nurturing the digital innovation system (leveraging data, $\mathrm{Al}$, and emerging technologies)

Providing broadband connectivity plans, including for remote and mountainous regions

Attracting investment in the digital economy

Partnering on digital solutions at the regional level through cooperation between ICT companies

Building digital resilience capacity (e-resilience for disasters, pandemics; data centers)

Developing leadership and management skills (e.g., for chief digital officers)

Facilitating trade (e.g., e-trade, cross-border e-commerce, e-customs)

Promoting smart energy management (e.g., control systems, utilities management, smart grid)

Digitization of key industry sectors across the region

Promoting digital tourism (e.g., data management, travel management, marketing)

Harmonizing public and private digital platforms

Reforming and harmonizing digital policies (privacy, security, interoperability)

Building smart transport (e.g., intelligent transport, railways, maritime, and roads asset management)

$\frac{n}{1}$
$\frac{1}{5}$
$\frac{t}{0}$
0
0
0

Cooperation on environmental and climate initiatives across the region

Engaging in strategic planning for CAREC digital cooperation

Establishing a governance structure for regional digital development

Formulating a regional data strategy: policies, governance, standards, skills

Promoting adoption and executive use of digital technologies by SMEs

(e.g., extention services, e-entrepreneurship)

Creating cross-border digital public sector services

Investing in advanced and equitable broadband access across the region

Building regional human capital to drive regional digital development

Creating a common digital labor market (labor market information, matching platforms, e-migration)

Creation of common CAREC digital health and education spaces

Pursuing cross-cutting goals (inclusion, innovation, sustainability, partnerships)

Harmonizing digital identification systems

Improving public procurement of ICT (open standards, transparent e-procurement)

Promoting regional digital content

Establishing a regional digital finance and payments system

Cooperation on smart cities across CAREC

Enabling smooth data flows across the region

Promoting digital partnerships via regional legislation and incentives

Creating a single digital marketplace in the CAREC region

Strengthening regional institutions for digital leadership

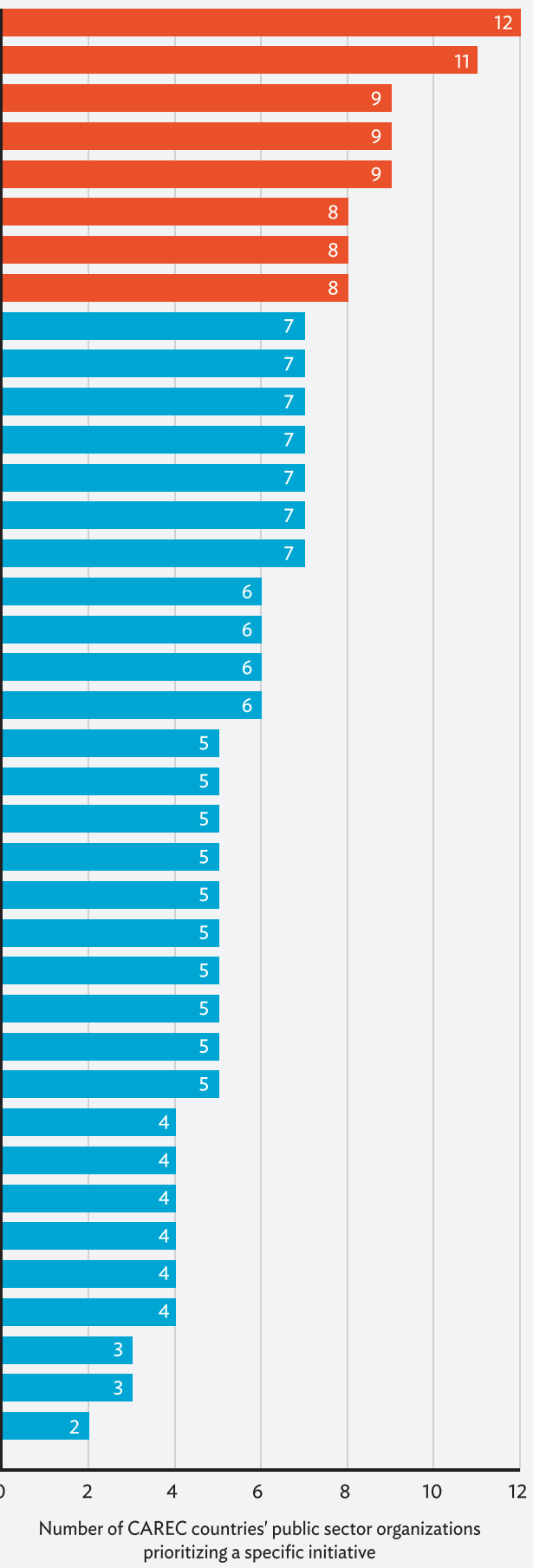

$\mathrm{Al}=$ artificial intelligence, $\mathrm{CAREC}=$ Central Asia Regional Economic Cooperation, $\mathrm{ICT}=$ information and communication technology, loT = internet of things, SME = small and medium-sized enterprise.

Note: Based on the analysis of public sector priorities conveyed through responses to CAREC questionnaires, June 2021.

Red color is used to highlight top priorities as identified by the responders.

Source: CAREC Secretariat. 


\section{Figure A3.2: Obstacles to Regional Digital Cooperation}

\section{Public Sector Perceptions}

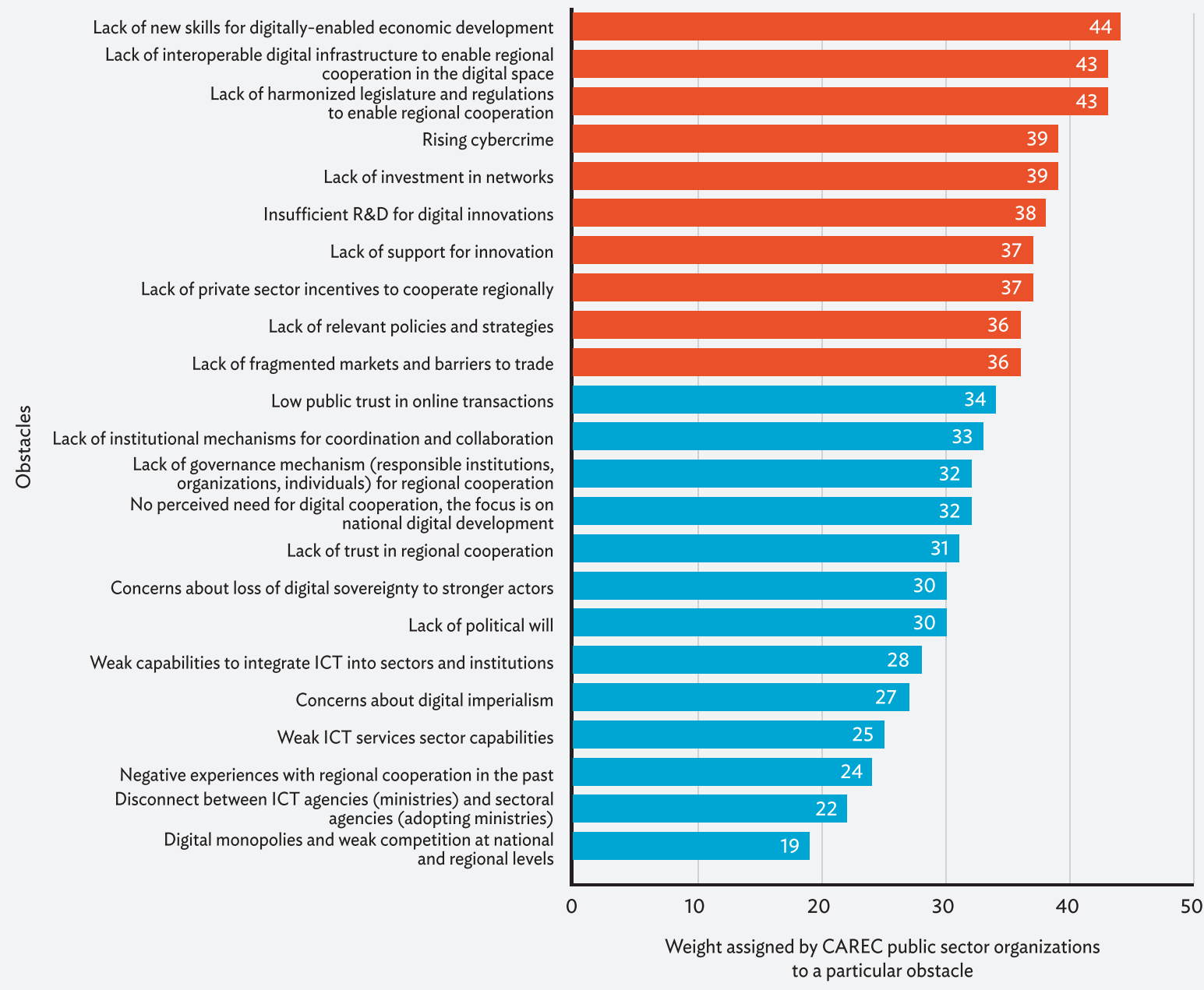

CAREC = Central Asia Reigonal Economic Cooperation, ICT = information and communication technology, R\&D = research and development.

Note: Based on the analysis of public sector perceptions of existing obstacles to regional digital cooperation conveyed through responses to CAREC questionnaires, June 2021. The red color is used to highlight the biggest obstacles as identified by the responders.

Source: CAREC Secretariat. 
Figure A3.3: Opportunities for Regional Digital Cooperation

\section{Private Sector Priorities}

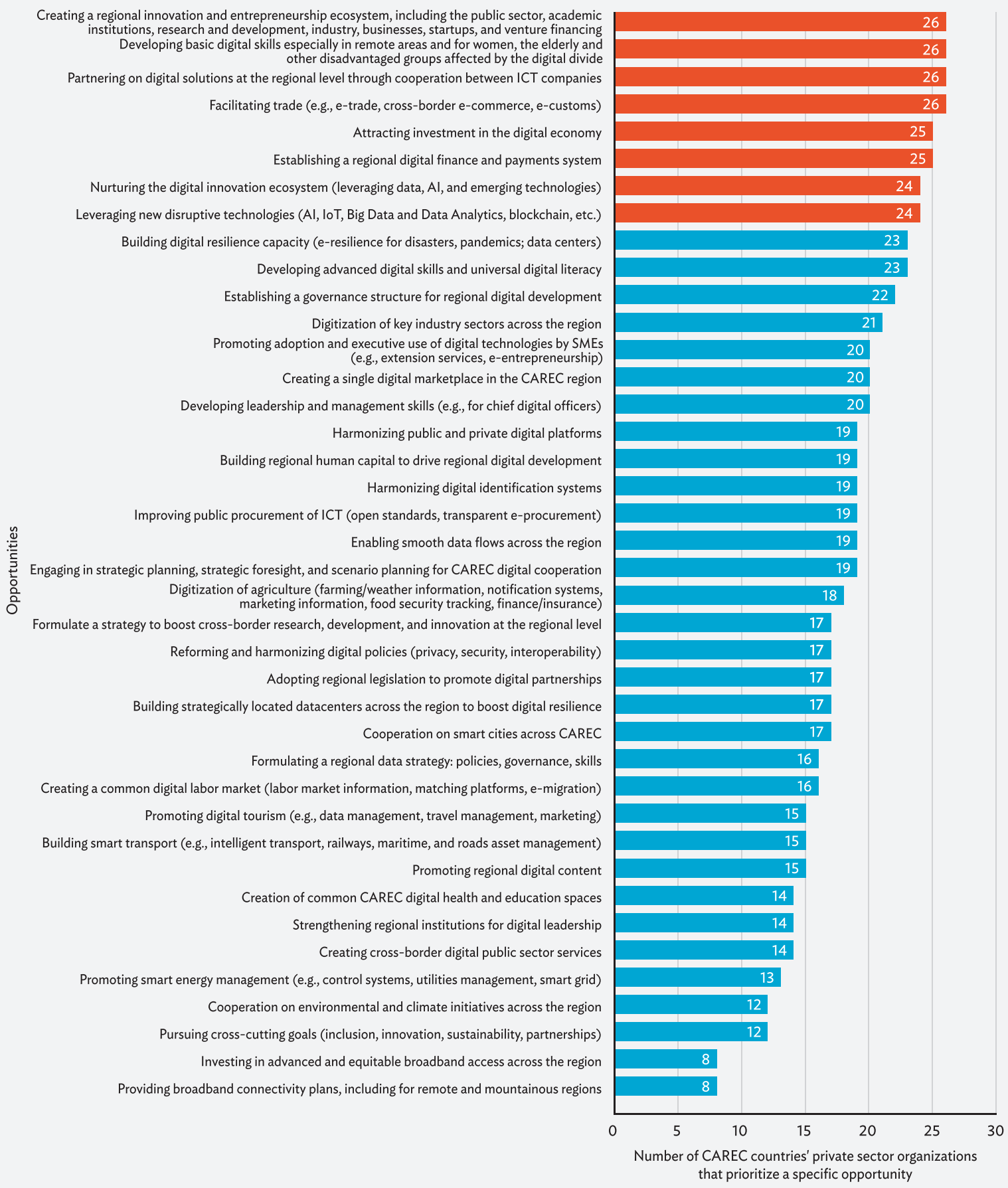

$\mathrm{Al}=$ artificial intelligence, $\mathrm{CAREC}=$ Central Asia Regional Economic Cooperation, $\mathrm{ICT}=$ information and communication technology, loT = internet of things, SME = small and medium-sized enterprise.

Note: Based on the analysis of private sector priorities conveyed through responses to CAREC questionnaires, June 2021. The red color is used to highlight top priorities as identified by the responders.

Source: CAREC Secretariat. 


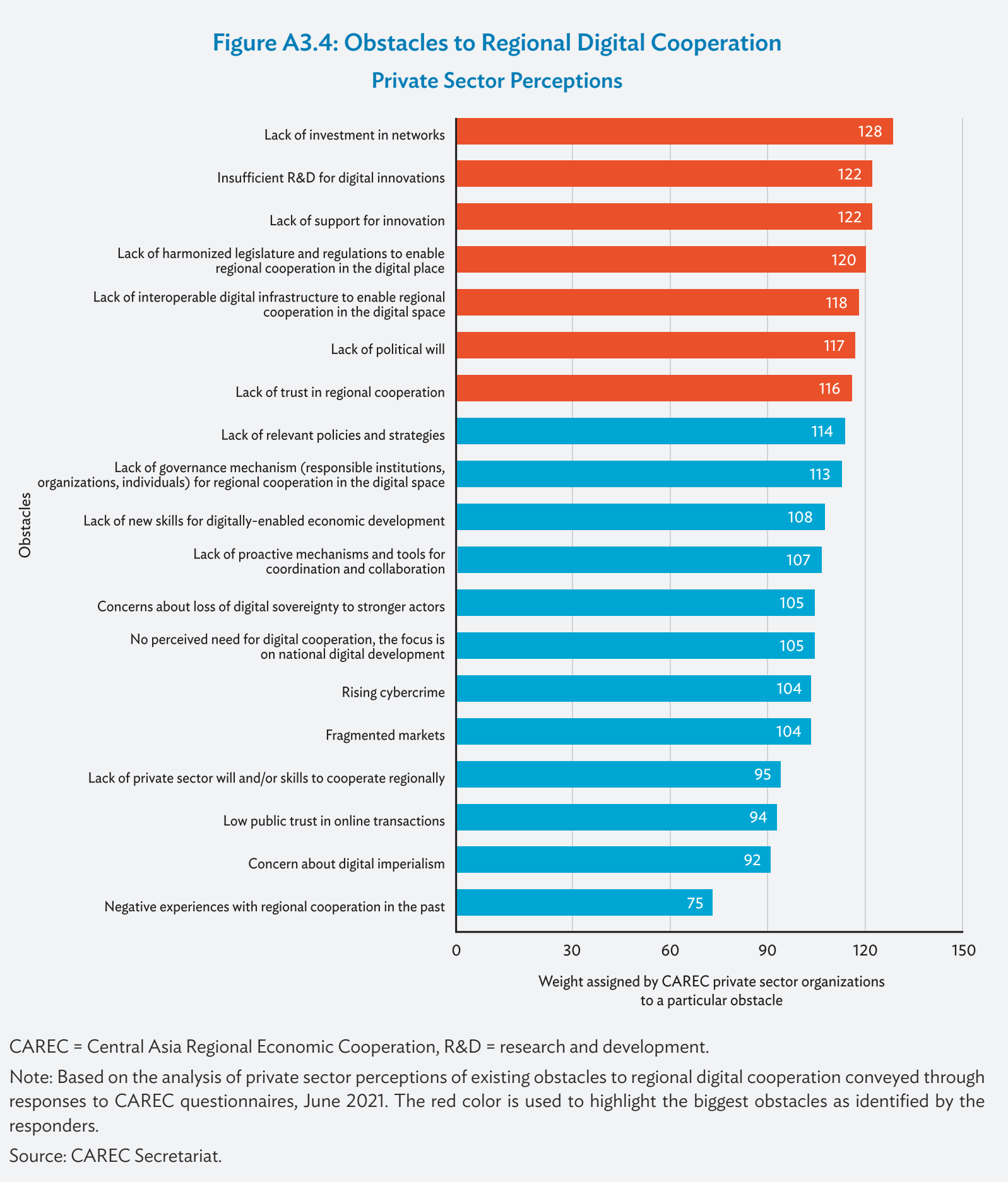


Appendix 4

\section{CAREC Member Countries' National Digital Transformation Strategies and Priorities as Reflected in Strategy Documents}

All Central Asia Regional Economic Cooperation (CAREC) member countries have prioritized digital transformation in their national development strategies. Some have adopted initial concept documents or more detailed programs, strategies, and plans related to various aspects of digital transformation. A reading of these documents reveals certain commonalities and priority focus areas across CAREC member countries. All CAREC members consider digital technologies and digital transformation to increase national competitiveness and citizen well-being. To achieve these goals, countries emphasize the importance of infrastructure investments to provide ubiquitous broadband access and develop digital platforms to enable e-learning and e-health service provision, especially in the wake of the coronavirus disease 2019 (COVID-19) pandemic. In addition, all countries stress the need to develop digital skills and competencies and boost innovation capabilities.

In their strategic documents, emerging countries like Afghanistan, Pakistan, Tajikistan, and Turkmenistan prioritize (i) infrastructure development for affordable internet access, improving the digital literacy of the population and bridging the digital divide; (ii) public sector reform aimed at the reengineering of government processes; and (iii) the provision of citizen-centric e-government services. They raise concerns about improving digital empowerment, closing the digital skills gap, creating opportunities for their young populations in the information and communication technology sector, and connecting to the rest of the region through e-commerce. Pakistan advocates a holistic technology strategy with digital technologies enabling sectoral transformation, boosting innovation and entrepreneurship, and empowering women and youth. Tajikistan aims to leverage digital technologies to fight poverty, achieve energy independence, boost food security, and create new jobs for the population.

Transition followers like the Kyrgyz Republic, Mongolia, and Uzbekistan prioritize broadband access, legislature for digital development, effective data management, cloud services, cybersecurity, smart cities, digital platforms, innovation ecosystem, and the introduction of disruptive technologies such as artificial intelligence (Al), the internet of things (loT), and big data for sectoral transformation. Mongolia is looking to Estonia's model for e-government transformation.

Transition leaders like Azerbaijan, Georgia, Kazakhstan, and the People's Republic of China prioritize effective data policies, cybersecurity, the use of disruptive technologies (such as AI, loT, and blockchain), investment in human capital for digital development, the use of digital technologies for inclusive and green growth, and investment in research and development. Azerbaijan focuses on green and sustainable growth and the launch of smart cities and villages. Georgia aims to close the digital divide and empower information and communication technology innovation and entrepreneurship. Kazakhstan prioritizes cybersecurity, digital agriculture, digital industry transformation, and digital skills and human capital development. 
At the regional level, CAREC member countries prioritize using digital technologies to combat the COVID-19 pandemic and its consequences, such as poverty and instability and other issues such as food security, which may lie beyond the capacity of any single country and can help sustain economic growth. They emphasize expanding broadband access to increase connectivity; close the digital divide; and facilitate online learning, e-health, and business continuity. They also point to the need to boost digital literacy and digital skills for human development. They stress the importance of knowledge and best practice sharing, as well as regional research and development. ${ }^{1}$

1 Asian Development Bank. 2021. CAREC at 20: Reimagining Regional Cooperation Through Digital Transformation. 54th Annual Meeting of the Board of Governors. 4 May. 


\section{Appendix 5}

\section{Regional Digital Transformation Opportunities and Challenges: Strengths, Weaknesses, Opportunities, and Threats Analysis}

The 2016 World Bank Report Reaping Digital Dividends: Leveraging the Internet for Development in Europe and Central Asia emphasized that not everyone takes equal advantage of the benefits of the internet. In fact, there can be an increase in inequality between countries and population groups within countries. Much of this depends on the appropriate implementation of digital transformation in the context of creating the conditions necessary for significant societal transformations. ${ }^{1}$ In some Central Asia Regional Economic Cooperation (CAREC) member countries, internet providers were, until recently, monopolized by the state, leading to high costs of internet access and low service quality. The reluctance of the private sector to take risks slowed down the adoption of internet technologies for business needs.

Moreover, geopolitical issues, weak diplomatic ties, and a certain reluctance to cooperate across some parts of the region are obstacles to digital adoption, preventing universal and low-cost broadband access, international transit traffic growth, and cooperation on a regional digital agenda to scale economic and social dividends of digital transformation, which can be significant. Thus, providing citizens and businesses with opportunities to prosper in the digital economy will depend on the political will of CAREC member countries' leaders to cooperate; the creation of effective governance institutions; investment in a secure, reliable, scalable, and interoperable regional digital infrastructure; effective integration mechanisms; and the adoption of a regulatory and legal framework that supports digital transformation, innovation, and sustainable investment.

Several key factors determine the success of digital transformation initiatives at the local, national, and regional levels. These factors include the (i) strength and consistency of leadership commitment to digital transformation; (ii) effectiveness of a region's governance and institutions to manage digital transformation initiatives in the short, medium, and long terms; (iii) quality of the enabling environment in the region that supports the implementation of digital strategies, initiatives, and projects and that incentivizes digital adoption in the public and private sectors; (iv) level of digital skills and competencies across the region, including advanced professional digital skills, as well as the population's general level of digital literacy required to function in a digital economy and society; ( $v$ ) access to digital technologies such as broadband and mobile connectivity, cloud technologies, etc.; and (vi) openness to and support of digital innovation across the region.

An assessment, conducted by the CAREC Secretariat in collaboration with the United Nations Economic and Social Commission for Asia and the Pacific, on the level of development of these factors across the region revealed the following strengths, weaknesses, opportunities, and threats across CAREC member countries. ${ }^{2}$

1 Kelly, T. et al. 2017. Reaping Digital Dividends: Leveraging the Internet for Development in Europe and Central Asia. Washington, DC: World Bank.

2 The strengths, weaknesses, opportunities, and threats (SWOT) discussion is based on inputs received through questionnaires, consultation sessions with CAREC member countries in 2021, United Nations Economic and Social Commission for Asia and the Pacific (UNESCAP) analysis, and World Bank research. 


\section{CAREC Strengths}

- Strategic location of CAREC member countries at the heart of Eurasia and the Silk Road with historical and modern-day links to Europe, the Russian Federation, South Asia, and East Asia

- Deregulation of telecommunications in most countries, leading to an emerging and largely competitive telecom sector across the region

Qualified information technology professionals in many countries of the region

- Access to cheap green energy

- Strong political commitment to digital transformation at the national level

- Digital transformation as a national priority across the region, and initial concept documents adopted by all governments, with leaders like Kazakhstan and the People's Republic of China (PRC) actively developing more detailed strategies and policies on data, artificial intelligence, cybersecurity, etc.

- Basic legal framework for digital development broadly in place at the country level ${ }^{3}$

- Basic foundations for digital public services in place, with digital adoption leaders ahead of others in the quality and variety of digital public services and regional efforts are focused on enabling cross-border transactions and e-commerce

- Growing activity in e-commerce with some local platforms and mobile payment apps in some countries and AliExpress active across the region

- Some local content developments

- Positive dynamics for supporting innovation and start-ups in the digital sector in digital adoption leaders like Georgia, Kazakhstan, and the PRC as well as in the Kyrgyz Republic and Uzbekistan (establishment of government support programs, accelerators, technology parks, venture funds, coworking spaces, etc.)

- Some participation in regional and global digital initiatives, e.g., the PRC's Belt and Road Initiative and the Digital Silk Road Initiative to build digital connectivity across the region ${ }^{4}$

- Digital skills programs developed by digital leaders like Kazakhstan and the PRC and introduced at some educational institutions in the Kyrgyz Republic and Uzbekistan

\section{CAREC Weaknesses}

Landlocked location of many CAREC member countries, many remote mountainous areas making connectivity costly and difficult

- Lack of political will for regional cooperation exacerbated by ongoing political conflicts in the region

- Lack of a regional focus on the digital economy, resulting in a lack of regional governance institutions focused on driving digital adoption

- Lack of a regional institution (based within the region) to drive regional cooperation on digital transformation

- Lack of trust in regional digital cooperation and a reluctance to cooperate

3 The transition leaders are updating key regulations and legislation driven by rapid changes in technology and environment.

4 Kazakhstan, the Kyrgyz Republic, and Uzbekistan are engaged with the International Telecommunication Union (ITU) - United Nations Children's Fund (UNICEF) Giga Initiative that aims to connect every school. Kazakhstan and the Kyrgyz Republic are part of the Eurasian Economic Union (EAEU) 2025 Digital Agenda. 
- Low international bandwidth and weak international infrastructure

- Ongoing protection of incumbent operators in some countries, including gateway control creating barriers to new entrants and causing reduced competition, higher prices, less innovation, fewer services, and lower quality of service

- Lack of broadband access, preventing the rollout of digital government and private sector services and resulting in poor access to telemedicine and distance learning that are critical to combat the coronavirus disease (COVID-19)

- Underdeveloped scientific and research networks in most countries, except the PRC

- High wholesale and consumer prices of telecom services, resulting in lower broadband adoption rates

- Lack of an adopted national digital transformation strategy and detailed implementation documents in most countries of the region ${ }^{5}$

- Regulatory mismatch over rapidly growing digital economy needs across most countries ${ }^{6}$

- Lack of progress in regional content development

- Underdeveloped instruments for monitoring digital transformation and assessing its economic and social impact across most countries

- Low level of digital skills across most countries among the general population and among professionals and senior private and public sector leaders who lack advanced professional and managerial digital skills

- Low digital literacy of the population and a growing digital divide across the region: urban-rural, gender, generational, income-related

- Insufficient private sector investment in digital infrastructure and services

- Lack of awareness of the benefits and opportunities of digital transformation in the public and private sectors and the general population across most countries

- Limited digital infrastructure and broadband access, and underdeveloped digital platforms in most countries

- Lack of compatibility and interoperability in digital government infrastructures across the region

- Lack of effective data policies and poor data usage practices ${ }^{7}$

- Significant demand-side barriers to the uptake of digital technologies in many CAREC countries, including the lack of digital skills and high cost of broadband access, smartphones, and laptops

- Lack of coordination and collaboration between digital transformation stakeholders within the digital ecosystem and beyond at both the national and regional levels

- Slow digital transformation of the public sector in most countries

- Even slower digital adoption of industry and businesses in most countries

- Weak innovation and research and development in most countries

- Lack of effective public-private partnerships in most countries

- Underdeveloped cybersecurity mechanisms in most countries except the PRC

5 The emerging countries and transition followers have high-level concept papers, while transition leaders have more focused digital strategy documents.

6 Legislation, standards, and policies are not harmonized to enable smooth digital interactions. Regional efforts are focused mainly on legislation enabling cross-border transactions and e-commerce.

7 In many CAREC countries, most data are still in paper form. 
- Limited funding for digital transformation initiatives in the public and private sectors in most countries

- Lack of active private sector engagement in digital transformation initiatives in most countries

\section{Opportunities}

- Deregulation of telecom markets and the development of competitive and affordable digital services

- $4 \mathrm{G}$ rollout across CAREC, which can boost the development of digital services and local digital content

- Availability of next generation telecommunications like $5 G$ to support disruptive technologies and sectoral transformation

- Emergence of new business models and smart solutions based on digital technologies

- Growing strategic importance of data and Al

- Human capital strengths and a young and growing population open to new technologies

- Boosting basic and advanced digital skills, which can help innovation and entrepreneurship in the region and create new jobs

- Technology transfer and best practice sharing opportunities across the region through global and regional initiatives such as the Belt and Road Initiative, Giga, Digital Central Asia-South Asia Program, Asia-Pacific Information Superhighway, etc.

- Successful solutions and best practice scaling opportunities between CAREC members

- An emerging vibrant start-up scene in several countries, especially Georgia, Kazakhstan, and the PRC

- Digital technologies applications in key economic sectors and clusters such as agriculture, tourism, smart cities, trade, etc.

\section{Threats}

Lack of political will for regional cooperation, ongoing conflicts between member states, geopolitical instability, and frequent crises

- Lack of commitment on the part of national and regional elites to regional digital project implementation

- COVID-19 impact and its economic and social consequences, including health-care systems collapse, unemployment, concerns about food security, disruption of education, social upheavals, etc.

- Exponential growth of cyberattacks and cybercrimes and low levels of digital resilience and cybersecurity in most CAREC member countries

- High barriers to entry into markets across the region and limited access to external markets

- Insufficient digital skills, both basic and advanced, in most countries

- Growing digital divide: urban-rural (exacerbated by topography in mountainous areas), generational, income, gender, other minorities

Low levels of trust in digital technologies across the region

To accelerate digital transformation across the CAREC region and achieve digital dividends, CAREC member countries should leverage the region's strengths, act on opportunities, address the weaknesses, and neutralize the threats revealed in the analysis. 


\section{Appendix 6 \\ Global Best Practices in Digital Strategy Implementation}

An analysis of global best practices in developing and implementing digital transformation strategies at the country, subregional, and regional levels can be summarized in the following guidelines to policy makers across the region.

\section{Develop Leadership and Governance}

Adopt a holistic vision and ecosystem approach

Develop an in-depth understanding of the existing digital ecosystem-beyond silos

- Prioritize digital foundations over stand-alone applications

- Build a consensus on a vision driven by development priorities and opportunities

- Develop a sense of urgency and commitment to transformation

- Use holistic digital diagnostics to set realistic targets

- Develop synergies among ecosystem elements

Take a long-term view, combined with agile implementation

- Encourage long-term thinking for outcomes and sustainability-marathon

- Capture low-hanging fruits to build commitment and demonstrate quick payoff

- Build agile implementation capabilities and processes

- Phase digital transformation programs in line with augmented capabilities

- Develop medium-term investment plans and diversify sources of finance, including international finance institutions

\section{Develop digital leadership and institutions}

- Build leadership institutions with clear roles and competencies

- Develop collaborative links with adopting sectors

- Build a cadre of digital transformation leaders - chief digital transformation officers

- Develop agile, independent regulatory agencies

- Balance central leadership with bottom-up innovation

Build institutions for national, regional, and global cooperation

\section{Develop Policies, Regulations, Data, and Cybersecurity}

- Develop enabling policies and safeguards to establish competition and trust

- Support and encourage reuse of open data, open standards, and open source

- Develop whole-of-society cybersecurity and resilience strategies

- Invest in digital public goods, in partnership with business and civil society 
- Develop artificial intelligence policy and strategy to enable innovation and accelerate adoption

- Promote the integration of data and processes among public agencies

build geospatial information platforms for environmental resilience

\section{Build Digital Infrastructure and Platforms}

- Encourage competition to build backbone, and a secure and affordable internet service

- Adopt innovative institutional and financing mechanisms to drive access and usage

- Develop and regulate digital platforms for identification, commerce, finance, and services

- Prioritize mobile connectivity and cloud infrastructure

- Promote sharing of infrastructure and spectrum

- Promote network interconnection and interoperability of services and platforms

- Promote partnerships for digital platforms in priority areas

- Promote open public platforms to serve the delivery of government services and as a common platform for innovation and delivery of private sector services

\section{Develop Skills and Competencies}

- Promote universal digital literacy and skills through education systems and enterprises

- Develop analytics, Al, and data management capabilities

- Develop centers of excellence for digital capacity development

- Develop, attract, and retain digital talents in public and private sectors

- Develop tailored and sustainable training systems for civil servants

- Integrate digital education into management programs

- Promote digital academies, competence centers, and apprenticeship schemes

- Promote digitally enabled learning at all education levels

\section{Promote information and communication technology (ICT) sector, innovation, and finance}

\section{Develop the digital sector to support local transformation}

- Develop a competitive digital services industry for jobs and ecosystem dynamism

- Prioritize digital sector mission as a key enabler for transforming the whole economy

- Advance "ease of doing business" for dynamic digital services

- Develop public-private partnerships to promote a competitive digital industry

- Promote export strategies for digital services in partnership with industry associations

- Adopt appropriate international standards and best practices in public procurement of ICT

- Promote the development of digitized, development-relevant local content

- Promote innovation and finance for transformation

- Nurture innovation and entrepreneurship ecosystems-demand-led techno parks 
- Develop programs to scale up and diffuse digital innovations among small and medium-sized enterprises (SMEs)

- Set priorities, pilots, and safeguards for emerging technologies

- Prioritize inclusive and frugal innovation and develop grassroots innovation networks

- Promote access to finance for digital start-ups and SMEs

- Promote digital financial literacy

- Promote fintech in mobile, digital payment, money transfer, and banking

\section{Transform business and public sectors}

\section{Develop ICT-enabled economy and sector-wide transformation strategies}

- Align digital strategy with country economic development strategies

- Prioritize adoption capabilities in key user clusters-adopt sector-wide approaches

- Promote the digital transformation of SMEs via business associations and local governments

- Emphasize sustainable, scalable, sector-wide digital applications

- Provide sector-specific complementary investments and training to maximize digital dividends

- Target country and regional comparative advantages for accelerated transformation

- Prioritize "intelligent" infrastructure for sustainability: smart transport, energy, cities

- Promote e-trade, particularly in digital services and products

Develop digital platforms for the transforming sectors

\section{Engineer effective adoption of digital government}

- Develop digital government vision, strategy, and implementation road map

- Use digital government as a platform for data, services, and PPPs

- Mobilize demand for good government and improved public services

- Adopt a whole-of-government approach for digitizing core systems and key services

- Digitize country registries covering citizens, businesses, and lands

- Support local initiatives for digitized local government services

- Use digital government for transparency and accountability

- Adopt best practices in e-gov: single window, interoperability, user-centric approach, multichannel integration, etc.

\section{Cross-cutting Goals (principles)}

\section{Promote digital inclusion}

- Address the digital divide and preexisting inequalities

- Use shared access, community centers, and low-cost channels to reach low-resource settings

- Identify and stimulate nascent demand in lagging regions-local content

- Promote digital culture and literacy to secure wide and effective adoption

- Prioritize affordable access and build transformation capabilities of small businesses 
- Build informational capabilities of social intermediaries and marginalized communities

- Prioritize youth and women for wide developmental impact

\section{Promote ownership and partnerships}

- Build broad multistakeholder ownership and participation

- Create digital platforms for consultation, collaboration, and project generation

- Develop a strategic communication strategy to generate a national consensus

- Build partnerships among stakeholders, across sectors, at all levels, and overtime

- Develop and partner with private ICT services associations

- Build capacity of weak stakeholders to participate effectively

- Develop country-led forums for digital cooperation with development finance partners

- Invest in collaborative tools among universities, suppliers, and users

\section{Maximize learning and adaptation}

- Shift from rigid blueprint plans to adaptive, learning, results-driven strategies

- Capture local knowledge and grassroots innovations-develop scaling up mechanisms

- Balance central direction with local initiative-integrate local learning into strategies

- Build foresight capabilities - scan and prepare for disruptive technologies

- Focus research on adoption, evaluation, and outcomes

- Engage local universities and think tanks in locally relevant applied research

- Keep score through timely monitoring and evaluation-multiple feedback

- Develop the statistical benchmarks of the digital economy

- Create platforms and centers of excellence to capture and diffuse best practice51, 


\section{Appendix 7 \\ Digital Adoption across CAREC: Current State Overview}

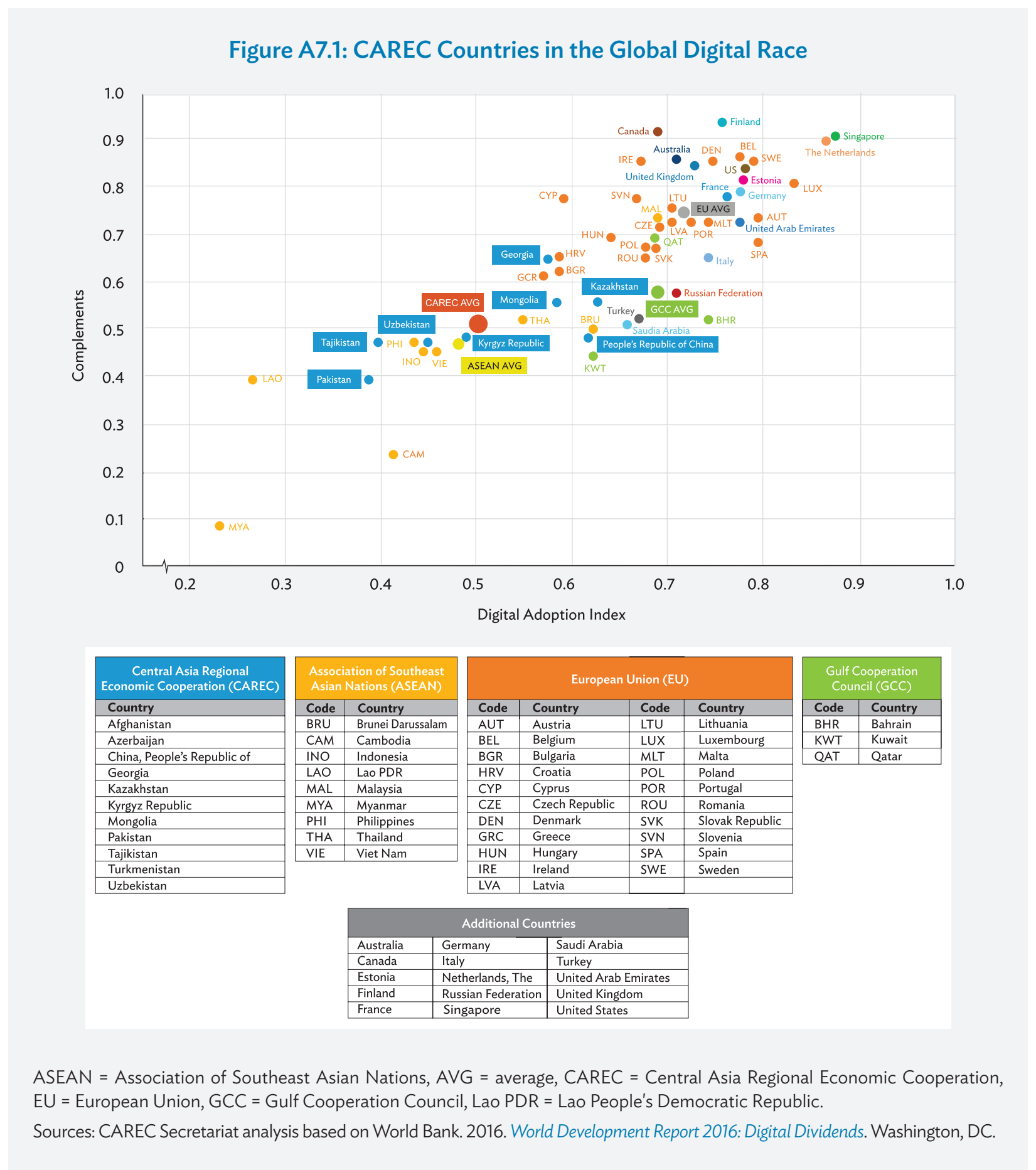


Figure A7.2: International Bandwidth per Internet User: CAREC vs. Other Regions (per 1,000 bits/second)

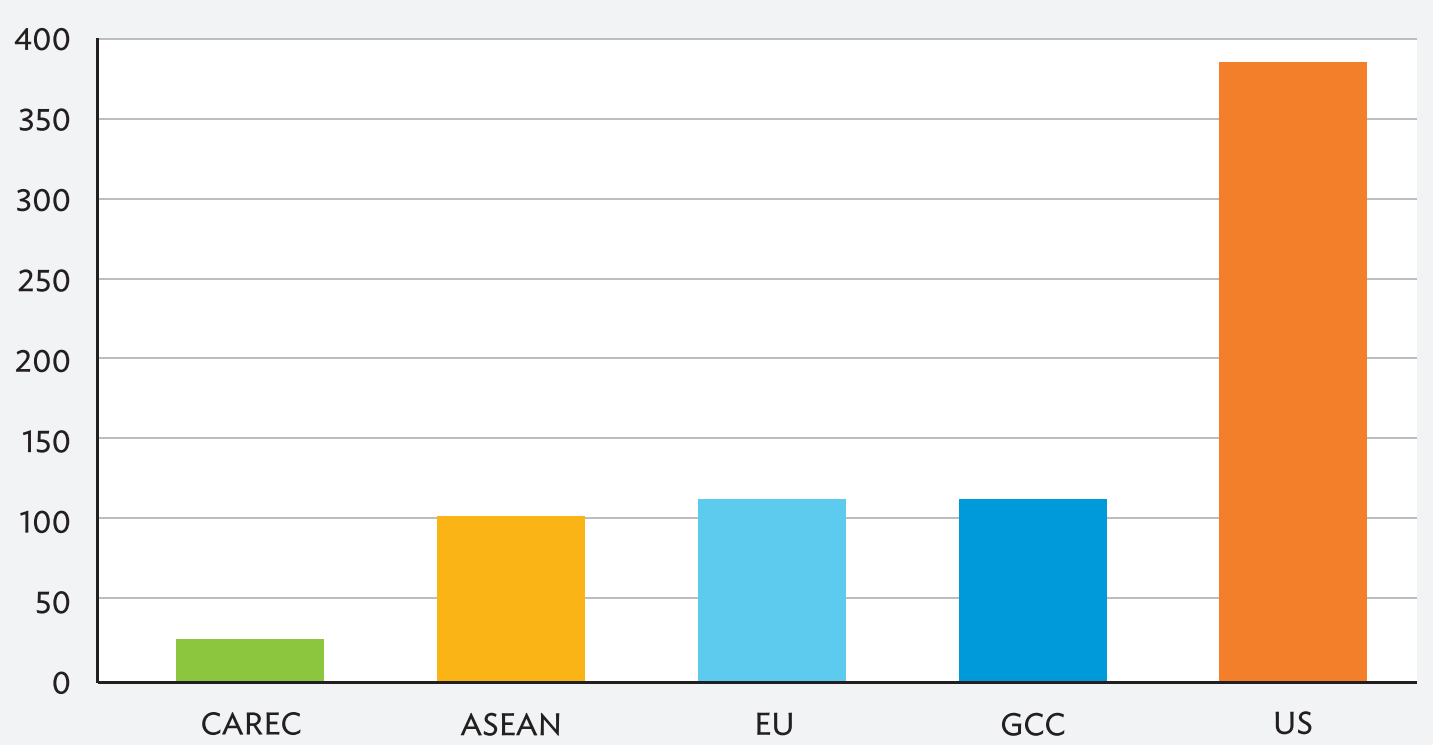

ASEAN = Association of Southeast Asian Nations, CAREC = Central Asia Regional Economic Cooperation, EU = European Union, GCC = Gulf Cooperation Council, US = United States.

Source: CAREC Secretariat analysis based on World Telecommunication/ICT Indicators Database 2019 (accessed May 2021).

Figure A7.3: Access to Fixed Broadband: CAREC vs. Other Regions (per 100 inhabitants)

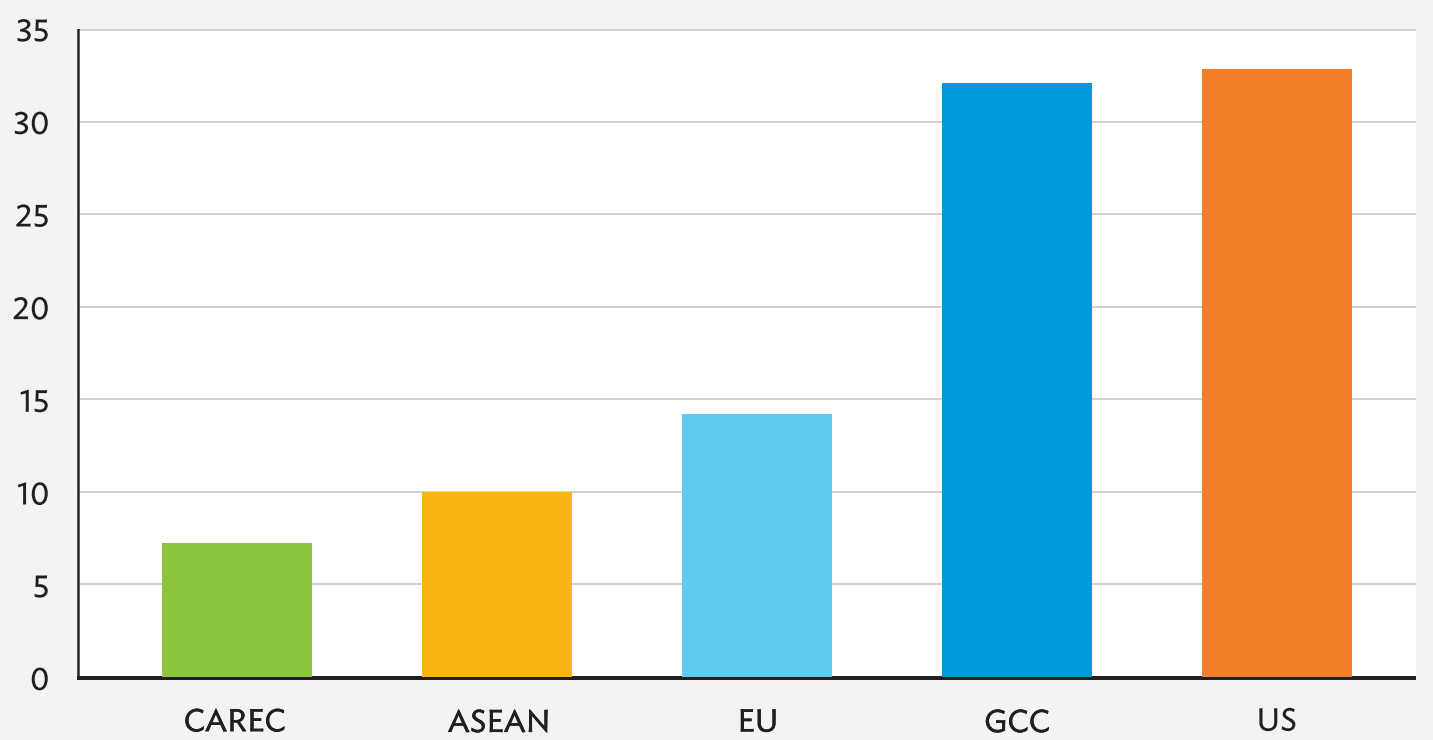

ASEAN = Association of Southeast Asian Nations, CAREC = Central Asia Regional Economic Cooperation, EU = European Union, GCC = Gulf Cooperation Council, US = United States.

Source: CAREC Secretariat analysis based on World Telecommunication/ICT Indicators Database 2019 (accessed May 2021). 
Figure A7.4: Internet Users: CAREC vs. Other Regions

(\%)

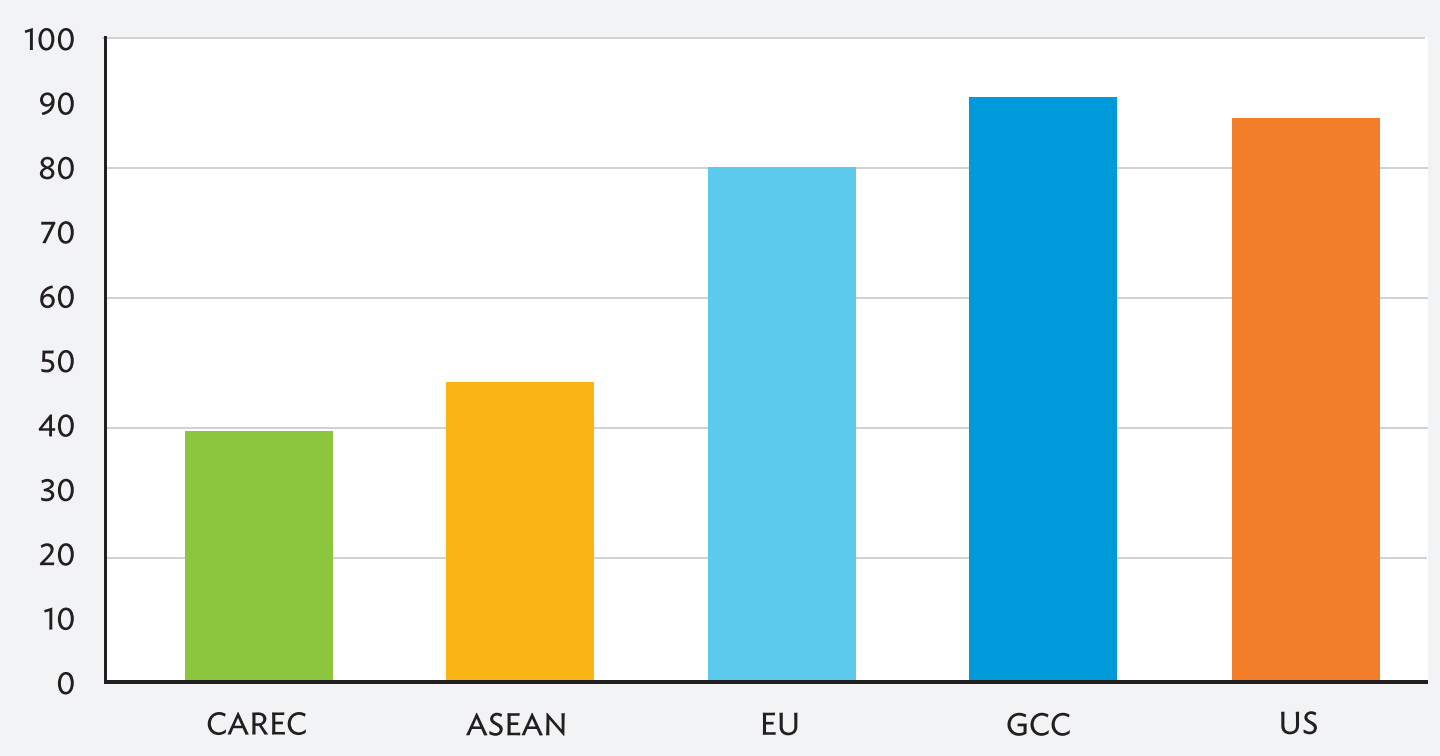

ASEAN = Association of Southeast Asian Nations, CAREC = Central Asia Regional Economic Cooperation, EU = European Union, GCC = Gulf Cooperation Council, US = United States.

Sources: CAREC Secretariat analysis based on World Telecommunication/ICT Indicators Database 2019 (accessed May 2021). 
Figure A7.5: International Indexes: CAREC Member Countries Average Ranking

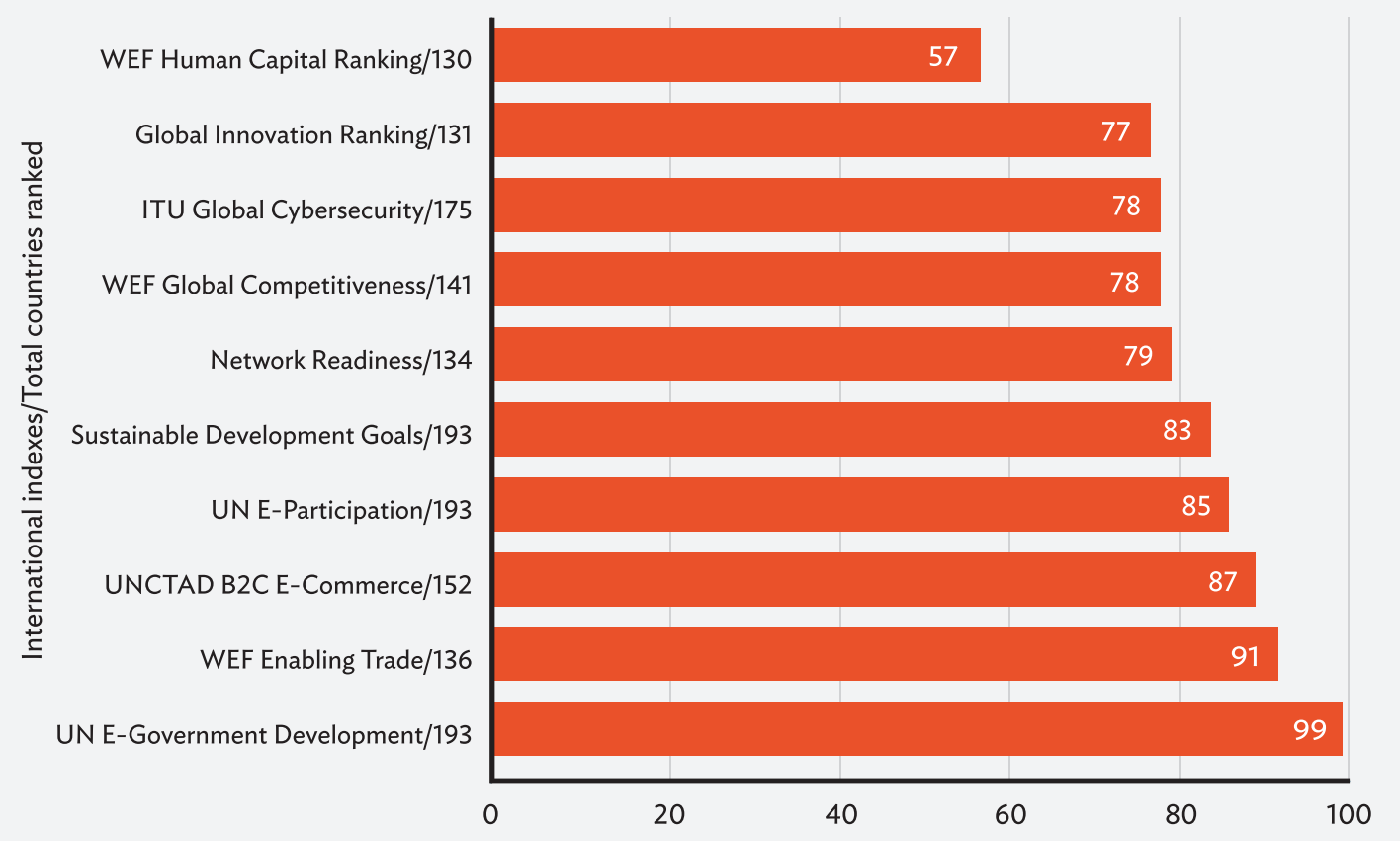

B2C = business-to-consumer, $\mathrm{CAREC}=$ Central Asia Regional Economic Cooperation, ITU = International Telecommunication Union, UN = United Nations, UNCTAD = United Nations Conference on Trade and Development, WEF = World Economic Forum.

Sources: CAREC Secretariat analysis using the following global indexes indicators: UN. 2020 E-Government Development Index (accessed 1 September 2021); UN. 2020 E-Participation Index (accessed 1 September 2021) (choose E-Participation Index in the dropdown menu under Data); Sustainable Development Report. Rankings (Performance by Sustainable Development Goals) (accessed 1 September 2021); ITU. 2021. Global Cybersecurity Index 2020: Measuring Commitment to Cybersecurity; K. Schwab, ed. 2019. The Global Competitiveness Report 2019. Cologny/Geneva: World Economic Forum; World Economic Forum. Enabling Trade Index 2016 (accessed 1 September 2021); Network Readiness Index. NRI 2020 Countries (accessed 1 September 2021); UNCTAD. 2020. The UNCTAD B2C E-Commerce Index 2020: Spotlight on Latin America and the Caribbean. UNCTAD Technical Notes on ICT for Development. No. 17; World Economic Forum. 2017. The Global Human Capital Report 2017: Preparing People for the Future of Work; World Bank. Human Capital Project (Percentage of Population with Secondary \& Tertiary Education) (accessed 1 September 2021); and World Intellectual Property Organization. 2021. Global Innovation Index 2021: Tracking Innovation through the COVID-19 Crisis. Geneva. 


\section{Table A7: International Indexes: CAREC Member Country Rankings}

\begin{tabular}{|c|c|c|c|c|c|c|c|c|c|c|c|c|}
\hline $\begin{array}{l}\text { International Indexes } \\
\text { (Rankings) }\end{array}$ & AFG & AZB & PRC & GEO & KAZ & KGZ & MON & PAK & TAJ & TKM & UZB & $\begin{array}{l}\text { CAREC } \\
\text { AVG }\end{array}$ \\
\hline $\begin{array}{l}\text { Global Innovation } \\
\text { Ranking/132 }\end{array}$ & N/A & 82 & 14 & 63 & 77 & 94 & 58 & 107 & 109 & N/A & 93 & 77 \\
\hline $\begin{array}{l}\text { ITU Global } \\
\text { Cybersecurity/182 }\end{array}$ & 126 & 55 & 27 & 18 & 40 & 111 & 85 & 94 & 107 & 142 & 52 & 78 \\
\hline Network Readiness/134 & N/A & 66 & 40 & 68 & 56 & 94 & 89 & 111 & 109 & N/A & N/A & 79 \\
\hline SDG/193 & 139 & 54 & 48 & 58 & 65 & 52 & 107 & 134 & 78 & 114 & 66 & 83 \\
\hline $\begin{array}{l}\text { UN E-Government } \\
\text { Development/193 }\end{array}$ & 169 & 70 & 45 & 65 & 29 & 83 & 92 & 153 & 133 & 158 & 87 & 99 \\
\hline UN E-Participation/193 & 118 & 73 & 9 & 80 & 26 & 66 & 87 & 103 & 146 & 179 & 46 & 85 \\
\hline $\begin{array}{l}\text { UNCTAD B2C } \\
\text { E-Commerce/152 }\end{array}$ & 143 & 65 & 55 & 47 & 60 & 97 & 61 & 116 & 121 & $\mathrm{~N} / \mathrm{A}$ & 107 & 87 \\
\hline WEF Enabling Trade/136 & N/A & 71 & 61 & 41 & 88 & 113 & 119 & 122 & 114 & $\mathrm{~N} / \mathrm{A}$ & N/A & 91 \\
\hline $\begin{array}{l}\text { WEF Global } \\
\text { Competitiveness/141 }\end{array}$ & N/A & 58 & 28 & 74 & 55 & 96 & 102 & 110 & 104 & N/A & N/A & 78 \\
\hline $\begin{array}{l}\text { WEF Human Capital } \\
\text { Ranking/130 }\end{array}$ & N/A & $\mathrm{N} / \mathrm{A}$ & 34 & N/A & 29 & 46 & 51 & 125 & 57 & N/A & N/A & 57 \\
\hline
\end{tabular}

AFG = Afghanistan, AZE = Azerbaijan, B2C = business-to-consumer, CAREC = Central Asia Regional Economic Cooperation Program, $\mathrm{GEO}=$ Georgia, ITU = International Telecommunication Union, KAZ = Kazakhstan, KGZ = Kyrgyz Republic, MON = Mongolia, $\mathrm{N} / \mathrm{A}=$ not applicable, PAK = Pakistan, PRC = People's Republic of China, SDG = Sustainable Development Goal, TAJ = Tajikistan, TKM = Turkmenistan, UN = United Nations, UNCTAD = United Nations Conference on Trade and Development, UZB = Uzbekistan, $\mathrm{WEF}=$ World Economic Forum.

Note: The blue color is used to highlight a stronger country ranking. The red color is used to highlight a weaker country ranking. Sources: CAREC Secretariat analysis using various indicators: UN. 2020 E-Government Development Index (accessed 1 September 2021); UN. 2020 E-Participation Index (accessed 1 September 2021) (choose E-Participation Index in the dropdown menu under Data); Sustainable Development Report. Rankings (Performance by Sustainable Development Goals) (accessed 1 September 2021); ITU. 2021. Global Cybersecurity Index 2020: Measuring Commitment to Cybersecurity; K. Schwab, ed. 2019. The Global Competitiveness Report 2019. Cologny/Geneva: World Economic Forum; World Economic Forum. Enabling Trade Index 2016 (accessed 1 September 2021); Network Readiness Index. NRI 2020 Countries (accessed 1 September 2021); UNCTAD. 2020. The UNCTAD B2C E-Commerce Index 2020: Spotlight on Latin America and the Caribbean. UNCTAD Technical Notes on ICT for Development. No. 17; World Economic Forum. 2017. The Global Human Capital Report 2017: Preparing People for the Future of Work; World Bank. Human Capital Project (Percentage of Population with Secondary \& Tertiary Education) (accessed 1 September 2021); World Intellectual Property Organization. 2021. Global Innovation Index 2021: Tracking Innovation through the COVID-19 Crisis. Geneva; Cornell University, INSEAD, and WIPO. 2020. The Global Innovation Index 2020: Who Will Finance Innovation? Ithaca, Fontainebleau, and Geneva. 


\section{Appendix 8 \\ Potential Areas for Regional Cooperation in the CAREC Digital Space}

Consultations with the public and private sectors across the region revealed several priority areas for collaboration. ${ }^{1}$ Both government and private sector respondents identified creating a regional innovation and entrepreneurship ecosystem as a top priority for regional digital cooperation. In addition, Central Asia Regional Economic Cooperation (CAREC) governments have expressed their willingness to work together on regional training, incubation, and acceleration programs for start-ups, whereas the private sector is ready to contribute solutions to enable digitalization of small and medium-sized enterprises (SMEs) across the region. This can be one of the first collaborative public-private sector projects to be launched within the framework of the CAREC Digital Strategy 2030 to catalyze regional collaboration and build momentum for the strategy implementation.

Specifically, several governments have volunteered to lead collaboration on top priority initiatives and build a platform to foster collaboration and best practice sharing, digital innovation, digital transformation of SMEs, digital skills, and capacity building. For example, for the top regional priority of digital innovation and SMEs enablement, (i) a regional acceleration program for start-ups was proposed by Georgia's Innovation and Technology Agency (GITA); (ii) a regional start-up hub was proposed by Kazakhstan; (iii) start-up training and acceleration were proposed by the Kyrgyz Republic; and (iv) joint incubation, acceleration, and training for start-ups were proposed by information technology (IT) Park, Uzbekistan. To drive this initiative, CAREC can consider establishing a virtual tax-free regional IT zone for start-ups, SMEs, and information and communication technology (ICT) companies across the region. Thus, the development of a regional digital innovation and SMEs enablement platform and a virtual tax-free regional IT zone followed by a physical digital innovation hub can become quick wins in implementing the CAREC Digital Strategy 2030.

For the top regional priority of digital skills and capacity building, the People's Republic of China (PRC) has offered digital competencies training, and Azerbaijan proposed training for digital leaders and change managers. Thus, developing a regional digital skills and competencies platform to host these trainings can become another quick win. This platform can also become the go-to resource for best practice sharing. Specific areas proposed by CAREC member countries include (i) e-government best practices from Kazakhstan, (ii) e-education and training best practices from the PRC, (iii) digital agriculture know-how from Pakistan, (iv) broadband rollout in remote and mountainous regions and digital transformation awareness-building best practices from Georgia, ( $v$ ) training and capacity building in the use of digital technologies for senior citizens from the PRC, (vi) leveraging digital technologies to address COVID-19 challenges from Kazakhstan, and (vii) smart cities and villages best practices from Azerbaijan.

Private sector companies propose a wide range of existing digital transformation solutions that can be scaled regionally to enable government and private sector transformation as well as SMEs enablement. Georgia, for example, has proposed to share its experience in leveraging broadband access for development, launching awareness-raising programs on the benefits of broadband for populations in rural, remote, and mountainous areas to help people understand how to make the internet work for them. It has also offered to share experience on developing SMEs and proposed specific SMEs solutions for e-commerce, e-business, and e-government. It has also suggested helping build a regional innovation and start-up ecosystem and host start-ups from

1 Consultations were conducted by the Central Asia Regional Economic Cooperation (CAREC) Secretariat in the summer of 2021. 
across the region in Georgia for training and networking. Kazakhstan proposed to host a regional hub for CAREC start-ups and launch regional cooperation on digital identity. It also offered to share its experience in mobile e-government services. Kazakhstan's Zerde National Infocommunication Holding proposed to share its experience in e-government services, intelligent transport, and e-freight initiative. Pakistan is willing to share its experience in digital agriculture.

\section{Pillar 1: Leadership, Governance, and Investment in the Digital Economy}

Figure A8.1: Government Incentives Needed to Encourage Private Sector Regional Digital Cooperation

\section{Private Sector Perceptions}

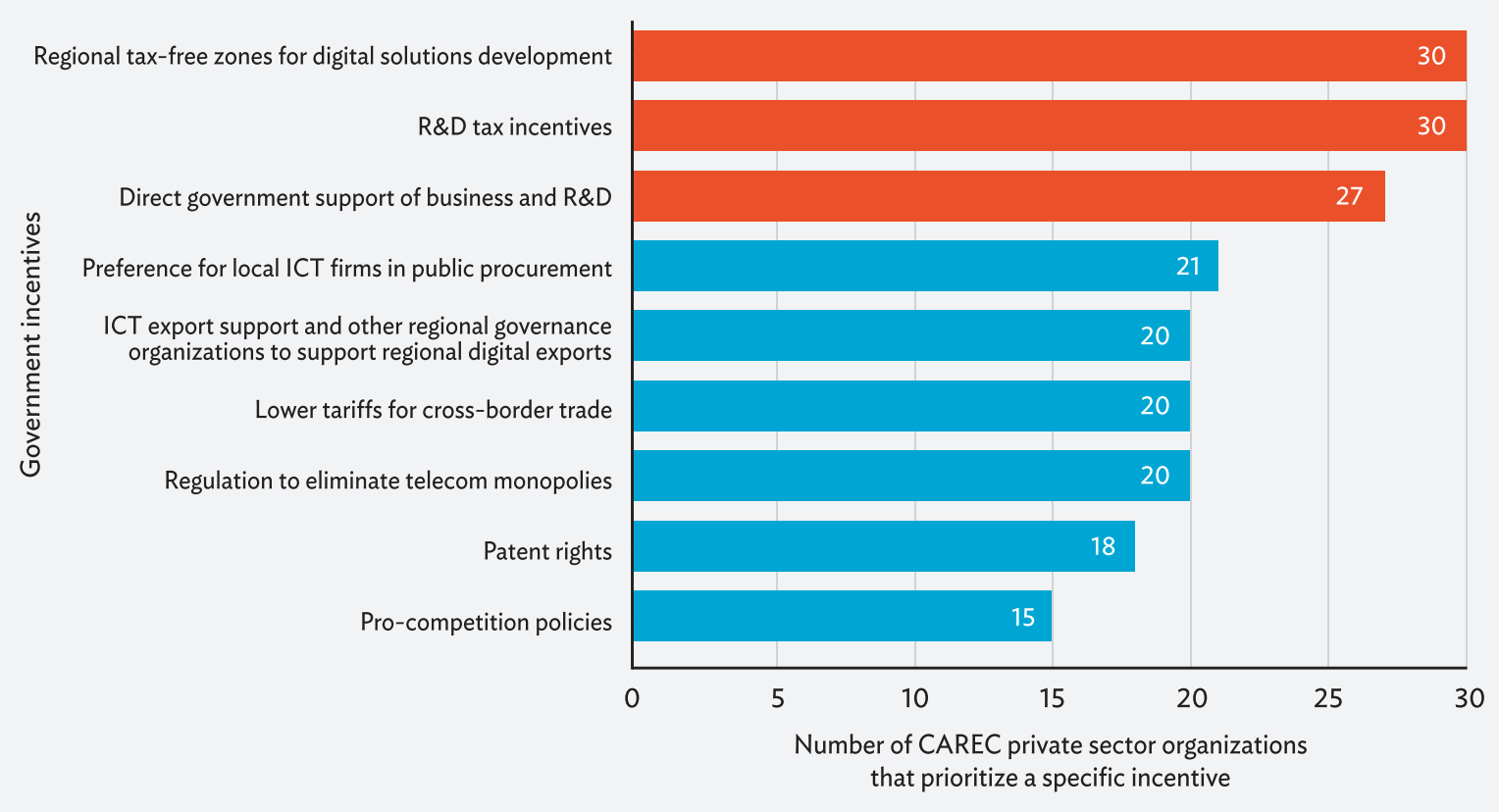

CAREC $=$ Central Asia Regional Economic Cooperation, ICT = information and communication technology, R\&D = research and development.

Note: Based on the analysis of private sector suggestions conveyed through responses to CAREC questionnaires, June 2021. The red color is used to highlight top priorities as identified by the responders.

Source: CAREC Secretariat.

\section{Pillar 2: Digital Policy Enablers and Safeguards}

\section{Proposed CAREC Cybersecurity Initiatives:}

Build awareness across the CAREC region of the need to strengthen cybersecurity and resilience in the face of rapidly rising global threats and attacks.

Develop communication mechanisms to spread awareness across the general population of the region.

- Develop a mechanism for best practice sharing across the region and globally and learn from global cybersecurity leaders like the PRC and the Russian Federation. 
Enable best practice sharing across the region and with global leaders in the field.

- Establish a regional focal point for cybersecurity issues.

- Set up a CAREC regional computer emergency response team.

- Develop, formulate, and align regulatory frameworks to protect critical regional infrastructure from cyberattacks.

- Enforce regular cybersecurity upgrades to national cyber defense systems.

- Strengthen regional cybersecurity expertise, organize regular training, and attract talent into the region.

- Focus on building cybersecurity skills and work with educational institutions and vocational training organizations to develop comprehensive cybersecurity training materials to be available online and at colleges and universities across the region.

Conduct regional cyberattack simulation exercises to test cyber defense systems in real-time situations and practice rapid response.

\section{Aligning Data Policies across CAREC}

Today, data have become the fuel of digital development. Effective data management is key to success in digital transformation and the achievement of digital dividends expressed in higher economic growth, new jobs, better services, and social inclusion. A data-driven approach can lead to improved citizen-centered service delivery, clearer policy development, evidence-based decision-making, and emerging innovative business models. New horizons for lagging regions and populations, new export areas and new markets for domestic industries and entrepreneurs, increases in productivity and efficiency in the public and private sectors, and creation of new markets and opportunities for local entrepreneurs are just some of the advantages of an effective approach to data management (Figure A8.2).

Figure A8.2: Role of Data in the Production Process: Pathways to Development

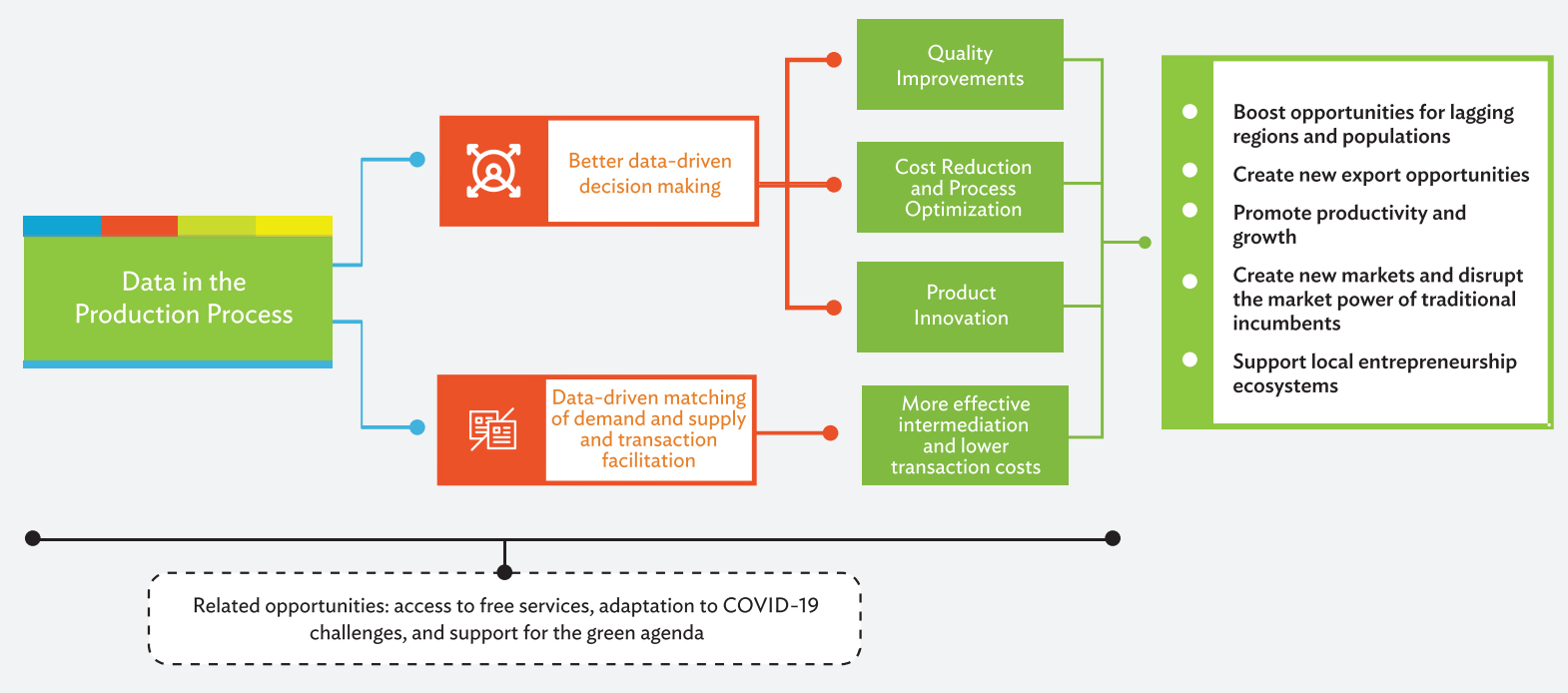

COVID-19 = coronavirus disease.

Source: World Bank. 2021. World Development Report 2021: Data for Better Lives. Washington, DC. 
Reliable statistical data are a serious challenge for most CAREC member countries. Data about many countries of the region are difficult to access. "While basic access data such as mobile penetration and broadband subscription indicators have become relatively common," the countries of the CAREC region, especially emerging countries, "still tend to show missing data across many basic statistical categories. And, often where data is apparent it is nationally defined and remains incomparable." 2 Except for the PRC, none of CAREC member countries have formulated a national data strategy to date. In Kazakhstan, the Kyrgyz Republic, and Uzbekistan, laws on personal data date back to 2013, 2008, and 2003, respectively. Attempting to keep up with the General Data Protection Regulation of the European Union (EU), ${ }^{3}$ Turkmenistan in 2017 and Tajikistan in 2018 adopted new policies that nevertheless remained limited in reach due to poor enforcement. ${ }^{4}$

CAREC data policies should be based on principles of open standards, technological neutrality, and interoperability. These principles expedite government service delivery through multiple channels and devices. CAREC member countries should also develop the institutional and regulatory frameworks for data security, protection, and privacy and stipulate that, apart from force majeure exceptions such as pandemics or other crises requiring government intervention, the privacy of citizens' data will be safeguarded.

It is important to coordinate multistakeholder actions aimed at ensuring privacy and personal data protection, and the protection of consumers and their rights on online platforms while ensuring access to public information and freedom of expression in the digital environment, restricting improper and unauthorized use of data, and strengthening mechanisms of collaboration between administrations across the region.

Adopting common standards on open data across CAREC "can guide the private and public sectors on how to provide open access to data sets, ensuring that more data become available as digital public goods, while respecting privacy and confidentiality. Central to the implementation of digital public goods are robust human rights and governance frameworks to enhance trust in technology and data use, while ensuring inclusion."

Effective data policies require creating a trust environment between all the players of the regional data ecosystem, including the public sector, the private sector, businesses, academia, and the citizens/end users. It is essential to establish the enabling conditions for a social contract between the government and the governed so that data can become a force for public good. As with all the key elements of digital transformation, the key challenge is not just technology, but the social and cultural transformation required to achieve an inclusive culture of data sharing and collaboration across government and nongovernment groups in traditionally conservative CAREC societies with low levels of institutional and interpersonal trust.

\section{Global and Local Best Practices in Developing Regional Data Strategies}

It would be useful to learn from global and local best practices in formulating regional data policies. Other regional organizations, notably the EU, have realized the importance of regional data strategies. The implementation of the European Interoperability Framework in the $27 \mathrm{EU}$ member states has been a key element of the EU data strategy as it contributes to the achievement of important initiatives such as the Digital Single Market Strategy, the eGovernment Action Plan, the Tallinn Ministerial Declaration on eGovernment, and the Once-Only Principle.

\footnotetext{
2 Asian Development Bank (ADB). 2015. Unleashing the Potential of the Internet in Central Asia, South Asia, the Caucasus and Beyond. Consultant's Report. Manila. pp. 69-70.

3 General Data Protection Regulation (GDPR).

4 Y. T. Yan. 2019. Smart Cities or Surveillance? Huawei in Central Asia. The Diplomat. 7 August.

5 United Nations. 2020. Report of the Secretary-General: Roadmap for Digital Cooperation. p. 9.
} 
The European Interoperability Framework supports national data strategies, the simplification of cross-border and cross-sector data exchanges. With its recommendations for semantic interoperability, a prerequisite for the sharing and reuse of data, it facilitates the emergence of Europe's data economy and the implementation of the European strategy for data.

\section{Pillar 3: Digital Infrastructure, Resilience, and Platforms}

Leveraging new disruptive technologies to accelerate digital transformation has been identified as a top priority by CAREC governments. To do so effectively across the region, the governments should strengthen the digital foundations, ensuring pervasive broadband connectivity to bridge the digital divide, boost digital skills (especially professional skills required to work with new digital technologies), harmonize legislature and regulations across the region, and ensure interoperability of digital infrastructures.

\section{Building a Regional Platform Economy in CAREC}

Figure A8.3: CAREC Platform Economy

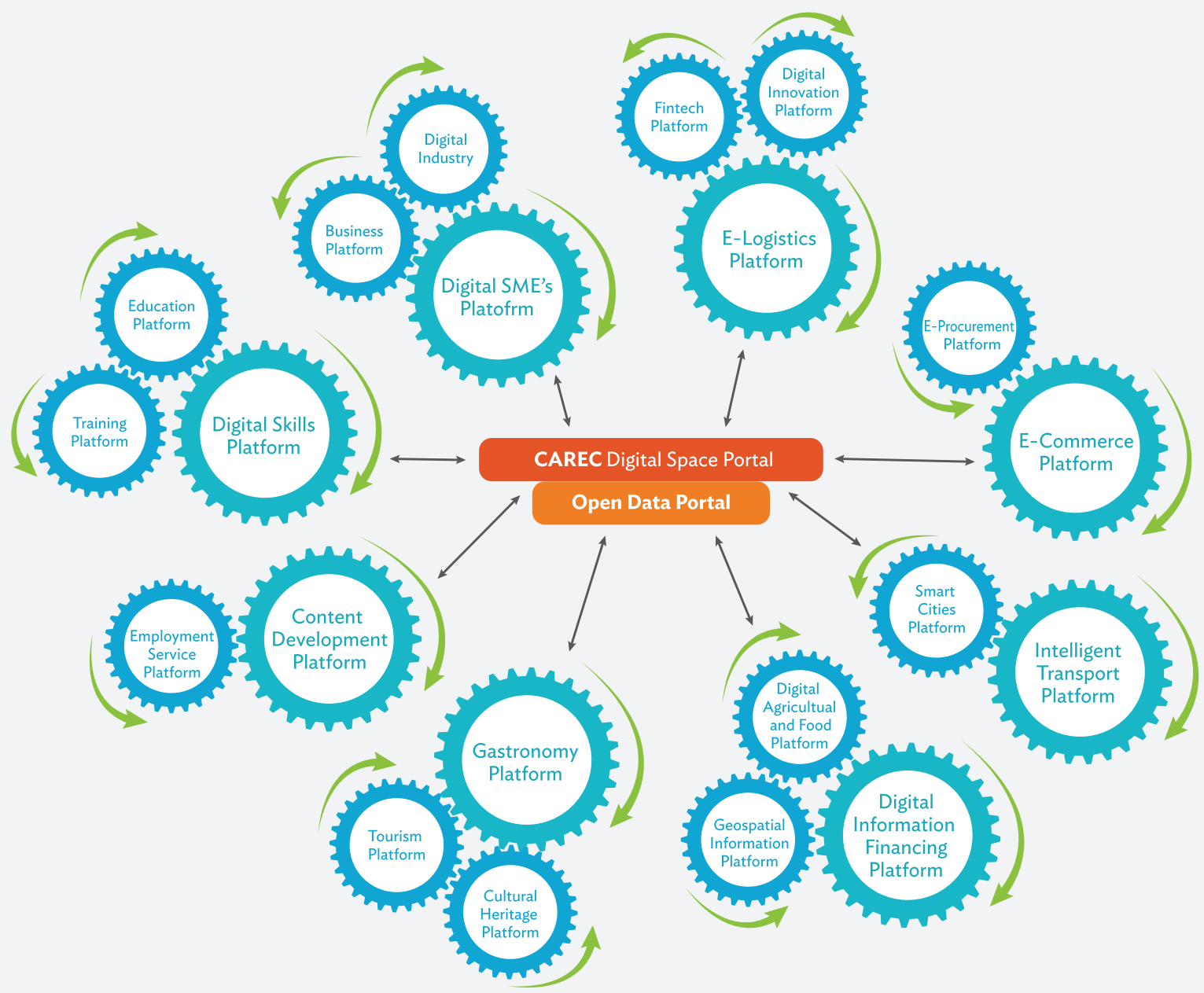

CAREC = Central Asia Regional Economic Cooperation, $\mathrm{SME}=$ small and medium-sized enterprise.

Source: CAREC Secretariat. 


\section{CAREC Open Data Portal}

Several CAREC member states have open data government portals. However, this is insufficient to unlock the full potential of shared and reusable public sector data across the region. A single point of access - the CAREC Open Data Portal-would improve accessibility and increase the value of CAREC's public data. Issues of metadata standards, data standards, and linked data need to be addressed. Guidelines should be provided for data providers and facilities to allow users to search, link, download, and reuse data for commercial or noncommercial purposes. Combining government data, business data, and scientific data can contribute to building the data economy, delivering innovative services and data-driven public policies that will benefit society.

For open government services to be provided, enough open data should be accessible to the public and businesses. Therefore, approving common open data standards and ensuring data's synchronization and quality are key. Creating an open data repository through the CAREC Open Data Portal will accelerate digital transformation in the region, leading to higher growth, new jobs, and better services.

\section{Pillar 4: Digital Skills and Competencies}

In today's economy, most jobs already require some level of digital skills. Given the accelerating rate of digital adoption, tomorrow's digital space jobs will require specific skills associated with new and emerging technologies. In most CAREC member countries, there is a shortage of skilled digital talent across all sectors of the economy. National and local governments lack the skills to reengineer government processes to deliver productivity and efficiency gains through digital adoption. They struggle to ensure systems interoperability and standards across all government agencies, enable the free flow of data within and beyond government, develop new and timely digital services for the one-stop-shop single window e-government portals launched across the region, and provide support to the users of digital government services.

There is a shortage of skilled digital professionals at the sectoral level in the industry, agriculture, business, and services to leverage digital technologies to increase private sector productivity and efficiency, whether in production, supply chain management, or customer relationship management. And there is a shortage of skilled digital talent at the start-up ecosystem level needed to leverage digital technologies to create new, innovative products and services. Therefore, CAREC public sector stakeholders have identified the lack of digital skills as the top obstacle to digital transformation in the region. Both public and private sector stakeholders have highlighted building basic, professional, and advanced digital skills across the region as a top priority for regional digital cooperation.

Some CAREC member countries are already collaborating with large multinational private sector companies in building digital skills across the region. For example, Huawei signed an agreement in 2014 with Tashkent University of Information Technologies that created educational opportunities for young Uzbek students to study in the PRC, culminating in the 2017 launch of the "Seeds for the Future" initiative through which Uzbek students were allowed to attend the Belt and Road Initiative International Forum and invited to visit and take classes at Huawei's headquarters in the PRC. Despite the ongoing pandemic, Huawei intends to continue the education program and is committed to seeking new talents and providing job opportunities. ${ }^{6}$ Cisco has been running Networking Academy programs across the region for many years, offering certified networking engineer qualifications.

\footnotetext{
6 Huawei. Seeds for the Future.
} 
Specific actions to address the lack of IT professionals include the following:

- Implement innovative educational training programs on breakthrough technologies from an early age, such as science, technology, engineering, and mathematics (STEM) and robotics.

- Update school and university curricula to incorporate digital skills and competencies in STEM courses and update digital educational resources and teaching standards accordingly.

- Develop undergraduate, graduate, and postgraduate courses in computer science and software engineering and courses in IT-related subjects including innovation and entrepreneurship. It is important to promote close collaboration between academic institutions and industry to design education programs and training courses.

- Develop special training courses for public sector employees and private sector companies to strengthen advanced digital, technical, and professional skills and competencies.

- Establish incentives for governments and companies across CAREC to provide opportunities for continuous learning to workers based on individual and local needs and labor market requirements.

- Promote an inclusive CAREC digital culture and government support to incentivize the youth, women, rural populations, and other disadvantaged groups to acquire digital skills.

- Develop a network of centers of digital competencies across the region by cooperating with educational institutions, nonprofit organizations, and business associations, and by attracting qualified experts from other countries.

- Nurture, support, and promote talented IT professionals and provide opportunities for development to prevent brain drain from the region.

- Develop effective incentives mechanisms to attract and retain highly professional IT specialists in the public sector (e.g., competitive wages, support for professional development, access to global knowledge, scholarships, and participation in competitions).

- Encourage local content creation across the region and create targeted training programs to create, record, and disseminate local content.

\section{Pillar 5: Innovation, Entrepreneurship, and Information and Communication Technology Competitiveness}

\section{Nurturing the Digital Innovation Ecosystem}

In recent years, "significant increases in investments in science and technology, particularly in [the PRC], but also in other emerging markets, have shifted the global distribution of knowledge and innovation resources in favor of Asia. Whereas innovation used to flow mostly in one direction, from highly developed to emerging economies, these flows are becoming increasingly two-way." 7 The Organisation for Economic Co-operation and Development (OECD) "predicts that while global production and diffusion of new knowledge will intensify, so will competition for talent and resources between countries and regions." 8

Some CAREC member countries are already nurturing their start-up and innovation environments. In addition to the PRC's investment in digital adoption and innovation leadership, other CAREC member countries, such as Georgia, Kazakhstan, the Kyrgyz Republic, Mongolia, and Uzbekistan, have also invested in their innovation

World Bank. 2018. Competing in the Digital Age: Policy Implications for the Russian Federation. Washington, DC. p. 101.

8 OECD. 2016. OECD Science, Technology and Innovation Outlook 2016. 
ecosystems by building start-up hubs and accelerators, and attracting venture capital. Kazakhstan's capital Nur-Sultan has won a maximum ranking for innovation funding growth from Startup Genome. The tax-free Astana Hub founded in 2018 houses more than 500 IT companies. The Astana International Financial Centre introduced a fintech regulatory sandbox and visa-free entry for residents of 57 countries. Georgia's Innovation and Technology Agency focuses on developing the innovation ecosystem in Georgia and collaborates with start-up platforms in Silicon Valley while also exploring avenues for regional cooperation for building a start-up ecosystem and launching digital awareness and digital skills training initiatives in CAREC member countries. Georgia and Kazakhstan have offered to apply and scale their innovation ecosystem development.

\section{Promoting the Adoption and Effective Use of Digital Technologies by Small and Medium-Sized Enterprises}

The regional CAREC Digital SMEs Program will do the following:

- Develop incentives, training, and regionally funded extension programs to support SMEs' adoption and effective use of e-business solutions.

- Establish a regional CAREC SMEs digital platform to fuel regional SMEs collaboration and provide access to programs and tools for effective digital development and collaboration.

- Leverage the platform to promote digital presence and effective adoption, dissemination, and use of advanced Industry 4.0 digital tools to foster business productivity and competitiveness, as well as entrepreneurship and structural change.

- Engage local government agencies and business associations in supporting local SMEs through their digital transformation process, including by bringing them onto the digital SMEs platform.

- Establish advisory centers across the region to help SMEs leverage digital technologies to increase efficiency, boost market access, improve customer relationship management, and develop new products and services.

- Provide SMEs with government incentives and subsidies for acquiring digital solutions and developing digital skills.

- Enable SMEs best practice sharing across the region and extend SMEs access to expertise and standard digital solutions such as customer relationship management, hosting, and data analytics tools via the CAREC SMEs Digital Platform. 


\section{Appendix 9}

\section{Accelerating the Digital Transformation of CAREC Operational Clusters}

Going forward, it is important to formulate sector-level digital transformation strategies to envisage the implementation of digital technologies in each operational cluster of Central Asia Regional Economic Cooperation (CAREC), as well as in other key sectors where the region has established comparative advantage, and focus on empowering these clusters through the use of new technologies such as the Internet of Things (IoT), Industry 4.0, artificial intelligence (AI), blockchain, etc. Furthermore, to encourage cluster-level innovation, CAREC member countries should introduce experimental "sandboxes" to pilot and test innovative solutions without fear of legal or other repercussions.

\section{Connecting Smart Cities and Villages across CAREC}

More than half of the world's population lives in cities. "By 2050, two-thirds of all humanity-6.5 billion people - will be urban." "The rapid growth of cities due to urbanization and a rise in migration has led to a boom in megacities, especially in the developing world. Global competition is increasingly taking place between cities, as they strive to attract the best talent and investment from around the world.

Leveraging new disruptive technologies, especially 5G-enabled loT, $\mathrm{Al}$, and big data to boost urban development and the quality of life, will determine the winners and losers in this competition, as smart cities compete on the strength of their nondigital and digital foundations, and the quality of their enabling environment and public services. Thus, the successful development of connected smart cities across a region like CAREC will attract talent and investment, leading to increased regional competitiveness and social and economic benefits for the region's population.

The CAREC region has also experienced urbanization and migration to cities over the last decade. Digital technologies can help governments in the region to manage these processes and address challenges such as public safety and security, extension of government services to newly arrived migrants, health care, education, employment, etc.

Many cities across the region are already implementing smart city projects and solutions focusing on leveraging digital technologies to transform municipal services ranging from traffic management, transportation, public safety and security, emergency response, and garbage disposal and procurement to education, health care, social support, and culture. For example, over 500 cities in the People's Republic of China (PRC) are launching smart city initiatives. In CAREC, Almaty, Astana, Ashgabat, Bishkek, Dushanbe, Kabul, Lahore, and Tashkent are all investing in smart city solutions, albeit with varying degrees of success. Kazakhstan's Almaty, for example, has implemented smart lighting solutions and automated mudslide hazard monitoring. Sergek's traffic video surveillance system is operational in both Almaty and Nur-Sultan.

Companies from the PRC are actively promoting their smart city solutions across CAREC, powered by $5 G$ technologies that support the loT and encouraged by the PRC's Belt and Road Initiative and the Digital Silk Road Strategy aimed at promoting the export of Chinese digital innovation, technologies, and infrastructure

\footnotetext{
United Nations Development Programme (UNDP). Goal 11: Sustainable Cities and Communities.
} 
and supported by Chinese financing across the region. ${ }^{2}$ This initiative has been well received by CAREC governments, especially in light of the increased need for digital solutions to address the coronavirus disease (COVID-19) crisis, with large implementations taking place across Kazakhstan, Tajikistan, Uzbekistan, and elsewhere in CAREC.

Smart villages can help bridge the urban-rural digital divide across the region. For example, the PRC's Alibaba Taobao platform can be an effective tool to bring villages across the region to participate in e-trade. ${ }^{3}$ Within the PRC, Taobao is transforming rural areas where about 40\% of the PRC's population live: in 2018, this platform generated $\$ 195$ billion worth of e-commerce sales, up 30.4\% year-over-year and outpacing the $24 \%$ growth seen in the PRC's overall e-commerce market. "E-commerce is enabling more rural residents to become entrepreneurs," creating new job opportunities, and raising incomes even in the most impoverished areas: "household incomes in Taobao Villages are almost three times that of the average rural household income in [the PRC] and are similar to urban household incomes." "E-commerce in rural areas has also led to higher household consumption," "reduced income inequality, and better job opportunities for women and young people (footnote 3)." In 2019, Taobao Villages created 6.8 million jobs throughout the e-commerce value chain. ${ }^{4}$ The Taobao model should be considered for scaling across the CAREC region to boost rural development in CAREC member countries.

In Azerbaijan, smart village development is a government priority and a focus of the rebuilding effort in Karabakh. ${ }^{5}$ The PRC's Huawei plans to help the Government of Azerbaijan by (i) supplying the most advanced technologies including the first-time implementation of Gigabit AirPON technologies to reduce optical-fiber cable requirements and save costs; and (ii) rolling out smart education, health, and agriculture systems. ${ }^{6}$

\section{Digital Agriculture}

Digital agriculture has been identified as a top priority for sectoral transformation by CAREC government stakeholders, which is not surprising given the predominance or high percentage of rural populations in most CAREC member countries.

The Food and Agriculture Organization of the United Nations (FAO) forecasts that by 2050, over 90\% of the demand for global food production will be met by increasing the yield of current arable land based on advances in agricultural research, ${ }^{7}$ a goal that is high on the agenda of CAREC member countries, especially in light of ensuring food security.

2 In 2018, Huawei Tech. Investment Tashkent, working with the State Committee of the Republic of Uzbekistan for Development of Tourism and Uzbek Ministry of Internal Affairs, agreed to implement the "Safe Tourism" pilot project in the city of Bukhara. Huawei. 2018. Huawei implements "Safe Tourism" pilot project in Bukhara. https://petition.gov.uz/ru/news/view/113. 13 July.

The Safe Tourism project is a part of the greater Safe City concept and combines a set of solutions including the creation of a converged command center, a unified LTE communication network, a data center, high-definition video cameras with face recognition function, and processing software for big data analysis to optimize urban management. The Bukhara project mirrors similar initiatives in Nairobi, Kenya; Lahore, Pakistan; Saudi Arabia; and Dushanbe, Tajikistan. UZA. Huawei Is implementing "Safe Tourism" Pilot Project in Bukhara; Y. T. Yan. 2019. Smart Cities or Surveillance? Huawei in Central Asia. The Diplomat. 7 August; S. Sukhankin. 2021. Tracking the Digital Component of the BRI in Central Asia, Part One: Exporting "Safe Cities" to Uzbekistan. The Jamestown Foundation. 11 February.

3 J. Wang. 2019. Taobao Villages Driving 'Inclusive Growth' in Rural China. Alizila. 25 November.

4 World Bank. 2019. Stimulating Jobs, Growth, Entrepreneurship, Income in Rural China through E-Commerce. Results briefs. 22 November.

5 M. Mehdiyev. 2021. As Azerbaijan Looks to Restore Its Karabakh Region, Global Know-How Could Be Key. Caspian News. 29 April.

6 AZERTAC. 2021. Huawei to Apply lts Most Advanced Technologies in Karabakh. 28 April.

7 FAO. 2009. Global Agriculture towards 2050. High-Level Expert Forum-How to Feed the World in 2050. 12-13 October. Rome. 
Figure A9: CAREC Population: Urban vs. Rural

(\%)

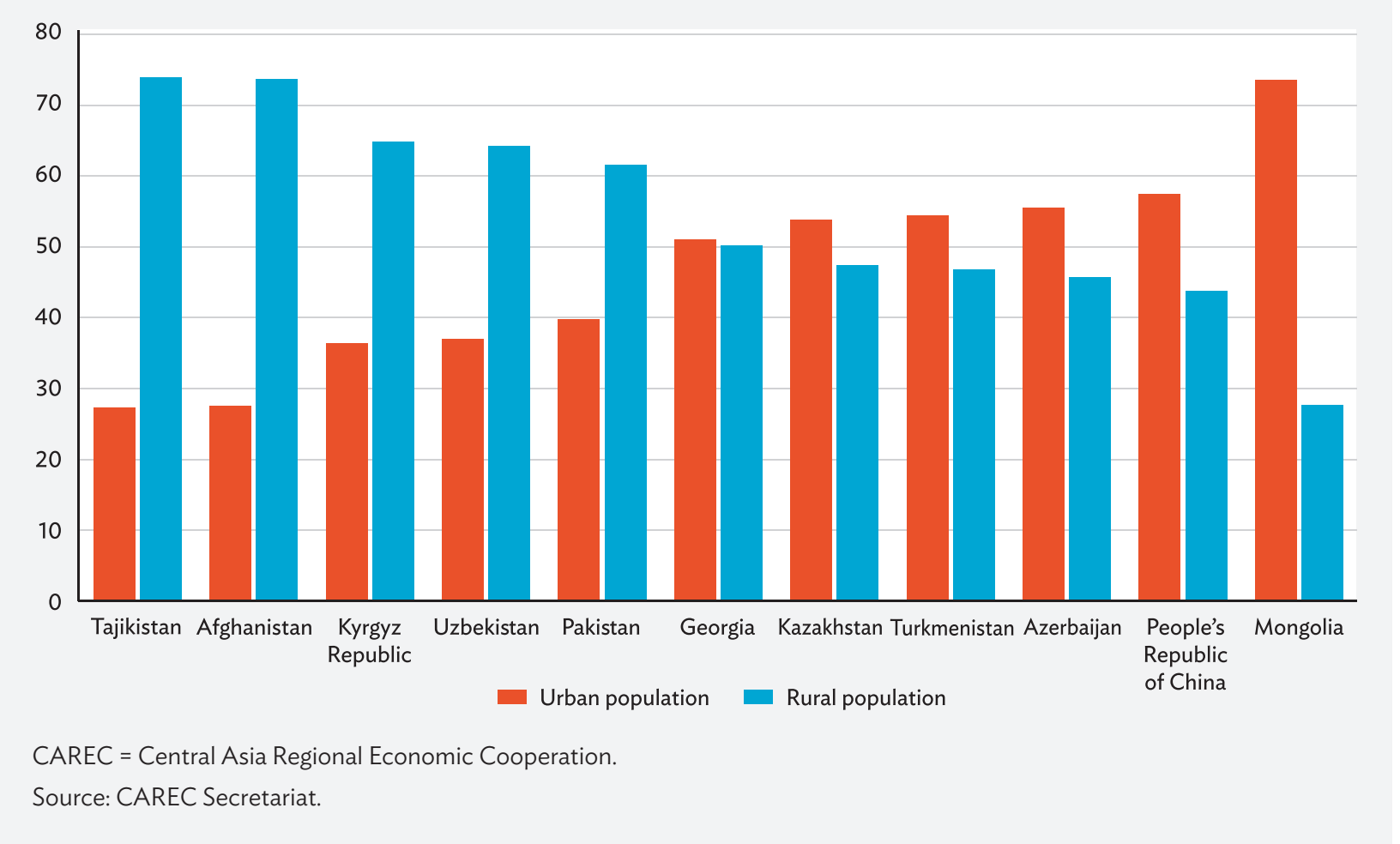

In the United States (US), enhancing digital agriculture technologies already in use today and increasing producers' usage to full scale could create at least $\$ 47$ billion each year in additional gross benefit for the US economy. Rural broadband e-connectivity is the driver of more than one-third of that potential value, equal to $\$ 18$ billion of annual economic improvements. ${ }^{8}$

Digital technologies such as the loT, Al, blockchain, and big data "are transforming farming and agribusiness across the globe, not only for large commercial players and small farms in the world's wealthier countries but [also for] the middle-income and emerging markets." ${ }^{9}$ Leveraging digital technologies in agriculture across the CAREC region can help raise farmers' productivity and efficiency, address water management and land arability problems high on the agenda of regional leaders, help manage environmental impacts, allow CAREC farmers access to global agricultural knowledge, link CAREC producers to new customers and markets, allow them to explore niche and higher value-added specializations such as organic agriculture, and increase the share of agriculture contribution to regional gross domestic product and exports.

Some CAREC member countries "have already made good progress towards adopting digital technologies in their agricultural sectors, including the use of precision agriculture, crop and livestock monitoring, and digital soil maps," although the adoption of new technologies is lagging for smallholder farmers due to the remaining rural digital divide affecting the availability and quality of internet access, connectivity costs,

8 United States Department of Agriculture (USDA). 2019. A Case for Rural Broadband: Insights on Rural Broadband Infrastructure and Next Generation Precision Agriculture Technologies.

9 International Bank for Reconstruction and Development and World Bank. 2018. Russia Digital Economy Report. Washington, DC. p. 72. 
lack of awareness, and digital skills gap. ${ }^{10}$ Several countries have included digital agriculture in their digital transformation documents, and some CAREC members, including the Kyrgyz Republic, Tajikistan, and Uzbekistan, have approached international organizations such as the FAO for assistance in the development of their national e-agriculture strategies. ${ }^{11}$

The CAREC Digital Food and Agriculture Platform would include a database of digital agricultural services, products, and projects. It would also complement other related regional and international platforms such as the Central Asia Climate Information Platform. ${ }^{12}$ Regional policies should set standards for agricultural data collection methods and systems, including agriculture-specific digital indicators, regional interoperability standards, procurement mechanisms, etc. Specific regional initiatives can include (i) creating a regional data repository for disease surveillance and monitoring of animal products to facilitate regional trade by allowing closer integration within regional and global value chains; (ii) cooperating further on existing initiatives to introduce common sanitary and phytosanitary measures; (iii) developing digital land and water accounting systems; (iv) addressing gaps in the provision and analysis of weather data, and other predictive tools for farmers, including the monitoring of regional water distribution, basin water management, and storage; and (v) using satellite imagery, procured and analyzed at the regional level, to support weather forecasting, agricultural monitoring, and water management. ${ }^{13}$

This platform approach will disseminate conceptual models, methodologies, and good practices regarding innovative technologies, interoperability standards, and open data access. Digitalization of agriculture across CAREC can accelerate the transformation toward more sustainable and inclusive agriculture and food systems, help bridge the digital divide, ensure food security, and achieve the Sustainable Development Goals (SDGs) even in remote areas. ${ }^{14}$

CAREC member countries must encourage broader adoption of digital technologies by small and large agriculture producers. They should "focus on the digital transformation of the entire agribusiness cluster that includes not only production but also storage, transportation, and logistics companies, financing and telecom service providers, the scientific community, venture capital, machinery, biotechnology and chemical industry players, and others and use digital platforms and other tools to enable collaboration, gain access, and provide products and services to new customers and market segments regionally, nationally, and globally."15

\section{Digital Tourism}

The CAREC Cultural Heritage Digital Platform can offer integrated online access to CAREC's rich cultural, religious, scientific, and historical heritage and create a digital library of cultural and scientific artifacts (books, paintings, music, films, etc.) from national libraries, galleries, archives, and museums. This platform would not only raise local, regional, and global awareness of CAREC history and culture and attract tourists to the region but also contribute to local and regional digital content creation and allow the emergence of new services in the content and media sectors. It would also, through value-added services, boost growth and jobs in the content and media sectors.

10 FAO. 2020. Central Asia Embraces Digital Agriculture. News. 8 December.

11 International Telecommunication Union (ITU) and FAO. 2020. Status of Digital Agriculture in 18 Countries of Europe and Central Asia. Geneva.

12 Central Asia Climate Information Platform.

13 CAREC Program. 2021. CAREC at 20: Reimagining Regional Cooperation through Digital Transformation: A Policy Note for the High-Level Session during the ADB Annual General Meeting. ADB 54th Annual General Meeting. 4 May. Manila.

14 UN Digital Transformation Group for Europe and Central Asia (UNDT4ECA) supports digitalization to achieve SDGs both at regional and country levels.

15 World Bank. 2018. Competing in the Digital Age: Policy Implications for the Russian Federation. Washington, DC. pp. xxiv-xxv. 
Given the richness of food traditions and cuisines across the CAREC region, creating the CAREC Gastronomy Platform is another initiative that can raise the region's tourism attractiveness while, at the same time, boost the growth of the food, agribusiness, and hospitality industries across CAREC. The CAREC Gastronomy Platform would bring together suppliers from across the region, such as local producers and farmers, bakers and winemakers, food experts and chefs, specializing in unique and specialized products, and enable them to promote and market their products and services to tourism organizations, restaurants, hotels, catering companies, retailers, and other types of consumers. Implementation of blockchain solutions on the platform can help trace the origins of all the products and ensure their adherence to quality and sanitary standards. Integration with the CAREC Cultural Heritage Platform will enable the development of gastronomy narratives linked to the region's cultural and historical origins and spur the creation of innovative products and services. Integration with the CAREC Digital Agriculture Platforms will help local suppliers find new consumers and markets for their products and services across the region. Integration with global gastronomy platforms would help raise CAREC's visibility globally and attract more visitors to the region. 


\section{Appendix 10 \\ Potential Areas of Implementation of the CAREC Digital Strategy 2030}

The economic connectivity cluster of Central Asia Regional Economic Cooperation (CAREC) can be boosted by closing the digital divide through ubiquitous broadband access. A portfolio of investment projects focused on building secure interoperable networking and data infrastructure across the region, bridging the digital divide, and providing universal broadband access, including in remote and mountainous areas, should be created and discussed with CAREC's digital ecosystem stakeholders.

CAREC's economic and financial stability cluster would benefit from financial inclusion and fintech solutions and initiatives to ensure the interoperability of mobile payment and banking systems to utilize mobile payments for transactions.

CAREC's trade, tourism, and economic corridors cluster can drive a wide range of projects including (i) digital trading platforms for the region to reduce transaction costs, improve transparency and accountability, and reduce delays and other associated risks; (ii) harmonization of regulation and legislation to enable e-commerce and the establishment of cross-border services; (iii) e-commerce, e-customs and digital taxation, online licensing and certification, and unified checkpoint systems; (iv) electronic queues at border points; and (v) various information sharing mechanisms.

Tourism in CAREC is seeing the benefits from the ongoing CAREC Tourism Portal, which can be improved to (i) support the digital silk road and e-visa regimes, (ii) adopt digital solutions to ensure health and safety for arrivals to the region, and (iii) promote cooperation on safety and security through the use of digital technologies.

Transportation in the region would be boosted by introducing automated payment systems for rail and road freight to improve efficiency and developing an integrated transit and transportation system to enable the freer movement of goods and services across the region.

The following can empower the development of the cluster in water and agriculture: (i) electronic land and water accounting systems, (ii) a regional data repository for disease surveillance, (iii) a monitoring mechanism for animal products, (iv) weather forecasting enabled by artificial intelligence (Al), and (v) agricultural monitoring and water management using predictive tools and satellite imagery.

In human development, the CAREC employment service and regional digital skills platforms, health-care platforms and telemedicine services, systems to monitor the pandemic and other communicable diseases, and early warning systems can be established.

The complete CAREC project portfolio should undergo prioritization. Projects that are strategically important will have a large impact, lead to digital dividends yet are easy to implement and do not require excessive funding, investment, or capacity building should be prioritized in the early stages of strategy implementation as quick wins. These projects will help manifest results, build positive momentum, and increase member countries' commitment to regional digital transformation initiatives and the CAREC Digital Strategy 2030. Projects that may not be of strategic importance yet are easy to implement in the short term at the regional level should also be prioritized as low-hanging fruit, as they too will help generate member country buy-in 
and a shared sense of achievement regarding digital adoption in the region. Projects that are of strategic importance, of high impact, and are likely to generate regional digital dividends yet are difficult to implement and require significant funding, investment, skill, and execution capacity should be planned for the mid to long term and carefully mapped out by using a phased approach with interim targets to ensure ongoing availability of financing and the time required for upskilling and capacity building. Projects that are not of strategic importance and not high impact yet are difficult and expensive to implement should be eliminated from the CAREC project portfolio. 


\section{References}

Accenture. 2018. Government as a Platform: 2018 GaaP Readiness Index.

Asian Development Bank (ADB). 2015. Unleashing the Potential of the Internet in Central Asia, South Asia, the Caucasus and Beyond. Consultant's report. Manila.

-2017. CAREC 2030: Connecting the Region for Shared and Sustainable Development. Manila.

_.2020a. CAREC Tourism Strategy 2030. Manila.

__ 2020b. Futures Thinking in Asia and the Pacific: Why Foresight Matters for Policy Makers. Manila.

- 2021. CAREC at 20: Reimagining Regional Cooperation through Digital Transformation. 54th Annual Meeting of the Board of Governors. 4 May.

AZERTAC. 2021. Huawei to Apply Its Most Advanced Technologies in Karabakh. 28 April.

CAREC Program. 2021. CAREC at 20: Reimagining Regional Cooperation through Digital Transformation: A Policy Note for the High Level Session during the ADB Annual General Meeting. ADB 54th Annual General Meeting. 4 May. Manila.

Columbia Center on Sustainable Investment. 2017. Toolkit on Cross-Sector Infrastructure Sharing. New York.

Cornell University, INSEAD, and WIPO. 2020. The Global Innovation Index 2020: Who Will Finance Innovation? Ithaca, Fontainebleau, and Geneva.

Deloitte. 2019. The Rise of the Platform Economy. Netherlands.

Economic Commission for Latin America and the Caribbean. 2020. Digital Agenda for Latin America and the Caribbean. Seventh Ministerial Conference on the Information Society in Latin America and the Caribbean. Virtual meeting. 23-26 November. p. 7.

Espinel, V. 2016. The Digital Economy: What Is It and How Will It Transform Our Lives? World Economic Forum. 10 November.

Food and Agriculture Organization of the United Nations (FAO). 2009. Global Agriculture towards 2050. High-Level Expert Forum-How to Feed the World in 2050. 12-13 October. Rome.

___. 2020. Central Asia Embraces Digital Agriculture. News. 8 December.

___ 2020. International Platform for Digital Food and Agriculture.

General Data Protection Regulation (GDPR).

Global System for Mobile Communications Association (GSMA). Mobile Connectivity Index (accessed 15 May 2021). 
Hanna, N. K. 2016. Mastering Digital Transformation: Towards a Smarter Society, Economy, City and Nation. Bingley, United Kingdom: Emerald Publishing Limited.

—_ 2020. Assessing the Digital Economy: Aims, Frameworks, Pilots, Results, and Lessons. Journal of Innovation and Entrepreneurship. 9 (16).

Huawei. Seeds for the Future.

Huawei. 2018. Huawei implements "Safe Tourism” pilot project in Bukhara. https://petition.gov.uz/ru/ news/view/113. 13 July.

—_. 2020. ASEAN to Accelerate Digital Integration for Post-COVID Economic Recovery. News. 10 December.

International Bank for Reconstruction and Development and World Bank. 2018. Russia Digital Economy Report. Washington, DC.

International Telecommunication Union (ITU). World Telecommunication/ICT Indicators Database Online (accessed 1 September 2021).

_. 2019. Global Cybersecurity Index (GCI) 2018.

_. 2021. Global Cybersecurity Index 2020: Measuring Commitment to Cybersecurity.

ITU and FAO. 2020. Status of Digital Agriculture in 18 Countries of Europe and Central Asia. Geneva.

Internet Corporation for Assigned Names and Numbers (ICANN). Community.

Internet Society, Organisation for Economic Co-operation and Development, and United Nations Educational, Scientific and Cultural Organization. The Relationship between Local Content, Internet Development and Access Prices.

Kelly, T., A. Liaplina, S. Tan, and H. Winkler. 2017. Reaping Digital Dividends: Leveraging the Internet for Development in Europe and Central Asia. Washington, DC: World Bank.

Laruelle, M. 2007. Central Asian Labour Migrants in Russia: The "Diasporization" of the Central Asian States? Central Asia-Caucasus Institute \& Silk Road Studies Program. China and Eurasia Forum Quarterly. 5 (3). pp. 101-119.

Levina, M. 2020. Central Asia Countries Switch to Remote Learning amid COVID-19 Outbreak. The Times of Central Asia. 3 April.

Mehdiyev, M. 2021. As Azerbaijan Looks to Restore Its Karabakh Region, Global Know-How Could Be Key. Caspian News. 29 April.

Navas-Sabater, J., and O. V. Petrov. 2018. The EAEU 2025 Digital Agenda: Prospects and Recommendations - Overview Report (English). Washington, DC: World Bank.

Network Readiness Index. NRI 2020 Countries (accessed 1 September 2021).

Organisation for Economic Co-operation and Development (OECD). 2016. OECD Science, Technology and Innovation Outlook 2016. 
Park, C., A. Yershov, and A. Kobsev. 2020. ICT Infrastructure Co Deployment with Transport and Energy Infrastructure in North and Central Asia. Asia-Pacific Information Superhighway Working Paper Series. Bangkok: UNESCAP.

Schwab, K., ed. 2019. The Global Competitiveness Report 2019. Cologny/Geneva: World Economic Forum.

Silva, F., and A. de Carvalho. 2016. Research and Development, Innovation and Productivity Growth in the Steel Sector. Paris: OECD.

Sioson, E. P., and C. J. Kim. 2019. Closing the Gender Gap in Financial Inclusion through Fintech. ADBI Policy Brief. No. 2019-3. Tokyo: ADB Institute.

Soliman, M. 2020. COVID-19 and the Digital Landscape in the Gulf. Middle East Institute. 13 May.

Stephenson, M. 2020. Digital FDI: Policies, Regulations and Measures to Attract FDI in the Digital Economy. World Economic Forum White Paper. September.

Sukhankin, S. 2021. Tracking the Digital Component of the BRI in Central Asia, Part One: Exporting "Safe Cities" to Uzbekistan. The Jamestown Foundation. 11 February.

Sussman, B. 2019. The List: Best and Worst Countries for Cybersecurity. Secure World. 13 November.

Sustainable Development Report. Rankings (Performance by Sustainable Development Goals) (accessed 1 September 2021).

Transparency International. Corruption Perceptions Index 2020 (accessed 1 September 2021).

Treagust, S. 2017. Fire Up Your Digital Transformation and Increase Profitability 26\% Using a Connected Strategy. IFS Blog. 23 March.

Umar, K. 2021. Financial Inclusion and Fintech in CAREC: Constraints and Prospects. CAREC Institute Working Paper. Urumqi.

United Nations. 2020 E-Government Development Index (accessed 1 September 2021).

- 2020. E-Participation Index (accessed 1 September 2021) (choose E-Participation Index in the dropdown menu under Data).

- 2020. Report of the Secretary-General: Roadmap for Digital Cooperation.

United Nations Conference on Trade and Development. 2020. The UNCTAD B2C E-Commerce Index 2020: Spotlight on Latin America and the Caribbean. UNCTAD Technical Notes on ICT for Development. No. 17.

United Nations Development Programme. Goal 11: Sustainable Cities and Communities.

United Nations Economic and Social Commission for Asia and the Pacific (UNESCAP). 2018. Enhancing E-Resilience for Digital Economy in Central Asia. Asia-Pacific Information Superhighway Policy Briefs. No. 2. Bangkok.

United States Department of Agriculture (USDA). 2019. A Case for Rural Broadband.

Vegas, E. 2020. School Closures, Government Responses, and Learning Inequality around the World during COVID-19. Brookings. 14 April. 
Wang, J. 2019. Taobao Villages Driving 'Inclusive Growth’ in Rural China. Alizila. 25 November.

World Bank. COVID-19 Crisis Response: Digital Development Joint Action Plan and Call for Action.

__. Human Capital Index (accessed 1 Septmber 2021).

- Human Capital Project (Percentage of Population with Secondary \& Tertiary Education) (accessed 1 September 2021).

___ 2016. World Development Report 2016: Digital Dividends. Washington, DC.

_- 2018. Competing in the Digital Age: Policy Implications for the Russian Federation. Washington, DC.

_. 2019. Stimulating Jobs, Growth, Entrepreneurship, Income in Rural China through E-Commerce. Results briefs. 22 November.

___ 2020. COVID-19 Prompts Urgency of Bridging Digital Divide in Central Asia. Press release. 2 December.

___ 2021. Thought Leadership and Fresh Insight from the World Bank's Digital Development Practice. Brief. 10 May.

World Economic Forum. Enabling Trade Index 2016 (accessed 1 September 2021).

___. 2017. The Global Human Capital Report 2017: Preparing People for the Future of Work.

World Intellectual Property Organization. 2021. Global Innovation Index 2021: Tracking Innovation through the COVID-19 Crisis. Geneva.

Yan, Y. T. 2019. Smart Cities or Surveillance? Huawei in Central Asia. The Diplomat. 7 August. 


\section{CAREC Digital Strategy 2030 \\ Accelerating Digital Transformation for Regional Competitiveness and Inclusive Growth}

Digital transformation can positively impact economic growth, jobs creation, and social inclusion.

As the Central Asia Regional Economic Cooperation (CAREC) region deals with the challenges posed by the coronavirus disease (COVID-19) pandemic, investing in national broadband infrastructure is more crucial than ever to enable connectivity and improve service delivery. Digitalization will allow CAREC member countries to develop robust solutions for areas including agriculture and water, e-commerce and trade, education and skills, energy, finance, health, transportation, and tourism. The CAREC Digital Strategy 2030 is intended as a catalyst for regional cooperation, promoting policy design, capacity building, and dialogue to address economic and social challenges in the region with the help of digital technologies.

\section{About the Central Asia Regional Economic Cooperation Program}

The Central Asia Regional Economic Cooperation (CAREC) Program is a partnership of member countries and development partners working together to promote development through cooperation, leading to accelerated economic growth and poverty reduction. It is guided by the overarching vision of "Good Neighbors, Good Partners, and Good Prospects." CAREC countries include: Afghanistan, Azerbaijan, the People's Republic of China, Georgia, Kazakhstan, the Kyrgyz Republic, Mongolia, Pakistan, Tajikistan, Turkmenistan, and Uzbekistan.

\section{About the Republic of Korea e-Asia and Knowledge Partnership Fund}

The Republic of Korea e-Asia and Knowledge Partnership Fund (EAKPF) was established in 2006 by the Republic of Korea to reduce poverty in Asia and the Pacific by improving access to advanced technologies, including information and communications technology, and facilitating knowledge sharing and partnerships.

\section{About the Asian Development Bank}

ADB is committed to achieving a prosperous, inclusive, resilient, and sustainable Asia and the Pacific, while sustaining its efforts to eradicate extreme poverty. Established in 1966, it is owned by 68 members -49 from the region. Its main instruments for helping its developing member countries are policy dialogue, loans, equity investments, guarantees, grants, and technical assistance.
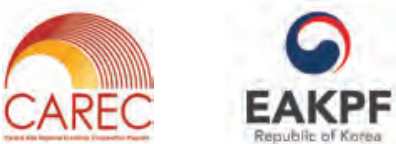

CAREC SECRETARIAT

www.carecprogram.org 